\title{
Preoptic BRS3 neurons increase body temperature and heart rate via multiple pathways
}

\author{
Ramón A. Piñol ${ }^{1 *}$, Allison S. Mogul ${ }^{1}$, Colleen K. Hadley ${ }^{1}$, Atreyi Saha ${ }^{1}, \mathrm{Chia} \mathrm{Li}^{1}$, Vojtěch Škop ${ }^{1}$, Haley \\ S. Province ${ }^{1}$, Cuiying Xiao¹, Oksana Gavrilova², Michael J. Krashes ${ }^{1}$, Marc L. Reitman ${ }^{1 * \#}$
}

1. Diabetes, Endocrinology, and Obesity Branch, National Institute of Diabetes and Digestive and Kidney Diseases, National Institutes of Health, Bethesda, MD 20892, USA

2. Mouse Metabolism Core, National Institute of Diabetes and Digestive and Kidney Diseases, National Institutes of Health, Bethesda, MD 20892, USA

\# lead contact

* corresponding authors. E-mail addresses: ramon.pinol@nih.gov, marc.reitman@nih.gov

\begin{abstract}
The preoptic area (POA) is a key region controlling body temperature $(\mathrm{Tb})$, dictating thermogenic, cardiovascular, and behavioral responses to regulate Tb. Known POA neuronal populations reduce $\mathrm{Tb}$ when activated; a population that increases $\mathrm{Tb}$ upon activation has not yet been reported. We now identify bombesin-like receptor 3 (BRS3)-expressing POA (POA ${ }^{\mathrm{BRS} 3}$ ) neurons as having this missing functionality. BRS3 is an orphan receptor that regulates energy and cardiovascular homeostasis, but the relevant neural circuits are incompletely understood. In mice, we demonstrate that $\mathrm{POA}^{\mathrm{BRS} 3}$ neuronal activation increases $\mathrm{Tb}$, heart rate, and blood pressure sympathetically, via projections to the paraventricular nucleus of the hypothalamus and dorsomedial hypothalamus. Acute $\mathrm{POA}^{\mathrm{BRS} 3}$ inhibition reduces Tb. Long-term inactivation of $\mathrm{POA}^{\mathrm{BRS} 3}$ neurons increased $\mathrm{Tb}$ variability with exaggerated $\mathrm{Tb}$ changes, overshooting both increases and decreases in $\mathrm{Tb}$ set point. BRS3 marks preoptic populations that regulate $\mathrm{Tb}$ and heart rate, contribute to cold-defense and fine-tune feedback control of $\mathrm{Tb}$. These findings advance understanding of homeothermy, a defining feature of mammalian biology.
\end{abstract}

\section{Introduction}

Homeothermy is the property of having a stable core body temperature $(\mathrm{Tb})$, which allows finer control of body processes. Endotherms, including mammals and birds, are homeotherms that use metabolism-generated heat to achieve a warm $\mathrm{Tb}$. To regulate $\mathrm{Tb}$, both environmental temperature $\mathrm{Ta}$ ) and $\mathrm{Tb}$ must be sensed and evaluated. The organism controls 
heat generation, including adaptive heat production from brown and beige/brite adipose tissue and muscle. Heat conservation/dissipation is also highly regulated, typically by vasodilation/vasoconstriction and species-determined mechanisms such as panting, sweating, and a variety of behavioral adaptations. The regulation of these processes is orchestrated by the central nervous system. As ultimately survival depends on proper Tb regulation, it is critical to understand this essential physiology.

The preoptic area (POA) is a major integratory hub regulating $\mathrm{Tb}$ and cardiovascular responses, and drinking, sleep, parenting, sex, and reward behaviors (Dulac et al., 2014; McHenry et al., 2017; McKinley et al., 2015; Simerly, 1998). The POA contributes to Tb regulation in response to a warm or cold $\mathrm{Ta}$, in producing fever, in hibernation and torpor, and during sleep (Morrison and Nakamura, 2019; Tan and Knight, 2018). Neuron chemotypes in various POA subregions that are activated by warm ambient temperatures and/or reduce $\mathrm{Tb}$ when activated include those expressing Vglut2/PACAP/leptin receptor, Vgat, BDNF, galanin, TRPM2, NOS1, QRFP, ER $\alpha$, and PGDS2 (Abbott and Saper, 2017; Harding et al., 2018; Hrvatin et al., 2020; Kroeger et al., 2018; Moffitt et al., 2018; Song et al., 2016; Takahashi et al., 2020; Tan et al., 2016; Wang et al., 2019; Yu et al., 2016; Zhang et al., 2020; Zhao et al., 2017). Many of these chemotypes specify overlapping populations. POA cold-sensitive neurons drive heat generation and conservation and increase heart rate (HR) (Nakamura and Morrison, 2008). The neuronal identity and circuitry of cold-sensitive neurons is incompletely understood. A proposed mechanism is disinhibition of an inhibitory POA to dorsomedial hypothalamus (DMH) pathway, but an excitatory POA to DMH projection has also been suggested (Dimitrov et al., 2011; Morrison and Nakamura, 2019; da Conceicao et al., 2020). Therefore, a major gap in our understanding of $\mathrm{Tb}$ control is that no specific population of POA neurons whose activation increases $\mathrm{Tb}$ has been identified. The POA population implicated in fever expresses EP3R and is inhibited by PGE2 to produce fever; this population may not overlap with the cold-defense neurons (Machado et al., 2020). It is not known if POA cold-responsive neurons drive thermogenesis via pathways other than to the DMH.

Bombesin-like receptor 3 (BRS3, BB3, bombesin receptor subtype-3) is an orphan G protein-coupled receptor that regulates energy metabolism and the cardiovascular system (OhkiHamazaki et al., 1997). BRS3 is expressed in some peripheral sites (Jensen et al., 2008), but its effects on food intake, metabolic rate, Tb, HR, and blood pressure are due to action in the brain (Guan et al., 2010; Xiao and Reitman, 2016). BRS3 has a restricted brain distribution (Maruyama et al., 2018; Pinol et al., 2018; Zhang et al., 2013), with its metabolic effects attributed to glutamatergic neurons and in part to those expressing MC4R and SIM1 (Xiao et al., 2020; Xiao et al., 2017). Activation of BRS3 neurons in the DMH (DMH ${ }^{\mathrm{BRS} 3}$ ) increased energy expenditure, Tb, HR, and blood pressure, while activation of paraventricular nucleus of the hypothalamus $(\mathrm{PVH})^{\mathrm{BRS} 3}$ neurons reduced food intake (Pinol et al., 2018). We now demonstrate that $\mathrm{POA}^{\mathrm{BRS} 3}$ neurons actively contribute to cold-defense and to the feedback control of Tb.

\section{Results}

Optogenetic activation of $P O A^{B R S 3}$ neurons rapidly increases $T b$, heart rate, and blood pressure Neurons expressing BRS3 in the preoptic area $\left(\mathrm{POA}^{\mathrm{BRS} 3}\right)$ were activated by exposure to a cold ambient temperature, as demonstrated by increased Fos expression (Figure 1a,b) (Pinol et 
al., 2018), so we tested the ability of $\mathrm{POA}^{\mathrm{BRS} 3}$ neurons to control Tb, HR, and mean arterial pressure (MAP). Optogenetic stimulation of $\mathrm{POA}^{\mathrm{BRS} 3}$ neurons increased $\mathrm{Tb}$ by $1.2 \pm 0.2^{\circ} \mathrm{C}, \mathrm{HR}$ by $134 \pm 18 \mathrm{bpm}$, and MAP by $20.4 \pm 1.4 \mathrm{~mm} \mathrm{Hg}$, with no increase in physical activity and no changes in control mice (Figure 1c,d). We varied stimulation times to characterize the onset of the HR and MAP increases. Stimulation for $0.5 \mathrm{~s}$ increased HR and MAP detectably. The halfmaximal HR response was elicited with $\sim 2 \mathrm{~s}$ of stimulation, with slightly more time needed for MAP. Stimulation for $20 \mathrm{~s}$ maximally increased both HR and MAP (Figure 1e,f). The Tb response was slow ( $50 \%$ at $6.3 \pm 0.5 \mathrm{~min})$ due to the body's heat capacity. Thus, activation of $\mathrm{POA}^{\mathrm{BRS3}}$ neurons increases $\mathrm{Tb}, \mathrm{HR}$, and MAP independent of physical activity.

The $\mathrm{Tb}$ increase caused by $\mathrm{POA}^{\mathrm{BRS} 3}$ neuron activation is in the opposite direction of that observed in most other POA neuron populations, activation of which reduces $\mathrm{Tb}$ (Morrison and Nakamura, 2019). This makes $\mathrm{POA}^{\mathrm{BRS3}}$ neurons functionally distinct from other POA populations. We next used a Cre-off ChR2-expressing virus to selectively activate POA neurons that do not express BRS3 ( $\mathrm{POA}^{\text {nonBRS3}}$ ). We compared non-selective stimulation of POA neurons $\left(\mathrm{POA}^{\mathrm{All}}\right)$ and stimulation of $\mathrm{POA}^{\mathrm{nonBRS} 3}$ neurons with stimulation of $\mathrm{POA}^{\mathrm{BRS3}}$ neurons (Figure 2). Optogenetic activation of either $\mathrm{POA}^{\mathrm{All}}$ or POA ${ }^{\text {nonBRS3 }}$ neurons drastically decreased $\mathrm{Tb}$ by almost $3{ }^{\circ} \mathrm{C}$ at the end of the 20 min stimulation, with no sign of plateauing. Stimulation of either $\mathrm{POA}^{\mathrm{All}}$ or POA ${ }^{\text {nonBRS3}}$ neurons also massively increased physical activity, which is opposite of the usual behavior during a Tb decrease. Together, these data demonstrate that POA ${ }^{\mathrm{BRS} 3}$ neurons are a distinct population of $\mathrm{Tb}$ - and HR-regulating neurons that function in the opposite direction from previously described POA neuronal populations.

\section{Inhibition of $P O A^{B R S 3}$ neurons reduces $T b$ and cold defense}

We used chemogenetics to manipulate $\mathrm{POA}^{\mathrm{BRS} 3}$ neurons bidirectionally. Stimulation of the activating DREADD, hM3Dq, with CNO had two effects (Figure 3a,b). First, the initial, handling-associated $\mathrm{Tb}$ increase returned to baseline more quickly after $\mathrm{CNO}$ than vehicle $(\mathrm{CNO}, 53 \pm 4 \mathrm{~min}$ vs vehicle, $71 \pm 4 \mathrm{~min} ; \mathrm{p}=0.03)$, with no difference in physical activity between treatments. Then, starting about 120 minutes after dosing, the $\mathrm{Tb}$ in the $\mathrm{CNO}$-treated mice increased by $0.72 \pm 0.09{ }^{\circ} \mathrm{C}$, with no increase after vehicle treatment $\left(-0.08 \pm 0.07{ }^{\circ} \mathrm{C} ; \mathrm{p}=\right.$ $0.00002 \mathrm{CNO}$ vs vehicle). Thus, chemogenetic stimulation of $\mathrm{POA}^{\mathrm{BRS3}}$ neurons produces a biphasic response, initially lowering $\mathrm{Tb}$, and then raising $\mathrm{Tb}$. The delayed $\mathrm{Tb}$ increase after chemogenetic activation contrasts with the near-immediate onset of the $\mathrm{Tb}$ increase upon optogenetic stimulation. The biphasic response suggests that there may be more than one population of $\mathrm{POA}^{\mathrm{BRS} 3}$ neurons regulating $\mathrm{Tb}$.

Chemogenetic inhibition of POA ${ }^{\mathrm{BRS} 3}$ neurons expressing the hM4Di DREADD decreased $\mathrm{Tb}$ by $0.50 \pm 0.12{ }^{\circ} \mathrm{C}$ (vs an increase of $0.39 \pm 0.05{ }^{\circ} \mathrm{C}$ with vehicle; $\mathrm{p}=0.0003 \mathrm{CNO}$ vs vehicle; Figure $3 \mathrm{c}, \mathrm{d})$. The $\mathrm{Tb}$ reduction started within minutes, blunting the handling-induced $\mathrm{Tb}$ increase with no effect on physical activity. These results demonstrate that $\mathrm{POA}^{\mathrm{BRS} 3}$ neuronal activity maintains $\mathrm{Tb}$ in a $22^{\circ} \mathrm{C}$ environment and suggests that $\mathrm{POA}^{\mathrm{BRS} 3}$ neurons contribute to cold defense.

Chemogenetic stimulation of BNST ${ }^{B R S 3}$ neurons does not change Tb, physical activity or food intake 
The bed nucleus of the stria terminalis (BNST) can regulate Tb (Craig, 2018; Schneeberger et al., 2019) and food intake (Jennings et al., 2013) and contains BRS3-expressing neurons $\left(\mathrm{BNST}^{\mathrm{BRS3}}\right)$. Chemogenetic activation of $\mathrm{BNST}^{\mathrm{BRS} 3}$ neurons expressing an excitatory DREADD had no effect on $\mathrm{Tb}$, physical activity, or food intake (either reduction or increase) (Figure S1). Thus, BNST ${ }^{\mathrm{BRS} 3}$ neurons do not appear to control $\mathrm{Tb}$ and $\mathrm{BNST}^{\mathrm{BRS} 3}$ and $\mathrm{POA}^{\mathrm{BRS} 3}$ neurons have distinct functions.

Optogenetic stimulation of $P O A^{B R S 3}$ neuron projections to $P V H$, DMH or PAG increases Tb.

To identify targets of $\mathrm{POA}^{\mathrm{BRS} 3}$ neurons, we used viral anterograde tracing (Figure S2a-c). $\mathrm{POA}^{\mathrm{BRS3}}$ neurons had dense local projections to preoptic regions and major projection fields in the PVH, DMH, and raphe pallidus ( $\mathrm{RPa})$. Moderate levels of projections were to the periaqueductal grey (PAG) and paraventricular nucleus of the thalamus (PVT). Other areas containing fiber terminals were the lateral septum, lateral hypothalamus, supraoptic nucleus, locus coeruleus, and Barrington's nucleus.

We next examined which POA ${ }^{\mathrm{BRS} 3}$ neuron projections increase Tb. Cre-dependent ChR2expressing virus was injected into the POA of BRS3-Cre mice and an optic fiber was implanted over the PVH, DMH, PVT, PAG, or RPa. Optogenetic stimulation of $\mathrm{POA}^{\mathrm{BRS} 3} \rightarrow \mathrm{PVH}$, $\mathrm{POA}^{\mathrm{BRS} 3} \rightarrow \mathrm{DMH}$, or $\mathrm{POA}^{\mathrm{BRS} 3} \rightarrow \mathrm{PAG}$ axons increased $\mathrm{Tb}$ by $1.2 \pm 0.2^{\circ} \mathrm{C}, 1.0 \pm 0.2^{\circ} \mathrm{C}$, or $0.6 \pm$ $0.05^{\circ} \mathrm{C}$, respectively (Figure $4 \mathrm{a}-\mathrm{c}$ ). Optogenetic stimulation of $\mathrm{POA}^{\mathrm{BRS} 3} \rightarrow \mathrm{PVT}$ (Figure $4 \mathrm{~d}$ ) and $\mathrm{POA}^{\mathrm{BRS} 3} \rightarrow \mathrm{RPa}$ (Figure $4 \mathrm{e}$ ) axons did not change $\mathrm{Tb}$. It is possible that PVH stimulation could activate $\mathrm{POA}^{\mathrm{BRS} 3} \rightarrow \mathrm{DMH}$ fibers passing through the $\mathrm{PVH}$, although this would not be expected to generate the observed full response. The projection-specific differences suggest that the downstream pathways of POA ${ }^{\mathrm{BRS} 3}$ neurons differentially contribute to $\mathrm{Tb}$ regulation. Laser light delivery in mCherry-expressing control mice did not alter Tb. Physical activity was slightly increased during activation of $\mathrm{POA}^{\mathrm{BRS} 3} \rightarrow \mathrm{PVH}$ mice, but not in the other areas. These experiments show that $\mathrm{POA}^{\mathrm{BRS} 3}$ neurons project to multiple brain nuclei, and stimulation of three of these populations increases $\mathrm{Tb}$.

The POA to DMH pathway is a previously characterized pathway for $\mathrm{Tb}$ regulation (Morrison and Nakamura, 2019). Therefore, we assessed if $\mathrm{POA}^{\mathrm{BRS} 3} \rightarrow \mathrm{DMH}$ neurons have collaterals. We found that $\mathrm{POA}^{\mathrm{BRS} 3} \rightarrow \mathrm{DMH}$ neurons have collaterals to $\mathrm{PVH}, \mathrm{PVT}, \mathrm{PAG}$, and $\mathrm{RPa}$ (Figure S2d-f). Other areas in which we observed collateral fibers strongly overlapped with the anterograde tracing experiment and included the lateral hypothalamus, supraoptic nucleus, locus coeruleus, and Barrington's nucleus.

$P O A^{B R S 3} \rightarrow P V H$ and $P O A^{B R S 3} \rightarrow D M H$ neurons activate brown adipose tissue

To determine if the $\mathrm{Tb}$ increase is mediated by retaining heat through tail vasoconstriction and/or by brown adipose tissue (BAT) activation, we measured skin temperature using infrared imaging (Figure $\mathrm{S} 3 \mathrm{a})$. Tail temperature $\left(\mathrm{T}_{\text {tail }}\right)$ was unchanged during the optogenetic stimulation (Figure S3b), indicating a lack of vasodilation, as the tail was already vasoconstricted at $25^{\circ} \mathrm{C}$.

We used temperatures of the interscapular $\left(\mathrm{T}_{\mathrm{BAT}}\right)$ and lumbar $\left(\mathrm{T}_{\text {lumbar }}\right)$ regions as biomarkers of BAT temperature and $\mathrm{Tb}$, respectively, although one cannot rule out unmeasured localized differential changes in local air temperature or skin blood flow with this assay. TBAT is $\sim 1{ }^{\circ} \mathrm{C}$ warmer than $\mathrm{T}_{\text {lumbar, }}$, consistent with heat production by BAT with transfer to the body. 
Optogenetic stimulation of $\mathrm{POA}^{\mathrm{BRS} 3} \rightarrow \mathrm{PVH}$ or $\mathrm{POA}^{\mathrm{BRS} 3} \rightarrow \mathrm{DMH}$ terminals each increased $\mathrm{T}_{\mathrm{BAT}}$ and $\mathrm{T}_{\text {lumbar }}$ (Figure $\mathrm{S} 3 \mathrm{c}, \mathrm{d}$ ). The $\mathrm{T}_{\mathrm{BAT}}-\mathrm{T}_{\text {lumbar }}$ difference increased at the onset of stimulation only in the $\mathrm{POA}^{\mathrm{BRS} 3} \rightarrow \mathrm{DMH}$ group and the gradient was maintained during warming, indicating continued BAT activation. Taken together, the results suggest that both $\mathrm{POA}^{\mathrm{BRS} 3} \rightarrow \mathrm{PVH}$ and $\mathrm{POA}^{\mathrm{BRS} 3} \rightarrow \mathrm{DMH}$ projections activate BAT.

$P O A^{B R S 3} \rightarrow P V H$ and $P O A^{B R S 3} \rightarrow D M H$ neurons stimulate heart rate through the sympathetic nervous system

Since activation of $\mathrm{POA}^{\mathrm{BRS3}}$ neurons increased HR and MAP, we queried whether this occurred via projections to the $\mathrm{PVH}$ or DMH. Optogenetic stimulation of either $\mathrm{POA}^{\mathrm{BRS} 3} \rightarrow \mathrm{PVH}$ or $\mathrm{POA}^{\mathrm{BRS} 3} \rightarrow \mathrm{DMH}$ terminals increased HR (by $94 \pm 9 \mathrm{bpm}$ or $89 \pm 27 \mathrm{bpm}$, respectively) and MAP (by $10.7 \pm 2.7 \mathrm{~mm} \mathrm{Hg}$ or $10.1 \pm 3.4 \mathrm{~mm} \mathrm{Hg}$, respectively) (Figure 5a). HR and MAP did not change in the mCherry controls and physical activity did not increase significantly in any group.

A rapid increase in HR could be due to activation of the sympathetic and/or inhibition of the parasympathetic nervous system. We used propranolol, a $\beta$-adrenergic antagonist (blocking $\beta 1$ and $\beta 2$ better than $\beta 3$ ), to inhibit the sympathetic nervous system. Propranolol's ED $D_{50}$ for $\mathrm{Tb}$ reduction was $48 \mathrm{mg} / \mathrm{kg}$ i.p. in wild-type mice (Figure S4). Propranolol at $5 \mathrm{mg} / \mathrm{kg}$ reduced HR $(-68 \pm 12$ bpm, $p=0.03)$ but did not change MAP $(-4.4 \pm 2.9 \mathrm{~mm} \mathrm{Hg}, \mathrm{p}=0.45)$. The $50 \mathrm{mg} / \mathrm{kg}$ dose profoundly reduced HR $(-133 \pm 23 \mathrm{bpm}, \mathrm{p}<0.0001)$ and had a biphasic effect on MAP, first reducing it to levels unreliably undetectable by the intra-aortic telemetry, then increasing it (Figure 5b). The effect of propranolol on the optogenetic responses of the $\mathrm{POA}^{\mathrm{BRS} 3} \rightarrow \mathrm{PVH}$ and $\mathrm{POA}^{\mathrm{BRS} 3} \rightarrow \mathrm{DMH}$ mice were similar: the HR increase was inhibited by $61 \pm 5 \%$ and $46 \pm 12 \%$, respectively, with $5 \mathrm{mg} / \mathrm{kg}$ and $91 \pm 2 \%$ and $82 \pm 7 \%$, respectively, with $50 \mathrm{mg} / \mathrm{kg}$ (Figure $5 \mathrm{c}, \mathrm{d})$. Propranolol's effects on the MAP increase were also similar in the $\mathrm{POA}^{\mathrm{BRS} 3} \rightarrow \mathrm{PVH}$ and $\mathrm{POA}^{\mathrm{BRS} 3} \rightarrow \mathrm{DMH}$ mice, but the MAP and HR dose responses differed. The MAP increase was not inhibited by $5 \mathrm{mg} / \mathrm{kg}$, but was inhibited $80 \pm 12 \%$ and $84 \pm 7 \%$, respectively, with $50 \mathrm{mg} / \mathrm{kg}$ (Figure $5 \mathrm{c}, \mathrm{d}$ ). Tb and physical activity were not changed by this brief optogenetic stimulation. The biphasic MAP response to $50 \mathrm{mg} / \mathrm{kg}$ propranolol complicates interpretation of the optogenetic effects. In contrast, the $5 \mathrm{mg} / \mathrm{kg}$ propranolol dose robustly suppressed optogeneticdriven $\mathrm{HR}$ increases in $\mathrm{POA}^{\mathrm{BRS} 3} \rightarrow \mathrm{PVH}$ and $\mathrm{POA}^{\mathrm{BRS} 3} \rightarrow \mathrm{DMH}$ mice, suggesting that these are sympathetic effects. The $5 \mathrm{mg} / \mathrm{kg}$ dose of propranolol did not affect MAP, suggesting divergence in the regulation of $\mathrm{HR}$ and MAP by these POA ${ }^{\mathrm{BRS} 3}$ neurons. Taken together, the results indicate that $\mathrm{POA}^{\mathrm{BRS} 3} \rightarrow \mathrm{PVH}$ and $\mathrm{POA}^{\mathrm{BRS} 3} \rightarrow \mathrm{DMH}$ projections increase HR through the sympathetic nervous system.

$P O A^{B R S 3} \rightarrow P V H$ and $P O A^{B R S 3} \rightarrow D M H$ neurons are mixed glutamatergic and GABAergic populations

We next assessed the neurotransmitters used by $\mathrm{POA}^{\mathrm{BRS} 3}$ neurons. In the median preoptic area (MnPO), $46 \pm 7 \%$ of BRS3 neurons were positive for Gad2 (Figure S5a,b). Other preoptic BRS3-expressing regions, ventromedial preoptic area (VMPO), ventrolateral preoptic area (VLPO), and medial preoptic area (MPA), had $56 \pm 7 \%, 54 \pm 12 \%$, and $40 \pm 5 \%$ colocalization, respectively. While Gad2 is often used as a marker for GABAergic neurons, it is also expressed 
in some preoptic glutamatergic (Vglut2-expressing) neurons. However, there are no identified BRS3 populations that express both Vglut2 and Vgat in the POA (Moffitt et al., 2018). The absence of Gad2 expression in a fraction of the preoptic BRS3 neurons suggests that a subpopulation of $\mathrm{POA}^{\mathrm{BRS} 3}$ neurons is glutamatergic.

We used ChR2-assisted circuit mapping to test if $\mathrm{POA}^{\mathrm{BRS} 3} \rightarrow \mathrm{PVH}$ and $\mathrm{POA}^{\mathrm{BRS} 3} \rightarrow \mathrm{DMH}$ projections use glutamate or GABA (Figure 6a). In PVH- or DMH-containing brain slices, optogenetic stimulation of $\mathrm{POA}^{\mathrm{BRS} 3}$ axons elicited both excitatory and inhibitory post-synaptic currents (Figure 6b,c). Thus, both the $\mathrm{POA}^{\mathrm{BRS} 3} \rightarrow \mathrm{PVH}$ and $\mathrm{POA}^{\mathrm{BRS} 3} \rightarrow \mathrm{DMH}$ neuron populations consist of both glutamatergic and GABAergic subpopulations.

Single-cell RNA sequencing data show that BRS3 is expressed in multiple POA region neuron populations (Moffitt et al., 2018). Reanalysis limited to the 581 BRS3-positive neurons in this dataset (avoiding false negatives due to low BRS3 expression) indicates that there are at least one glutamatergic and five GABAergic populations (Figures 6d,e, S5c). The e1 glutamatergic cluster may contain multiple subclusters, as the cluster heterogeneously expresses markers found in thermoregulatory neurons (eg., Bdnf, Adcyap1, Ptgds, and Nos1) and 44\% are positive for galanin. Two clusters, i2-Meis 2 and i5-Sst may be in regions neighboring the POA, based on the expression pattern of some of the marker mRNAs (Figure S5d). These results demonstrate that there are multiple populations of $\mathrm{POA}^{\mathrm{BRS} 3}$ neurons.

\section{Permanent silencing of $P O A^{B R S}$ neurons increases Tb variability, exaggerates Tb changes and} delays adaptation to Ta below thermoneutrality

To study the effect of chronic inactivation of $\mathrm{POA}^{\mathrm{BRS} 3}$ neurons, we used Cre-dependent tetanus toxin (TeNT)-expressing virus (POA ${ }^{\mathrm{BRS} 3}:$ :TeNT mice; control mice expressed EYFP) (Figure 7a,b, S6a). After inactivation, the $\mathrm{POA}^{\mathrm{BRS} 3}$ ::TeNT mice gained less weight than control mice, with decreased food intake during weeks 4-6 after starting tamoxifen treatment (Figure $\mathrm{S} 6 \mathrm{~b}, \mathrm{c})$.

The baseline Tb phenotype of the $\mathrm{POA}^{\mathrm{BRS} 3}:$ :TeNT mice was subtle, consisting of unchanged 24-h mean $\mathrm{Tb}$, generally non-significantly higher dark and lower light phase mean $\mathrm{Tb}$, and a larger SD for both of these. More sensitive metrics were the circadian amplitude ( $\mathrm{Tb}_{\text {dark }}$-Tb $\left.b_{\text {light }}\right)$ and the Tb span $\left(95^{\text {th }}-5^{\text {th }}\right.$ Tb percentiles during $\left.24 \mathrm{~h}\right)$ (Figure S6d). The phenotype of increased $\mathrm{Tb}$ variability was stable through 23 weeks after tamoxifen treatment, the last time studied.

We next explored the response of $\mathrm{POA}^{\mathrm{BRS} 3}::$ TeNT mice to various stimuli that increase $\mathrm{Tb}$. The fever response to lipopolysaccharide (LPS) was intact, as was the Tb increase in response to cage switch (Figure 7c, Figure S6f), but not the increase in light-phase Tb produced by a BRS3 agonist (Figure S6e). Thus, POA ${ }^{\mathrm{BRS} 3}$ neurons are not necessary for the Tb effects of LPS (unlike EP3R/Vglut2-expressing neurons (Machado et al., 2020)) or cage switch. The increased $\mathrm{Tb}$ variability of the silenced mice meant these experiments are underpowered to detect if the rise in $\mathrm{Tb}$ was augmented.

To explore the response to a Tb-lowering condition, the mice were fasted for $24 \mathrm{~h}$. Both control and silenced mice entered torpor, with the $\mathrm{POA}^{\mathrm{BRS} 3}::$ TeNT mice showing an exaggerated hypothermic response (Figure $7 \mathrm{~d}$ ). 
We next studied the effect of ambient temperature (Ta). $\mathrm{POA}^{\mathrm{BRS} 3}:$ :TeNT mice at $22{ }^{\circ} \mathrm{C}$ were brought to $30^{\circ} \mathrm{C}$ for three days and then returned to $22^{\circ} \mathrm{C}$. There was no major phenotype during the first two stages, but upon return to $22{ }^{\circ} \mathrm{C}$ there was a remarkable reduction in $\mathrm{Tb}(2.8$ ${ }^{\circ} \mathrm{C}$ below controls) and energy expenditure (31\% below controls) (Figure 7e,f). We next explored the acclimation in more detail. After acclimation for $>5$ days to either $22{ }^{\circ} \mathrm{C}$ or $30{ }^{\circ} \mathrm{C}$, mice were acutely exposed ( $3 \mathrm{~h}$, light phase) to various Ta (Figure $7 \mathrm{~g}$ ). After $22^{\circ} \mathrm{C}$ acclimation, the POA ${ }^{\mathrm{BRS} 3}$ ::TeNT mice responded to $10-22{ }^{\circ} \mathrm{C}$ the same as controls, while at 30 or $34{ }^{\circ} \mathrm{C}$ they had a slightly higher $\mathrm{Tb}$. In contrast, when acclimated to $30^{\circ} \mathrm{C}$, the $\mathrm{POA}^{\mathrm{BRS} 3}:$ :TeNT mice at 16 or $22{ }^{\circ} \mathrm{C}$ were much cooler than controls, while still warmer at $34{ }^{\circ} \mathrm{C}$.

Since $\mathrm{Tb}$ acclimation to Ta extremes is poorly understood in mice and the $\mathrm{POA}^{\mathrm{BRS} 3}:$ :TeNT mice provide a robust phenotype, we studied acclimation further. Whether acclimated for 3 or 10 days to $30{ }^{\circ} \mathrm{C}$, the Tb response to $22{ }^{\circ} \mathrm{C}$ was similar, taking about 5 days to completely return to baseline (Figure S6g). Thus, these data suggest that acclimation from 22 ${ }^{\circ} \mathrm{C} \rightarrow 30{ }^{\circ} \mathrm{C}$ occurs by $\sim 3$ days and acclimation from $30{ }^{\circ} \mathrm{C} \rightarrow 22{ }^{\circ} \mathrm{C}$ takes $\sim 3-5$ days.

Taken together, the phenotype of the $\mathrm{POA}^{\mathrm{BRS} 3}::$ TeNT mice can be summarized as showing increased $\mathrm{Tb}$ variability and exaggerated $\mathrm{Tb}$ changes, both increases and decreases, in response to multiple challenges. It appears there is eventually appropriate setting of the target $\mathrm{Tb}$ or "set point" in response to various interventions, but poor feedback control of keeping the Tb at the set point.

\section{Discussion}

\section{Role of $P O A^{B R S 3}$ neurons in $T b$ and cardiovascular regulation}

We demonstrate that activating $\mathrm{POA}^{\mathrm{BRS} 3}$ neurons increased $\mathrm{Tb}, \mathrm{HR}$, and MAP, which is the opposite effect of activating other POA neuron populations, such as those identified by expression of Vglut2/PACAP/leptin receptor (Abbott and Saper, 2017; Hrvatin et al., 2020; Moffitt et al., 2018; Tan et al., 2016; Yu et al., 2016), QRFP (Takahashi et al., 2020), Esr1 (Zhang et al., 2020), Vgat (Zhao et al., 2017), BDNF (Tan et al., 2016), galanin (Kroeger et al., 2018), TRPM2 (Song et al., 2016), NOS1 (Harding et al., 2018), and/or PGDS2 (Wang et al., 2019). There is a POA population expressing Vglut2 and EP3R that mediates LPS-induced fever (Machado et al., 2020). However, PGE2 binding to EP3R inhibits the MnPO ${ }^{\mathrm{EP} 3 \mathrm{R} / \mathrm{Vglut} 2}$ neurons, increasing $\mathrm{Tb}$ upon inhibition, which is the reverse polarity of $\mathrm{POA}^{\mathrm{BRS} 3}$ neurons. Thus, the $\mathrm{POA}^{\mathrm{BRS3}}$ neurons are a novel population that increases $\mathrm{Tb}$ when activated.

Activated $\mathrm{POA}^{\mathrm{BRS} 3}$ neurons increase $\mathrm{Tb}$ via at least three output pathways (DMH, PVH, and PAG) (Figure S7). Previously, the importance of POA $\rightarrow \mathrm{DMH}$ and POA $\rightarrow \mathrm{RPa}$ pathways had been recognized (Morrison and Nakamura, 2019; Tan and Knight, 2018). Here we add the $\mathrm{POA}^{\mathrm{BRS} 3} \rightarrow \mathrm{PVH}$ and $\mathrm{POA}^{\mathrm{BRS} 3} \rightarrow \mathrm{PAG}$ pathways to the $\mathrm{Tb}$ regulation landscape. The $\mathrm{RPa}$ receives input from the $\mathrm{DMH}$ and drives preganglionic sympathetic neurons that activate BAT and the cardiovascular system (Cao et al., 2004; Cao and Morrison, 2003), e.g. in response to cold (Nakamura and Morrison, 2007), but $\mathrm{POA}^{\mathrm{BRS} 3} \rightarrow \mathrm{RPa}$ activation does not increase $\mathrm{Tb}$. Earlier reports suggest $\mathrm{POA} \rightarrow \mathrm{RPa}$ populations are glutamatergic and can express EP3R (Nakamura et al., 2009, Neuroscience; Machado et al., 2020) or QRFP (Takahashi et al., 2020), but activation of the latter did not change $\mathrm{Tb}$. The PVH might increase $\mathrm{Tb}$ by direct projections 
to preganglionic sympathetic neurons (Sutton et al., 2014), however, see (Madden and Morrison, 2009). The PAG output pathway has not been defined. It is also not known if these nuclei contribute equally to other thermoregulatory physiology, such as blood flow redistribution to regulate heat conservation/loss.

The HR response to stimulation of $\mathrm{POA}^{\mathrm{BRS} 3} \rightarrow \mathrm{DMH}$ and $\mathrm{POA}^{\mathrm{BRS} 3} \rightarrow \mathrm{PVH}$ neurons is mediated by the sympathetic nervous system. Propranolol at $5 \mathrm{mg} / \mathrm{kg}$ partially and at $50 \mathrm{mg} / \mathrm{kg}$ more completely inhibits sympathetic innervation of the heart (Prando et al., 2018). With a small $\mathrm{HR}$ increase persisting during optogenetic stimulation of $\mathrm{POA}^{\mathrm{BRS} 3}$ neurons with $50 \mathrm{mg} / \mathrm{kg}$ propranolol, one cannot rule out a small parasympathetic contribution, but the predominant route is clearly sympathetic. As part of the cold-defense response in small mammals such as rats and mice, the HR increases, increasing cardiac output to provide fuel and oxygen to BAT and to distribute heat from BAT to the body, and possibly to directly generate heat from cardiac work. In contrast, mild cold exposure in humans slightly reduces HR, likely via a reflex bradycardia compensating for increased blood pressure due to vasoconstriction (Brychta et al., 2019; Hess et al., 2009). While the $\mathrm{POA}^{\mathrm{BRS} 3} \rightarrow \mathrm{RPa}$ activation did not alter $\mathrm{Tb}$, we did not test if this pathway regulates the cardiovascular system.

\section{Classes of $P O A^{B R S 3}$ neurons-unraveling the complexity \\ POA $^{\mathrm{BRS3}}$ neurons are not a single population, as analysis of the Moffit et al dataset} identifies a minimum of one glutamatergic and five GABAergic POA ${ }^{\mathrm{BRS} 3}$ populations. Since Vglut2-expressing neurons mediate the metabolic actions of BRS3 (Xiao et al., 2017), we hypothesize that the $\mathrm{POA}^{\mathrm{BRS} 3}$ neurons that increase $\mathrm{Tb}$ and HR use glutamatergic transmission. This would be in line with findings showing a glutamatergic POA $\rightarrow \mathrm{DMH}$ pathway involved in cold defense (da Conceicao et al., 2020). Intersectional strategies to selectively manipulate discrete subsets of BRS3 populations $\left(\mathrm{POA}^{\mathrm{BRS} 3 / \mathrm{Vglut} 2}\right.$ vs $\mathrm{POA}{ }^{\mathrm{BRS} 3 / \mathrm{Vgat} 2}$ and also those expressing other markers of thermogenic neurons--BDNF, PACAP, and/or NOS1) can address this question.

The POA is an anatomically complex region. We optogenetically activated the anteroventral POA that includes the ventral MnPO, VMPO, and VLPO while the chemogenetic experiments additionally included the dorsal MnPO and MPA. These anatomic differences may account for the differences between the optogenetic (increasing $\mathrm{Tb}$ ) vs chemogenetic (biphasic effect) activation. Further studies are needed to examine anatomical subgroupings of $\mathrm{POA}^{\mathrm{BRS} 3}$ neurons.

Activating $\mathrm{POA}^{\mathrm{BRS} 3} \rightarrow \mathrm{PVH}, \mathrm{POA}^{\mathrm{BRS} 3} \rightarrow \mathrm{DMH}$, or $\mathrm{POA}^{\mathrm{BRS} 3} \rightarrow \mathrm{PAG}$ neurons each increased $\mathrm{Tb}$. This could be via three distinct neuronal populations projecting to one area each or via one population of neurons having collaterals to three areas. The $\mathrm{POA}^{\mathrm{BRS} 3} \rightarrow \mathrm{PVT}$ and $\mathrm{POA}^{\mathrm{BRS} 3} \rightarrow \mathrm{RPa}$ populations are distinct, as their activation did not affect $\mathrm{Tb}$. Thus, consideration of projections may also increase the number of $\mathrm{POA}^{\mathrm{BRS} 3}$ classes, and we have studied the function of only five of the output pathways. Investigation is needed to precisely define $\mathrm{POA}^{\mathrm{BRS} 3}$ neuron classes by mRNA expression pattern, neurotransmitter type, cell body location, output field, and physiologic effect.

Functions of $P O A^{B R S 3}$ neurons 
The POA ${ }^{\mathrm{BRS3}}$ neurons increase Tb and HR to contribute to cold defense. The effector pathway for POA neurons to activate BAT has been summarized as a POA $\rightarrow$ DMH inhibitory pathway, which is inhibited to warm up the animal (Morrison and Nakamura, 2019), although a POA $\rightarrow$ DMH excitatory pathway also contributes (da Conceicao et al., 2020). One example illustrating the greater underlying complexity is a glutamatergic parathyroid hormone 2 receptorexpressing POA $\rightarrow$ DMH neuron population that can activate BAT (Dimitrov et al., 2011). The $\mathrm{POA}^{\mathrm{BRS} 3}$ neurons increase $\mathrm{Tb}$ by projections to the $\mathrm{DMH}, \mathrm{PVH}$, and $\mathrm{PAG}$, adding the $\mathrm{PVH}$ and PAG as direct POA thermogenic pathways beyond the DMH and RPa. A prior report proposed that the DMH mediates all autonomic responses evoked from the POA (Hunt et al., 2010). That observation is consistent with the result of optogenetic stimulation of POA ${ }^{\text {All }}$ neurons, but is superseded by the more nuanced information from studying neuronal subpopulations such as $\mathrm{POA}^{\mathrm{BRS} 3}$.

The PVH is considered an essential contributor to cold defense, regulating BAT sympathetic activity through projections to the spinal cord intermediolateral column (Amir, 1990; Cano et al., 2003; Saper et al., 1976), but see also (Madden and Morrison, 2009). The PVH also originates sympathetic signaling to other organs, including the heart (Nunn et al., 2011). The $\mathrm{POA} \rightarrow \mathrm{PVH}$ pathway has been implicated in autonomic cardiovascular and renal regulation (Frazier et al., 2020; Llewellyn et al., 2012; Marciante et al., 2020; McKinley et al., 2015; Sawchenko and Swanson, 1983; Stocker and Toney, 2005), but less in Tb regulation. We now show that $\mathrm{POA}^{\mathrm{BRS} 3} \rightarrow \mathrm{PVH}$ neurons regulate $\mathrm{Tb}, \mathrm{HR}$, and MAP through the sympathetic nervous system.

$\mathrm{MnPO} \rightarrow \mathrm{PAG}$ neurons are activated by various challenges (Uschakov et al., 2009; Yoshida et al., 2005): neurons in the PAG can activate BAT (Cano et al., 2003; Chen et al., 2002) and stimulation of hypothalamic projections to PAG increased Tb (de Git et al., 2018). We now report that selectively stimulating $\mathrm{POA}^{\mathrm{BRS} 3} \rightarrow \mathrm{PAG}$ projections increased $\mathrm{Tb}$. More experiments will further establish the function of this pathway.

Together, we establish BRS3 as a marker for the thermogenic POA $\rightarrow$ DMH pathway and add two new pathways, $\mathrm{POA}^{\mathrm{BRS} 3} \rightarrow \mathrm{PVH}$ and $\mathrm{POA}^{\mathrm{BRS} 3} \rightarrow \mathrm{PAG}$, that can increase $\mathrm{Tb}$ when activated. All possibly contribute to the cold defense response.

$P O A^{B R S 3}$ neurons fine-tune regulation of $T b$

$\mathrm{POA}^{\mathrm{BRS} 3}$ neurons are not merely upstream drivers of BAT activation. They also provide the interesting function of fine-tuning $\mathrm{Tb}$ regulation. When $\mathrm{POA}^{\mathrm{BRS} 3}$ neurons were constitutively silenced, $\mathrm{Tb}$ was more variable with a tendency to bidirectionally overshoot the $\mathrm{Tb}$ of the controls. Although non-significant in some cases, mice with silenced $\mathrm{POA}^{\mathrm{BRS} 3}$ neurons generally had a lower $\mathrm{Tb}$ during times with lower $\mathrm{Tb}$ (fasting-induced hypothermia, cold Ta, light phase) and a higher $\mathrm{Tb}$ during times with higher $\mathrm{Tb}$ (hot Ta, dark phase, handling, LPS treatment, BRS3 agonist treatment).

Taking advantage of the robust signal in $\mathrm{POA}^{\mathrm{BRS} 3}$ silenced mice, we studied the timing of central thermal acclimation. In the silenced mice, $\mathrm{Tb}$ acclimation occurred by $\sim 3$ days after shifting from $22{ }^{\circ} \mathrm{C} \rightarrow 30{ }^{\circ} \mathrm{C}$, while acclimation from $30{ }^{\circ} \mathrm{C} \rightarrow 22{ }^{\circ} \mathrm{C}$ took $\sim 3-5$ days. To our knowledge the timing of central thermal adaptation in mice has not been reported previously. 
Longer times, 1-2 weeks, are required for full remodeling of peripheral BAT in response to cold exposure (Cinti, 2009).

It is notable that in each situation studied, the silenced mice made the physiologically appropriate underlying response to the intervention, albeit accompanied by overshoot and increased variability. The mice did not overcome this mis-regulation - it was stable over the 6 months they were studied. Since the Tb variability of $B r s 3^{-y}$ mice is not increased (Lateef et al., 2014), this effect is a property of POA ${ }^{\mathrm{BRS} 3}$ neurons and not due to a deficit in BRS3 signaling perse.

In other examples of $\mathrm{Tb}$ overshoot, the overshoot is not bidirectional. Mice with ablated $\mathrm{MnPO}^{\mathrm{Vgat}}$ or $\mathrm{MnPO}^{\mathrm{Vglut} 2}$ neurons have the same or higher Tb in both hot and cold environments (Machado et al., 2020). Mice lacking adipose tissue (Gavrilova et al., 1999), overexpressing FGF21 (Inagaki et al., 2007), or with ablated orexin neurons (Futatsuki et al., 2018) have lower $\mathrm{Tb}$ upon challenge with cold or fasting, while none appears to overshoot an increased $\mathrm{Tb}$ situation. Thus, one possibility is that the overshoots in $\mathrm{POA}^{\mathrm{BRS} 3}$ silenced mice are due to silencing of two opposing $\mathrm{POA}^{\mathrm{BRS3}}$ neuronal populations. This is supported by the faster return to baseline in our chemogenetic activation data. Furthermore, some POA BRS3 populations also express PTGDS, BDNF, PACAP, ER1a, NOS1 and galanin, all markers for neurons driving hypothermia when activated and/or involved in the heat or torpor response.

A different possible mechanistic explanation for the overshoot is impaired sensation and evaluation of the internal and/or external environment. Multiple ion channels contribute to

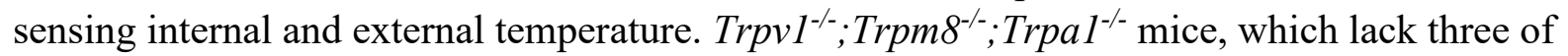
these channels, have remarkably normal thermal biology and Tb variability (Skop et al., 2020a). In contrast, mice with neonatal ablation of sensory neurons with resiniferatoxin do show increased $\mathrm{Tb}$ variability and their $\mathrm{Tb}$ is even more poikilothermic (lower in a cold Ta and higher in a warm Ta) than the POA ${ }^{\mathrm{BRS} 3}$ silenced mice (Skop et al., 2020a). It is possible that POA ${ }^{\mathrm{BRS} 3}$ neurons integrate sensory information for $\mathrm{Tb}$ regulation. Along these lines, another possibility for the increased $\mathrm{Tb}$ variability is that the thermal sensory information from the LPB is not properly integrated in the POA integrative thermoregulatory circuitry when the POA ${ }^{\mathrm{BRS} 3}$ neurons are permanently silenced. This could make the system more labile.

BRS3 is a marker for multiple neuronal populations in the POA that are involved in increasing $\mathrm{Tb}, \mathrm{HR}$, and MAP via sympathetic nerves. $\mathrm{POA}^{\mathrm{BRS} 3}$ neurons contribute to cold defense and fine-tuning of $\mathrm{Tb}$ regulation. Further identification of $\mathrm{POA}^{\mathrm{BRS} 3}$ neuron subclasses, and their connectivity and function, will advance our understanding of homeothermy, a defining feature of mammalian biology.

\section{Limitations of Study}

One limitation is the existence of multiple POA ${ }^{\mathrm{BRS} 3}$ neuronal populations. Thus, further studies are needed to identify molecular markers allowing selective study of POA ${ }^{\text {BRS3 }}$ subpopulations, with elucidation of each neuronal subpopulation's neurotransmitters, functions, inputs, and projections. For instance, an unanswered question is if the thermogenic POA ${ }^{\mathrm{BRS} 3}$ neurons are glutamatergic, GABAergic or both. Also, the identities of the downstream neurons in $\mathrm{PVH}$ and DMH and their pathways are need for a fuller picture of the circuits. Finally, we have not performed in vivo imaging to correlate neuronal activation with specific thermal biology. 
Acknowledgments We thank Alice Franks for superb technical assistance, Yuning Huang for EMitter implantation, Naili Liu for indirect calorimetry, and Audrey Noguchi and Danielle Springer of the NHLBI Murine Phenotyping Core for the cardiovascular telemetry implantation surgeries. This research was supported by the Intramural Research Program of the National Institutes of Health, National Institute of Diabetes and Digestive and Kidney Diseases (ZIA DK075062; ZIA DK075063, ZIA DK075064, ZIA DK070002, ZIA DK075087, ZIA DK075088).

Author contributions RAP and MLR conceived and designed the study with input from MJK, OG, and CX. RAP performed and analyzed the experiments. RAP, ASM, CKH and AS performed optogenetic experiments, immunohistochemistry and counted cells. RAP, CKH and AS performed tracing experiments. OG performed indirect calorimetry experiments. VS and RAP performed IR experiments. CL and RAP performed electrophysiology experiments. CKH analyzed expression profiling data. ASM, RAP, and HSP performed chronic silencing experiments. RAP wrote the manuscript with input from MLR and all other authors.

Declaration of Interests The authors declare no competing interests.

\section{Methods}

Animals. Animal studies were approved by the NIDDK/NIH Animal Care and Use Committee (protocol K016-DEOB-20). Mice were singly housed after surgery at $21-22{ }^{\circ} \mathrm{C}$ with lights on 6 am-6 pm. Chow (7022, Envigo, Indianapolis, IN) and water were available ad libitum, including during drug treatments, indirect calorimetry, and optogenetic experiments, with exception of infrared thermography and food intake experiments as indicated. Mice used were: Brs3-2ACreER $^{\mathrm{T} 2}$ (BRS3-Cre; Jax\# 032614) (Pinol et al., 2018), B6.Cg-Gt.(Rosa)26Sortm6(CAGZsGreen1)Hze/J, with Cre-dependent ZsGreen (Ai6; Jax\# 007906) (Madisen et al., 2010), B6.Cg-Gt(ROSA)26Sortm14(CAG-tdTomato)Hze/J, with Cre-dependent tdTomato (Ai14; Jax\# 007914) (Madisen et al., 2010), Gad2-2a-NLS-mCherry (Gad2-mCherry; Jax\# 023140)(Peron et al., 2015), and C57BL/6J (Jax\# 000664). Brs3 is on the X chromosome and male mice were used, unless otherwise noted. For all behavioral and physiological studies, male mice were between 8 and 45 weeks of age. Mice for ChR2-assisted circuit mapping (CRACM) studies (male) were between 5 and 13 weeks of age. Mice were on a mixed C57BL/6J and 129SvEv background. Mice from multiple litters were used for all studies.

Tamoxifen. Cre-mediated recombination was achieved by treatment with tamoxifen (75-110 $\mathrm{mg} / \mathrm{kg}$ i.p. in corn oil; Sigma Aldrich) daily for 5 consecutive days, with mice studied $\geq 4$ weeks after the first dose.

Stereotaxic injections. General surgical procedures. Mice were anesthetized with $0.5-1.5 \%$ isoflurane (1 L/min oxygen) or a ketamine/xylazine mix $(80 / 10 \mathrm{mg} / \mathrm{kg}$, i.p.), placed in a stereotaxic instrument (Digital Just for Mouse Stereotaxic Instrument, Stoelting), and ophthalmic ointment (Puralube, Dechra) was applied. Brain injections were done with pulled-glass pipettes (pulled 20-40 $\mu \mathrm{m}$ tip diameter; $0.275 \mathrm{~mm}$ ID, $1 \mathrm{~mm}$ OD, Wilmad Lab Glass) at a visually controlled rate of $\sim 50 \mathrm{nl}$ per min with an air MAP system regulator (Grass Technologies, Model S48 Stimulator). The pipette was kept in place for $5 \mathrm{~min}$ after injection. Post-surgery, mice 
received subcutaneous saline injections to prevent dehydration and analgesic (buprenorphine, 0.1 $\mathrm{mg} / \mathrm{kg}$, s.c.).

Viral vectors. We used the following viruses: AAV1-efla-DIO-ChR2-EYFP (gift from K. Deisseroth; Addgene viral prep 20298-AAV1); AAV9-Ef1a-DO-hChR2(H134R)-mCherry (gift from B. Sabatini; Addgene plasmid 37082(Saunders et al., 2012); Vigene Biosciences, Inc.); AAV8-Ef1a-DIO-synaptophysin-mCherry (Virovek, Inc.); AAV-DJ-CMV-DIO-eGFP-2A-TeNT (Stanford Viral Core GVVCAAV-71; Similar to (Campos et al., 2018)); AAV5-EF1a-DIOEYFP-WPRE-pA (UNC Vector Core); pAAV8-hSyn-DIO-hM4D(Gi)-mCherry (gift from B. Roth; Addgene viral prep \# 44362-AAV8), pAAV8-hSyn-DIO-hM3D(Gq)-mCherry (gift from B. Roth; Addgene viral prep 44361-AAV8), AAV8-Efla-DIO-mCherry (gift from B. Roth; Addgene viral prep \# 50459-AAV8)(Krashes et al., 2011); AAV8-Ef1a-FLEX-TVA-mCherry (UNC vector core); EnvA-G-Deleted-Rabies-Egfp (Gene Transfer, Targeting and Therapeutics Core at Salk Institute).

Immunohistochemistry. Tissue Preparation. Mice were anesthetized (chloral hydrate, 500 $\mathrm{mg} / \mathrm{kg}$, i.p.), perfused transcardially with $0.9 \%$ saline followed by $10 \%$ neutral buffered formalin, and the brain was removed. Brains were post-fixed (10\% formalin, room temperature, overnight) and incubated in $30 \%$ sucrose in $0.1 \mathrm{M}$ PBS $\left(4^{\circ} \mathrm{C}\right.$, overnight or until use $)$, sectioned coronally into three equal series (50 $\mu \mathrm{m}$ sections) on a sliding microtome (SM2010 R, Leica) and collected in $0.1 \mathrm{M}$ PBS. Sections were washed $3 \times 10$ minutes in $0.1 \mathrm{M}$ PBS and the following steps were performed with shaking at room temperature and in $0.1 \mathrm{M}$ PBS solutions, unless noted otherwise: $m$ Cherry. Sections were incubated for 1 hour in $0.3 \%$ Triton X-100, 3\% normal goat serum (NGS) and then incubated overnight with 1:2000 rabbit-anti-DsRed (632496, Clontech) (Geerling et al., 2017) in $0.3 \%$ Triton X-100, 3\% NGS. Sections were washed, incubated (2 hours) with secondary antibody (1:500 Alexa-555 goat-anti-rabbit; A-21428, Thermo Fisher) in $0.3 \%$ Triton X-100 and $2 \%$ NGS.

GFP. Sections were processed as for mCherry, using 1:1000 chicken-anti-GFP (13970, Abcam) and 1:500 Alexa-488 goat-anti-chicken (A-11039, Thermo Fisher) as the primary and secondary antibodies.

After incubation with secondary antibody, sections were washed, mounted and cover slipped with Prolong mounting medium containing DAPI (Thermo Fisher).

Optogenetics. Virus injections and fiber implantation. BRS3-Cre or BRS3-Cre;Ai14 mice were injected with $50 \mathrm{nl}$ AAV1-Efla-DIO-ChR2-EYFP, AAV9-Efla-DIO-hChR2(H134R)-mCherry, AAV9-Ef1a-DO-hChR2(H134R)-mCherry or, as controls, AAV8-Ef1 a-DIO-mCherry in the anteroventral POA (AP: 0.35; ML: 0.3; DV: -5.25, mm from bregma). Following virus injection, optical fibers (200 $\mu \mathrm{m}$ diameter core; NA 0.22 ; Nufern), glued to ceramic zirconia ferrules (230 $\mu \mathrm{m}$ bore; 1.25 OD diameter; Precision Fiber Products), were implanted unilaterally over the anteroventral POA (AP: 0.35; ML: 0.3; DV: -4.5, mm from bregma), PVH (AP: -0.9; ML: 0.25; DV: -4.5 , mm from bregma), DMH (AP: -1.85; ML: 0.3; DV: -4.5, mm from bregma), PVT (AP: -1.85; ML: 0.3; DV: -2.2, mm from bregma), RPa (AP: -6.1; ML: 0; DV; -5.50, mm from bregma) or PAG (AP: -4.5; ML: 0.5; DV: -2.0, mm from bregma). Fibers were fixed to the skull using C\&B Metabond Quick Cement and dental acrylic. 
Experimental procedures. Mice were allowed to adapt to the fiber patch cord for at least two days prior to experiments and typically not handled on the day of the experiment. Fiber optic cables (200 $\mu \mathrm{m}$ diameter, NA 0.22, $1 \mathrm{~m}$ long, Doric Lenses; or, 0.5m long, ThorLabs) were connected to the implanted fiber optic cannulas with zirconia sleeves (Precision Fiber Products) and coupled to lasers via a fiber optic rotary joint (Doric Lenses). We adjusted the light power of the laser (473 nm; Laserglow or Opto Engine) such that the light power (measured with a fiber optic power meter; PM20A; ThorLabs) at the end of the fiber optic cable was $\sim 10 \mathrm{~mW}$. Using an online light transmission calculator for brain tissue (https://web.stanford.edu/group/dlab/cgibin/graph/chart.php), we estimated the light power at tip of implanted fiber between 3 and 6 $\mathrm{mW} / \mathrm{mm}^{2}$. This is an upper limit due to possible light loss between the fiber optic cable and the implanted optic fiber. Light pulses were controlled by a programmable waveform generator (Arduino). Pulses were $10 \mathrm{~ms}$ delivered at $20 \mathrm{~Hz}$ and stimulation was on for $1 \mathrm{~s}$, followed by $3 \mathrm{~s}$ off (POA and IR study) or $1 \mathrm{~s}$ on/ $1 \mathrm{~s}$ off $\left(\mathrm{POA}^{\mathrm{BRS} 3}\right.$ projections) or continuous (short stimulations in POA). After completion of experiments, fiber placement and ChR2 expression were assessed. Animals without ChR2 expression or incorrect placement of optic fibers were excluded from analysis.

Analysis: Within each mouse, the multiple optogenetic stimulation epochs (5-10) were normalized to the baseline immediately before laser on and averaged. Because of the body's heat capacity, $\mathrm{Tb}$ changes are gradual (unlike HR and MAP), so we used 10 to 19 min from laser on as the $\mathrm{Tb}$ response period, but 0 to $9 \mathrm{~min}$ for $\mathrm{HR}$, MAP, and physical activity. Response period is indicated as On. Off is -10 to $-1 \mathrm{~min}$ before laser On.

Chemogenetics experiments $P O A$ virus injection. BRS3-Cre or BRS3-Cre;Ai6 mice received bilateral injections of $50 \mathrm{nl}$ AAV8-hSyn-DIO-hM3Dq-mCherry or AAV8-hSyn-DIO-hM4DimCherry in the anterior POA (AP: +0.35; ML: +/- 0.30; DV: $-5.30, \mathrm{~mm}$ from bregma). Expression was verified after IHC for mCherry. All included POA $^{\mathrm{BRS} 3}:: \mathrm{hM} 3 \mathrm{Dq}$ mice had bilateral expression in MnPO, VMPO, and MPA.

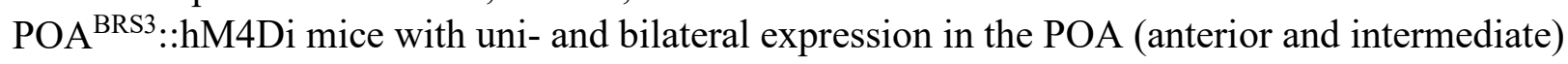
were used. Mice without hM4Di-mCherry expression were excluded. BNST virus injection. BRS3-Cre or BRS3-Cre;Ai6 mice received bilateral injections of $50 \mathrm{nl}$ AAV8-hSyn-DIO-hM3Dq-mCherry or AAV8-hSyn-DIO-mCherry in the BNST (AP: -0.22; ML: +/- 0.85; DV: -3.75, mm from bregma). Mice with uni- and bilateral hits were used. Mice without hM3Dq-mCherry expression were excluded.

Tb telemetry. $\mathrm{Tb}$ experiments were performed described as below and in legends. The return to baseline $\mathrm{Tb}$ was measured as the minute the $\mathrm{Tb}$ is within $0.05^{\circ} \mathrm{C}$ of the mean baseline $(-150$ to $30 \mathrm{~min}$ ). One mouse consistently did not return to baseline and was excluded from analysis. Food intake inhibition. Mice were fasted five hours before the onset of their dark cycle. Mice were dosed with $\mathrm{CNO}$ or vehicle 15 minutes prior to lights out. Food intake was measured two hours following dosing.

Food intake stimulation. Ad-lib fed mice were dosed with CNO or vehicle four hours into the light cycle and food was removed. After 15 minutes food was returned and food intake was measured over the next two hours.

Body temperature telemetry. Animals were anesthetized as above and E-Mitters (Starr Life Sciences) were implanted intraperitonially (Lute et al., 2014). At least two days before 
experiments, mice were housed in temperature-controlled chamber in their home cages on ER4000 energizer/receivers (Starr Life Sciences). Tb and activity were continuously measured by telemetry with 1-min means collected with VitalView software (Starr Life Sciences). Experiments were performed at $22{ }^{\circ} \mathrm{C}$, unless indicated otherwise. Physical activity is measured in arbitrary units.

Blood pressure and heart rate telemetry. In a subset of mice with a $\mathrm{Tb}$ response to optogenetic stimulation, we replaced the E-Mitter with an intra-arterial pressure telemetry probe (model HDX10 or HD-X11; Data Sciences International, St Paul, MN) and continuous ambulatory blood pressure, heart rate, physical activity and subcutaneous (HD-X10) or intraperitoneal (HD-X11) Tb were measured (Kim et al., 2008). Data were sampled at $1000 \mathrm{~Hz}$, processed using a PhysioTel RPC-1 receiver, and collected with Ponemah v6.30 (Data Sciences International). Unless noted, $1 \mathrm{~min}$ averages were used for analysis. Physical activity is measured in arbitrary counts.

Drugs. Lipopolysaccharide from Salmonella enterica serotype typhimurium (LPS; Sigma) was dissolved in sterile saline and administered at $100 \mu \mathrm{g} / \mathrm{kg}$ i.p. MK-5046 (Sebhat et al., 2011) (MedChemExpress, Monmouth Junction, NJ) was dissolved in vehicle of 10\% Tween 80/0.25\% methylcellulose in saline and administered at $10 \mathrm{mg} / \mathrm{kg}$ i.p. Propranolol is a $\beta$-adrenergic antagonist that has $\sim 100$-fold selectivity for $\beta 1$ and $\beta 2$ over $\beta 3$ adrenergic receptors (Baker, 2005; Cernecka et al., 2014; Popp et al., 2004). Propranolol (Sigma) was dosed i.p. at 0-100 $\mathrm{mg} / \mathrm{kg}$ (vehicle was 10\% DMSO for $30-100 \mathrm{mg} / \mathrm{kg}$; water for lower doses) for the $\mathrm{Tb}$ dose response. For the cardiovascular response propranolol (vehicle, 10\% DMSO) was injected at 0 , 5 , or $50 \mathrm{mg} / \mathrm{kg}$, i.p., at $5 \mu \mathrm{l} / \mathrm{g}$.

Anterograde and collateral tracing. Anterograde tracing. BRS3-Cre or BRS3-Cre;Ai6 mice were injected with $25 \mathrm{nl}$ of AAV8-Efla-DIO-synaptophysin-mCherry in the anteroventral POA (AP: 0.35; ML: 0.3; DV: -5.25, mm from bregma). Mice were euthanized 5-8 weeks after start of tamoxifen treatment and brains processed for immunohistochemistry (see above). All 5 mice with expression limited to the anterior POA had consistent axonal projections to described areas. $P O A^{B R S 3} \rightarrow D M H$ collateral tracing AAV-DIO-TVA-mCherry was unilaterally injected in the POA of BRS3-Cre mice $(50 \mathrm{nl})$. $>4$ weeks after tamoxifen treatment retrograde G-deletedRabies-GFP (100 nl) was (ipsilateral as the first viral injection) injected in the DMH. Mice were perfused $12 \mathrm{~d}$ after last injection and brains processed for IHC for GFP and mCherry.

Quantitative thermal imaging in freely moving mice. Shaved skin temperatures in the interscapular and dorsal lumbar regions were used as measures of BAT and core body temperature, respectively (Gachkar et al., 2017; Pinol et al., 2018; Vianna and Carrive, 2012) (Skop et al., 2020b). In brief, one day prior to study, the interscapular region and a 2 x $2 \mathrm{~cm}$ midline area $2 \mathrm{~cm}$ above the tail were shaved under isoflurane anesthesia. After housing overnight in their home cage with the optical fiber attached, mice were placed in a $20 \times 20 \mathrm{~cm}$ enclosure with bedding, $170 \mathrm{~cm}$ below the infrared (IR) camera (T650sc, FLIR Systems, Wilsonville, OR), and acclimated for $3 \mathrm{~h}$. Mice then underwent 3 cycles of 20 min baseline, 20 min laser on, and 40 min post-stimulation, with IR images collected continuously using ResearchIR software (FLIR Systems, Wilsonville, OR; 7.5 frames per second; IR emissivity set 
to 0.97 (Pinol et al., 2018)). Maximum interscapular and lumbar temperatures were determined by a blinded observer every 2 minutes using FLIR Tools ${ }^{\circledR}$ (FLIR Systems, Wilsonville, OR). Tail temperature was measured $1 \mathrm{~cm}$ from the body at baseline ( 0 to 20 minutes before stimulation onset) and during stimulation (6 to 10 minutes after stimulation onset). A limit of this assay is that the mice need to be awake and moving for the camera to capture the tail. The ambient temperature was $25-26^{\circ} \mathrm{C}$. Infrared data were exported as a video file, from which physical activity was determined by EthoVision XT software (Noldus, Leesburg, VA).

Neurochemical identity. We bred triple transgenic mice (BRS3-Cre;Ai6;Gad2-mCherry) in which Gad2 neurons express mCherry and BRS3 neurons express ZsGreen. We performed immunohistochemistry for mCherry and counted the colocalization of BRS3-positive neurons and Gad2-positive neurons in every third coronal brain section. Data are presented as mean with individual mice.

Electrophysiology. BRS3-Cre mice (5-10 weeks) received bilateral $50 \mathrm{nl}$ injections of AAV1Efla-DIO-ChR2-EYFP in the anteroventral POA (AP: 0.5; ML: +/- 0.3; DV: -5.25, mm from bregma). Four to 6 weeks later, brain slices were obtained and stored at $30^{\circ} \mathrm{C}$ in a heated, oxygenated chamber containing aCSF (in mmol/1) $124 \mathrm{NaCl}, 4.4 \mathrm{KCl}, 2 \mathrm{CaCl}_{2}, 1.2 \mathrm{MgSO}_{4}, 1$ $\mathrm{NaH}_{2} \mathrm{PO}_{4}, 10.0$ glucose, and 26.0 sodium bicarbonate before being transferred to a submerged recording chamber maintained at $30^{\circ} \mathrm{C}$ (Warner Instruments, Hamden, CT). Recording electrodes (3-5 M $\Omega$ ) were pulled with a Flaming-Brown Micropipette Puller (Sutter Instruments, Novato, CA) using thin-walled borosilicate glass capillaries.

Light evoked excitatory and inhibitory postsynaptic currents (EPSCs and IPSCs, respectively) were measured in voltage-clamp mode using electrodes filled with an intracellular recording solution containing (in $\mathrm{mM}$ ): $135 \mathrm{Cs}$-methanesulfonate, $10 \mathrm{KCl}, 10 \mathrm{HEPES}, 1 \mathrm{MgCl}_{2}$, 0.2 EGTA, 4 Mg-ATP, 0.3 GTP, 20 phosphocreatine, 2 QX314. Neurons were held at $-55 \mathrm{mV}$ to isolate glutamatergic synaptic transmission and record EPSCs, or $+10 \mathrm{mV}$ to isolate GABAergic synaptic transmission and record spontaneous IPSCs within individual neurons. Tetrodotoxin (TTX, $500 \mathrm{nM}$ ) and 4-aminopyridine (4-AP, $100 \mu \mathrm{M})$ were included in the bath aCSF.

Tetanus toxin (TeNT) treatment. AAV injections and expression. TeNT cleaves synaptobrevin, leaving neurons viable but permanently unable to release neurotransmitters (Sweeney et al., 1995). BRS3-Cre or BRS3-Cre;Ai14 mice received $50 \mathrm{nl}$ bilateral injection of AAV-DJ-CMVDIO-eGFP-2A-TeNT (control: AAV5-EF1a-DIO-EYFP-WPRE-pA) into the POA (AP: 0.35; ML: 0.3; DV: $-5.25, \mathrm{~mm}$ from bregma) to chronically silence, but not kill, $\mathrm{POA}^{\mathrm{BRS} 3}$ neurons. They were also implanted with E-Mitters (see above). After completion of the experiments, brains were processed for immunohistochemistry for GFP and histological analysis. GFP-TeNTexpressing neurons were counted in every third $50 \mu \mathrm{m}$ coronal section in POA (median preoptic area (MnPO), ventromedial preoptic area (VMPO), and ventrolateral preoptic area (VLPO)) in 4 sections per mouse.

Fasting. Mice in their home cages were food-deprived for $24 \mathrm{~h}$, starting just before the onset of the dark cycle. 
Responses to acute Ta changes. Tb and physical activity were recorded in response to acute $3 \mathrm{~h}$ Ta changes (last $2 \mathrm{~h}$ used for analysis) after $>3 \mathrm{~d}$ adaptation to regular housing $\mathrm{Ta}\left(22^{\circ} \mathrm{C}\right)$ or a warmer Ta $\left(30^{\circ} \mathrm{C}\right)$.

Drug studies. Drug or respective vehicles were administered 4-6 $\mathrm{h}$ into the light cycle in a crossover design.

Cage switch. Mice were switched to a clean cage, which causes a stress response (Balcombe et al., 2004; Rasmussen et al., 2011).

Indirect calorimetry. An Oxymax/CLAMS (Columbus Instruments) was used to measure Tb, total energy expenditure (TEE), RER (respiratory exchange ratio, $\mathrm{O}_{2}$ consumed: $\mathrm{CO}_{2}$ produced), and activity by beam break simultaneously in mice implanted with E-Mitters (Lute et al., 2014). Mice were acclimated in the chambers for 2 days before start of the experiment. Experiments were performed at $22^{\circ} \mathrm{C}$ and $30^{\circ} \mathrm{C}$, as indicated. Sampling was every 13 minutes, measuring from 12 chambers.

scRNA analysis. The scRNA seq count matrix for GSE113576 (Moffitt et al., 2018) was analyzed with R (v. 4.0.3) using Seurat (v.3.2.2) (Butler et al., 2018; Stuart et al., 2019). Raw counts were normalized, scaled, and the 2,000 most variable genes were used as input for principal component (PC) analysis. Cells were then clustered (PC: 75, resolution: 1.2) and visualized with t-SNE. Clusters enriched for neuronal markers (Snap25, Eno2, Tubb3, Stmn2) and de-enriched for non-neuronal markers were selected for downstream analysis. Of the 18,401 neuronal cells, we re-clustered the 581 neurons with $\geq 1$ UMI corresponding to Brs 3 using the same pipeline as above (PC: 15 , resolution: 0.5 ). Differentially expressed genes (DEGs) and cluster marker genes were identified using the Wilcoxon Rank Sum test. Cluster names were assigned with one significantly enriched marker gene (average log2 fold change $\geq 0.75$ and FDR adjusted p-value $\leq 1.238 \mathrm{E}-20$ ). Clusters labeled beginning with 'i' represent inhibitory clusters enriched with Vgat, while that labeled with 'e' represents an excitatory cluster enriched with Vglut2. The cluster labeled 'Apoptotic' is enriched for several mitochondrial genes, suggesting cell death.

Image capture and processing. General procedure. Overview images to verify optic fiber placement and viral expression were captured using an Olympus BX61 motorized microscope with Olympus BX-UCB hardware (VS120 slide scanner) and processed using Olympus OlyVIA software (Olympus). Confocal imaging for images of viral expression and optic fiber placement and quantification of BRS3-positive/GAD2-positive and TeNT-EGFP neurons was performed with an upright Zeiss Axio Observer Z1 microscope with a 10X objective, Zeiss 700 confocal hardware, and Zen software (2012; Zeiss). Images were minimally processed to adjust brightness and contrast.

Analysis. Images of every third $50 \mu \mathrm{m}$ coronal brain section were acquired and neuron counting and colocalization analysis was performed using neuroanatomical landmarks (Franklin and Paxinos, 2007). Neurons were counted manually with the experimenter blinded to the experimental group.

\section{QUANTIFICATION AND STATISTICAL ANALYSIS}

All data are presented as mean \pm SEM or mean + SEM, unless otherwise indicated. No statistical methods were used to pre-determine sample size but our sample sizes are similar to those 
reported in previous publications (Lute et al., 2014). Data distribution was assumed to be normal, but this was not formally tested in experiments other than the permanent inactivation TeNT experiment. The TeNT mice group had higher variance (Figure S6d, bottom panels) and in comparing TeNT and CTRL mice an unequal variance t-test was used. All t-tests were twosided. All $\mathrm{n}$ numbers refer to number of mice used in the experiment; in some experiments, as indicated, data are the average of multiple observations per mouse. Data collection and analysis were not performed blind to the conditions of the experiments, except for IR camera imaging.

We used paired t-tests (2-sided) for within-mouse comparison of the effect of stimulation or unpaired when comparing two groups (e.g. TeNT vs Control). For comparisons between more than 2 groups, we used a one-way ANOVA with multiple comparison testing. 


\section{References}

Abbott, S.B.G., and Saper, C.B. (2017). Median preoptic glutamatergic neurons promote thermoregulatory heat loss and water consumption in mice. J Physiol 595, 6569-6583.

Amir, S. (1990). Stimulation of the paraventricular nucleus with glutamate activates interscapular brown adipose tissue thermogenesis in rats. Brain Res 508, 152-155.

Baker, J.G. (2005). The selectivity of beta-adrenoceptor antagonists at the human beta1, beta2 and beta3 adrenoceptors. Br J Pharmacol 144, 317-322.

Balcombe, J.P., Barnard, N.D., and Sandusky, C. (2004). Laboratory routines cause animal stress. Contemp Top Lab Anim Sci 43, 42-51.

Brychta, R.J., Huang, S., Wang, J., Leitner, B.P., Hattenbach, J.D., Bell, S.L., Fletcher, L.A., Perron Wood, R., Idelson, C.R., Duckworth, C.J., et al. (2019). Quantification of the Capacity for Cold-Induced Thermogenesis in Young Men With and Without Obesity. J Clin Endocrinol Metab 104, 4865-4878. Butler, A., Hoffman, P., Smibert, P., Papalexi, E., and Satija, R. (2018). Integrating single-cell transcriptomic data across different conditions, technologies, and species. Nat Biotechnol 36, 411-420. Campos, C.A., Bowen, A.J., Roman, C.W., and Palmiter, R.D. (2018). Encoding of danger by parabrachial CGRP neurons. Nature 555, 617-622.

Cano, G., Passerin, A.M., Schiltz, J.C., Card, J.P., Morrison, S.F., and Sved, A.F. (2003). Anatomical substrates for the central control of sympathetic outflow to interscapular adipose tissue during cold exposure. J Comp Neurol 460, 303-326.

Cao, W.H., Fan, W., and Morrison, S.F. (2004). Medullary pathways mediating specific sympathetic responses to activation of dorsomedial hypothalamus. Neuroscience 126, 229-240.

Cao, W.H., and Morrison, S.F. (2003). Disinhibition of rostral raphe pallidus neurons increases cardiac sympathetic nerve activity and heart rate. Brain Res 980, 1-10.

Cernecka, H., Sand, C., and Michel, M.C. (2014). The odd sibling: features of beta3-adrenoceptor pharmacology. Mol Pharmacol 86, 479-484.

Chen, X.M., Nishi, M., Taniguchi, A., Nagashima, K., Shibata, M., and Kanosue, K. (2002). The caudal periaqueductal gray participates in the activation of brown adipose tissue in rats. Neurosci Lett 331, 1720.

Cinti, S. (2009). Transdifferentiation properties of adipocytes in the adipose organ. Am J Physiol Endocrinol Metab 297, E977-986.

Craig, A.D.B. (2018). Central neural substrates involved in temperature discrimination, thermal pain, thermal comfort, and thermoregulatory behavior. Handb Clin Neurol 156, 317-338.

da Conceicao, E.P.S., Morrison, S.F., Cano, G., Chiavetta, P., and Tupone, D. (2020). Median preoptic area neurons are required for the cooling and febrile activations of brown adipose tissue thermogenesis in rat. Sci Rep 10, 18072.

de Git, K.C.G., van Tuijl, D.C., Luijendijk, M.C.M., Wolterink-Donselaar, I.G., Ghanem, A., Conzelmann, K.K., and Adan, R.A.H. (2018). Anatomical projections of the dorsomedial hypothalamus to the periaqueductal grey and their role in thermoregulation: a cautionary note. Physiol Rep 6, e13807. Dimitrov, E.L., Kim, Y.Y., and Usdin, T.B. (2011). Regulation of hypothalamic signaling by tuberoinfundibular peptide of 39 residues is critical for the response to cold: a novel peptidergic mechanism of thermoregulation. J Neurosci 31, 18166-18179.

Dulac, C., O'Connell, L.A., and Wu, Z. (2014). Neural control of maternal and paternal behaviors. Science 345, 765-770.

Franklin, K.B.J., and Paxinos, G. (2007). The Mouse Brain in Stereotaxic Coordinates. (New York: Academic Press).

Frazier, C.J., Harden, S.W., Alleyne, A.R., Mohammed, M., Sheng, W., Smith, J.A., Elsaafien, K., Spector, E.A., Johnson, D.N., Scott, K.A., et al. (2020). An Angiotensin-responsive Connection from the Lamina 
Terminalis to the Paraventricular Nucleus of the Hypothalamus Evokes Vasopressin Secretion to Increase Blood Pressure in Mice. J Neurosci.

Futatsuki, T., Yamashita, A., Ikbar, K.N., Yamanaka, A., Arita, K., Kakihana, Y., and Kuwaki, T. (2018). Involvement of orexin neurons in fasting- and central adenosine-induced hypothermia. Sci Rep 8, 2717. Gachkar, S., Oelkrug, R., Martinez-Sanchez, N., Rial-Pensado, E., Warner, A., Hoefig, C.S., Lopez, M., and Mittag, J. (2017). 3-lodothyronamine Induces Tail Vasodilation Through Central Action in Male Mice. Endocrinology 158, 1977-1984.

Gavrilova, O., Leon, L.R., Marcus-Samuels, B., Mason, M.M., Castle, A.L., Refetoff, S., Vinson, C., and Reitman, M.L. (1999). Torpor in mice is induced by both leptin-dependent and -independent mechanisms. Proc Natl Acad Sci U S A 96, 14623-14628.

Geerling, J.C., Yokota, S., Rukhadze, I., Roe, D., and Chamberlin, N.L. (2017). Kolliker-Fuse GABAergic and glutamatergic neurons project to distinct targets. J Comp Neurol 525, 1844-1860.

Guan, X.M., Chen, H., Dobbelaar, P.H., Dong, Y., Fong, T.M., Gagen, K., Gorski, J., He, S., Howard, A.D., Jian, T., et al. (2010). Regulation of energy homeostasis by bombesin receptor subtype-3: selective receptor agonists for the treatment of obesity. Cell Metab 11, 101-112.

Harding, E.C., Yu, X., Miao, A., Andrews, N., Ma, Y., Ye, Z., Lignos, L., Miracca, G., Ba, W., Yustos, R., et al. (2018). A Neuronal Hub Binding Sleep Initiation and Body Cooling in Response to a Warm External Stimulus. Curr Biol 28, 2263-2273 e2264.

Hess, K.L., Wilson, T.E., Sauder, C.L., Gao, Z., Ray, C.A., and Monahan, K.D. (2009). Aging affects the cardiovascular responses to cold stress in humans. J Appl Physiol (1985) 107, 1076-1082.

Hrvatin, S., Sun, S., Wilcox, O.F., Yao, H., Lavin-Peter, A.J., Cicconet, M., Assad, E.G., Palmer, M.E., Aronson, S., Banks, A.S., et al. (2020). Neurons that regulate mouse torpor. Nature.

Hunt, J.L., Zaretsky, D.V., Sarkar, S., and Dimicco, J.A. (2010). Dorsomedial hypothalamus mediates autonomic, neuroendocrine, and locomotor responses evoked from the medial preoptic area. Am J Physiol Regul Integr Comp Physiol 298, R130-140.

Inagaki, T., Dutchak, P., Zhao, G., Ding, X., Gautron, L., Parameswara, V., Li, Y., Goetz, R., Mohammadi, M., Esser, V., et al. (2007). Endocrine regulation of the fasting response by PPARalpha-mediated induction of fibroblast growth factor 21. Cell Metab 5, 415-425.

Jennings, J.H., Rizzi, G., Stamatakis, A.M., Ung, R.L., and Stuber, G.D. (2013). The inhibitory circuit architecture of the lateral hypothalamus orchestrates feeding. Science 341, 1517-1521.

Jensen, R.T., Battey, J.F., Spindel, E.R., and Benya, R.V. (2008). International Union of Pharmacology. LXVIII. Mammalian bombesin receptors: nomenclature, distribution, pharmacology, signaling, and functions in normal and disease states. Pharmacol Rev 60, 1-42.

Kim, S.M., Eisner, C., Faulhaber-Walter, R., Mizel, D., Wall, S.M., Briggs, J.P., and Schnermann, J. (2008). Salt sensitivity of blood pressure in NKCC1-deficient mice. Am J Physiol Renal Physiol 295, F1230-1238. Kozorovitskiy, Y., Saunders, A., Johnson, C.A., Lowell, B.B., and Sabatini, B.L. (2012). Recurrent network activity drives striatal synaptogenesis. Nature 485, 646-650.

Krashes, M.J., Koda, S., Ye, C., Rogan, S.C., Adams, A.C., Cusher, D.S., Maratos-Flier, E., Roth, B.L., and Lowell, B.B. (2011). Rapid, reversible activation of AgRP neurons drives feeding behavior in mice. The Journal of clinical investigation 121, 1424-1428.

Kroeger, D., Absi, G., Gagliardi, C., Bandaru, S.S., Madara, J.C., Ferrari, L.L., Arrigoni, E., Munzberg, H., Scammell, T.E., Saper, C.B., et al. (2018). Galanin neurons in the ventrolateral preoptic area promote sleep and heat loss in mice. Nat Commun 9, 4129.

Lateef, D.M., Abreu-Vieira, G., Xiao, C., and Reitman, M.L. (2014). Regulation of body temperature and brown adipose tissue thermogenesis by bombesin receptor subtype-3. Am J Physiol Endocrinol Metab 306, E681-687. 
Llewellyn, T., Zheng, H., Liu, X., Xu, B., and Patel, K.P. (2012). Median preoptic nucleus and subfornical organ drive renal sympathetic nerve activity via a glutamatergic mechanism within the paraventricular nucleus. Am J Physiol Regul Integr Comp Physiol 302, R424-432.

Lute, B., Jou, W., Lateef, D.M., Goldgof, M., Xiao, C., Pinol, R.A., Kravitz, A.V., Miller, N.R., Huang, Y.G., Girardet, C., et al. (2014). Biphasic effect of melanocortin agonists on metabolic rate and body temperature. Cell Metab 20, 333-345.

Machado, N.L.S., Bandaru, S.S., Abbott, S.B.G., and Saper, C.B. (2020). EP3R-Expressing Glutamatergic Preoptic Neurons Mediate Inflammatory Fever. J Neurosci 40, 2573-2588.

Madden, C.J., and Morrison, S.F. (2009). Neurons in the paraventricular nucleus of the hypothalamus inhibit sympathetic outflow to brown adipose tissue. Am J Physiol Regul Integr Comp Physiol 296, R831843.

Madisen, L., Zwingman, T.A., Sunkin, S.M., Oh, S.W., Zariwala, H.A., Gu, H., Ng, L.L., Palmiter, R.D., Hawrylycz, M.J., Jones, A.R., et al. (2010). A robust and high-throughput Cre reporting and characterization system for the whole mouse brain. Nat Neurosci 13, 133-140.

Marciante, A.B., Wang, L.A., Little, J.T., and Cunningham, J.T. (2020). Caspase lesions of PVN-projecting $\mathrm{MnPO}$ neurons block the sustained component of $\mathrm{ClH}$-induced hypertension in adult male rats. Am J Physiol Heart Circ Physiol 318, H34-H48.

Maruyama, M., Hotta, N., Nio, Y., Hamagami, K., Nagi, T., Funata, M., Sakamoto, J., Nakakariya, M., Amano, N., Nishida, M., et al. (2018). Bombesin receptor subtype-3-expressing neurons regulate energy homeostasis through a novel neuronal pathway in the hypothalamus. Brain Behav 8, e00881.

McHenry, J.A., Otis, J.M., Rossi, M.A., Robinson, J.E., Kosyk, O., Miller, N.W., McElligott, Z.A., Budygin, E.A., Rubinow, D.R., and Stuber, G.D. (2017). Hormonal gain control of a medial preoptic area social reward circuit. Nat Neurosci 20, 449-458.

McKinley, M.J., Yao, S.T., Uschakov, A., McAllen, R.M., Rundgren, M., and Martelli, D. (2015). The median preoptic nucleus: front and centre for the regulation of body fluid, sodium, temperature, sleep and cardiovascular homeostasis. Acta Physiol (Oxf) 214, 8-32.

Moffitt, J.R., Bambah-Mukku, D., Eichhorn, S.W., Vaughn, E., Shekhar, K., Perez, J.D., Rubinstein, N.D., Hao, J., Regev, A., Dulac, C., et al. (2018). Molecular, spatial, and functional single-cell profiling of the hypothalamic preoptic region. Science 362.

Morrison, S.F., and Nakamura, K. (2019). Central Mechanisms for Thermoregulation. Annu Rev Physiol. Nakamura, K., and Morrison, S.F. (2007). Central efferent pathways mediating skin cooling-evoked sympathetic thermogenesis in brown adipose tissue. Am J Physiol Regul Integr Comp Physiol 292, R127136.

Nakamura, K., and Morrison, S.F. (2008). A thermosensory pathway that controls body temperature. Nat Neurosci 11, 62-71.

Nunn, N., Womack, M., Dart, C., and Barrett-Jolley, R. (2011). Function and pharmacology of spinallyprojecting sympathetic pre-autonomic neurones in the paraventricular nucleus of the hypothalamus. Curr Neuropharmacol 9, 262-277.

Ohki-Hamazaki, H., Watase, K., Yamamoto, K., Ogura, H., Yamano, M., Yamada, K., Maeno, H., Imaki, J., Kikuyama, S., Wada, E., et al. (1997). Mice lacking bombesin receptor subtype-3 develop metabolic defects and obesity. Nature 390, 165-169.

Peron, S.P., Freeman, J., Iyer, V., Guo, C., and Svoboda, K. (2015). A Cellular Resolution Map of Barrel Cortex Activity during Tactile Behavior. Neuron 86, 783-799.

Pinol, R.A., Zahler, S.H., Li, C., Saha, A., Tan, B.K., Skop, V., Gavrilova, O., Xiao, C., Krashes, M.J., and Reitman, M.L. (2018). Brs3 neurons in the mouse dorsomedial hypothalamus regulate body temperature, energy expenditure, and heart rate, but not food intake. Nat Neurosci 21, 1530-1540. Popp, B.D., Hutchinson, D.S., Evans, B.A., and Summers, R.J. (2004). Stereoselectivity for interactions of agonists and antagonists at mouse, rat and human beta3-adrenoceptors. Eur J Pharmacol 484, 323-331. 
Prando, V., Da Broi, F., Franzoso, M., Plazzo, A.P., Pianca, N., Francolini, M., Basso, C., Kay, M.W., Zaglia, T., and Mongillo, M. (2018). Dynamics of neuroeffector coupling at cardiac sympathetic synapses. J Physiol 596, 2055-2075.

Rasmussen, S., Miller, M.M., Filipski, S.B., and Tolwani, R.J. (2011). Cage change influences serum corticosterone and anxiety-like behaviors in the mouse. J Am Assoc Lab Anim Sci 50, 479-483. Saper, C.B., Loewy, A.D., Swanson, L.W., and Cowan, W.M. (1976). Direct hypothalamo-autonomic connections. Brain Res 117, 305-312.

Saunders, A., Johnson, C.A., and Sabatini, B.L. (2012). Novel recombinant adeno-associated viruses for Cre activated and inactivated transgene expression in neurons. Front Neural Circuits 6, 47.

Sawchenko, P.E., and Swanson, L.W. (1983). The organization of forebrain afferents to the paraventricular and supraoptic nuclei of the rat. J Comp Neurol 218, 121-144.

Schneeberger, M., Parolari, L., Das Banerjee, T., Bhave, V., Wang, P., Patel, B., Topilko, T., Wu, Z., Choi, C.H.J., Yu, X., et al. (2019). Regulation of Energy Expenditure by Brainstem GABA Neurons. Cell. Sebhat, I.K., Franklin, C., Lo, M.-C., Chen, D., Jewell, J.P., Miller, R., Pang, J., Palyha, O., Kan, Y., Kelly, T.M., et al. (2011). Discovery of MK-5046, a Potent, Selective Bombesin Receptor Subtype-3 Agonist for the Treatment of Obesity. ACS Med Chem Lett 2, 43-47.

Simerly, R.B. (1998). Organization and regulation of sexually dimorphic neuroendocrine pathways. Behav Brain Res 92, 195-203.

Skop, V., Guo, J., Liu, N., Xiao, C., Hall, K.D., Gavrilova, O., and Reitman, M.L. (2020a). Mouse Thermoregulation: Introducing the Concept of the Thermoneutral Point. Cell Rep 31, 107501. Skop, V., Liu, N., Guo, J., Gavrilova, O., and Reitman, M.L. (2020b). The contribution of the mouse tail to thermoregulation is modest. Am J Physiol Endocrinol Metab 319, E438-E446.

Song, K., Wang, H., Kamm, G.B., Pohle, J., Reis, F.C., Heppenstall, P., Wende, H., and Siemens, J. (2016). The TRPM 2 channel is a hypothalamic heat sensor that limits fever and can drive hypothermia. Science 353, 1393-1398.

Stocker, S.D., and Toney, G.M. (2005). Median preoptic neurones projecting to the hypothalamic paraventricular nucleus respond to osmotic, circulating Ang II and baroreceptor input in the rat. J Physiol 568, 599-615.

Stuart, T., Butler, A., Hoffman, P., Hafemeister, C., Papalexi, E., Mauck, W.M., 3rd, Hao, Y., Stoeckius, M., Smibert, P., and Satija, R. (2019). Comprehensive Integration of Single-Cell Data. Cell 177, 1888-1902 e1821.

Sutton, A.K., Pei, H., Burnett, K.H., Myers, M.G., Jr., Rhodes, C.J., and Olson, D.P. (2014). Control of food intake and energy expenditure by Nos1 neurons of the paraventricular hypothalamus. J Neurosci 34, 15306-15318.

Sweeney, S.T., Broadie, K., Keane, J., Niemann, H., and O'Kane, C.J. (1995). Targeted expression of tetanus toxin light chain in Drosophila specifically eliminates synaptic transmission and causes behavioral defects. Neuron 14, 341-351.

Takahashi, T.M., Sunagawa, G.A., Soya, S., Abe, M., Sakurai, K., Ishikawa, K., Yanagisawa, M., Hama, H., Hasegawa, E., Miyawaki, A., et al. (2020). A discrete neuronal circuit induces a hibernation-like state in rodents. Nature.

Tan, C.L., Cooke, E.K., Leib, D.E., Lin, Y.C., Daly, G.E., Zimmerman, C.A., and Knight, Z.A. (2016). WarmSensitive Neurons that Control Body Temperature. Cell 167, 47-59 e15.

Tan, C.L., and Knight, Z.A. (2018). Regulation of Body Temperature by the Nervous System. Neuron 98, 31-48.

Uschakov, A., McGinty, D., Szymusiak, R., and McKinley, M.J. (2009). Functional correlates of activity in neurons projecting from the lamina terminalis to the ventrolateral periaqueductal gray. Eur J Neurosci 30, 2347-2355. 
Vianna, D.M.L., and Carrive, P. (2012). Stress-induced hyperthermia is not mediated by brown adipose tissue in mice. J Thermal Biol 37, 125-129.

Wang, T.A., Teo, C.F., Akerblom, M., Chen, C., Tynan-La Fontaine, M., Greiner, V.J., Diaz, A., McManus, M.T., Jan, Y.N., and Jan, L.Y. (2019). Thermoregulation via Temperature-Dependent PGD2 Production in Mouse Preoptic Area. Neuron 103, 309-322 e307.

Xiao, C., Liu, N., Province, H., Pinol, R.A., Gavrilova, O., and Reitman, M.L. (2020). BRS3 in both MC4Rand SIM1-expressing neurons regulates energy homeostasis in mice. Mol Metab 36, 100969.

Xiao, C., Pinol, R.A., Carlin, J.L., Li, C., Deng, C., Gavrilova, O., and Reitman, M.L. (2017). Bombesin-like receptor 3 (Brs3) expression in glutamatergic, but not GABAergic, neurons is required for regulation of energy metabolism. Mol Metab 6, 1540-1550.

Xiao, C., and Reitman, M.L. (2016). Bombesin-Like Receptor 3: Physiology of a Functional Orphan. Trends Endocrinol Metab 27, 603-605.

Yoshida, K., Konishi, M., Nagashima, K., Saper, C.B., and Kanosue, K. (2005). Fos activation in hypothalamic neurons during cold or warm exposure: projections to periaqueductal gray matter. Neuroscience 133, 1039-1046.

Yu, S., Qualls-Creekmore, E., Rezai-Zadeh, K., Jiang, Y., Berthoud, H.R., Morrison, C.D., Derbenev, A.V., Zsombok, A., and Munzberg, H. (2016). Glutamatergic Preoptic Area Neurons That Express Leptin Receptors Drive Temperature-Dependent Body Weight Homeostasis. J Neurosci 36, 5034-5046. Zhang, L., Parks, G.S., Wang, Z., Wang, L., Lew, M., and Civelli, O. (2013). Anatomical characterization of bombesin receptor subtype-3 mRNA expression in the rodent central nervous system. J Comp Neurol 521, 1020-1039.

Zhang, Z., Reis, F., He, Y., Park, J.W., DiVittorio, J.R., Sivakumar, N., van Veen, J.E., Maesta-Pereira, S., Shum, M., Nichols, I., et al. (2020). Estrogen-sensitive medial preoptic area neurons coordinate torpor in mice. Nat Commun 11, 6378.

Zhao, Z.D., Yang, W.Z., Gao, C., Fu, X., Zhang, W., Zhou, Q., Chen, W., Ni, X., Lin, J.K., Yang, J., et al. (2017). A hypothalamic circuit that controls body temperature. Proc Natl Acad Sci U S A 114, 2042-2047. 


\section{Graphical abstract}

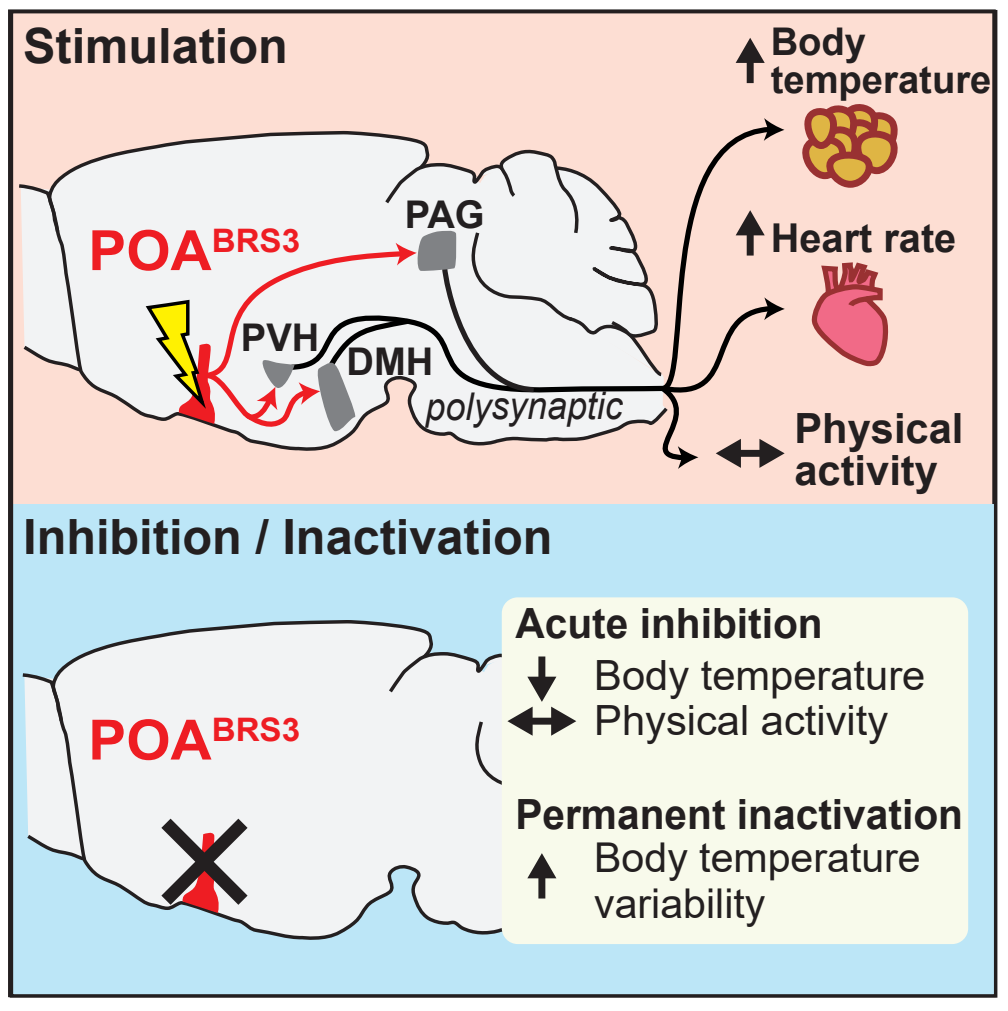


a
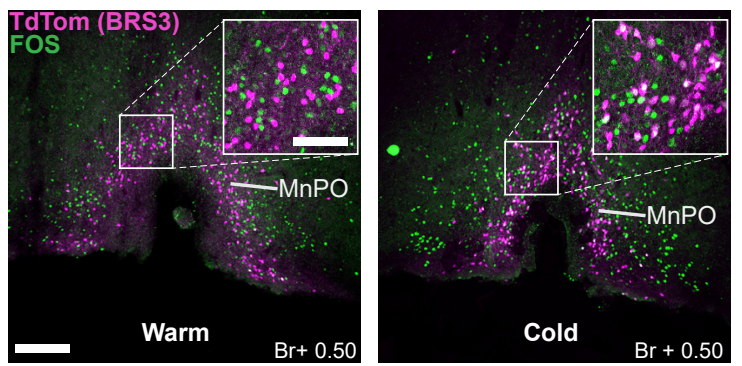

C

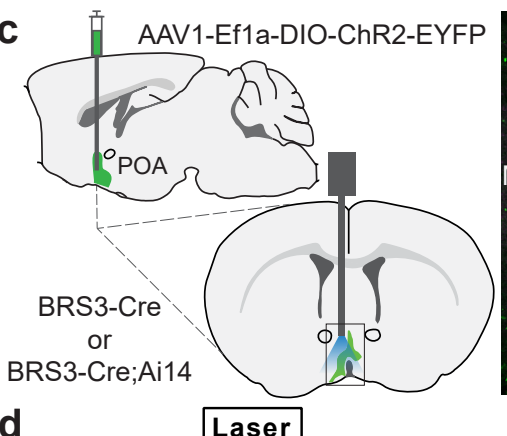

d
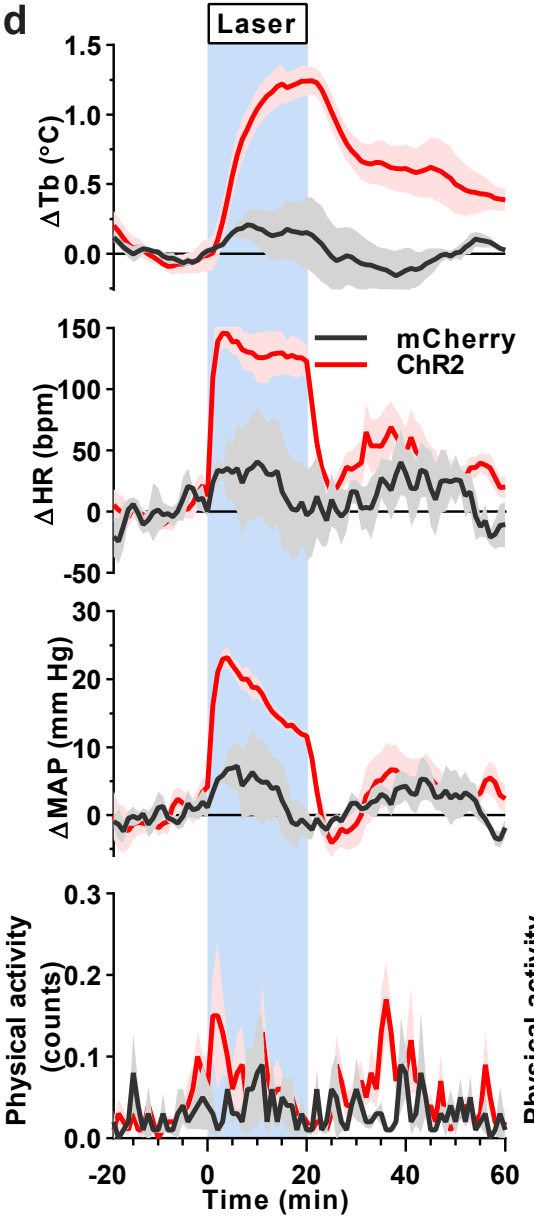
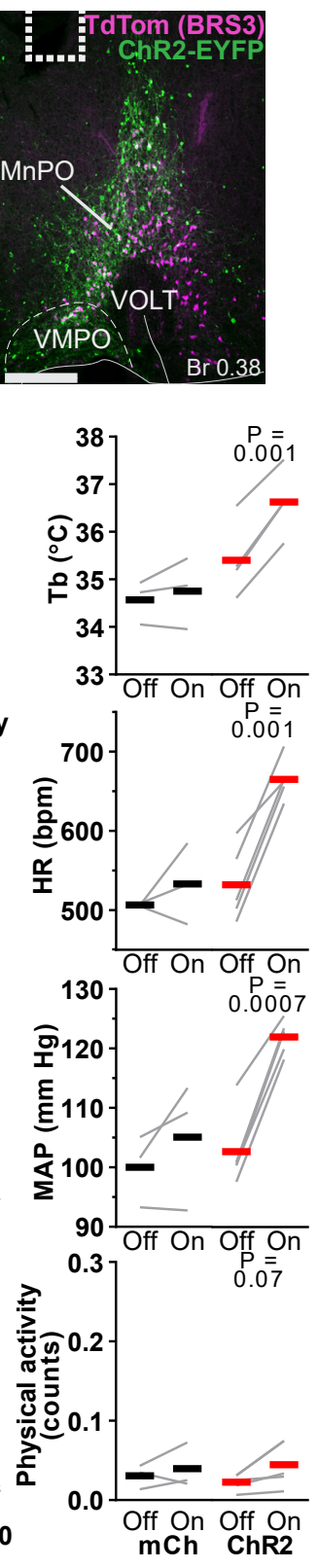

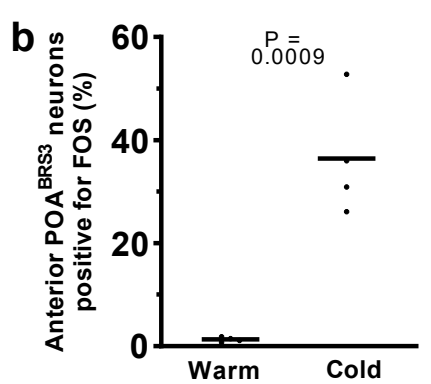

e
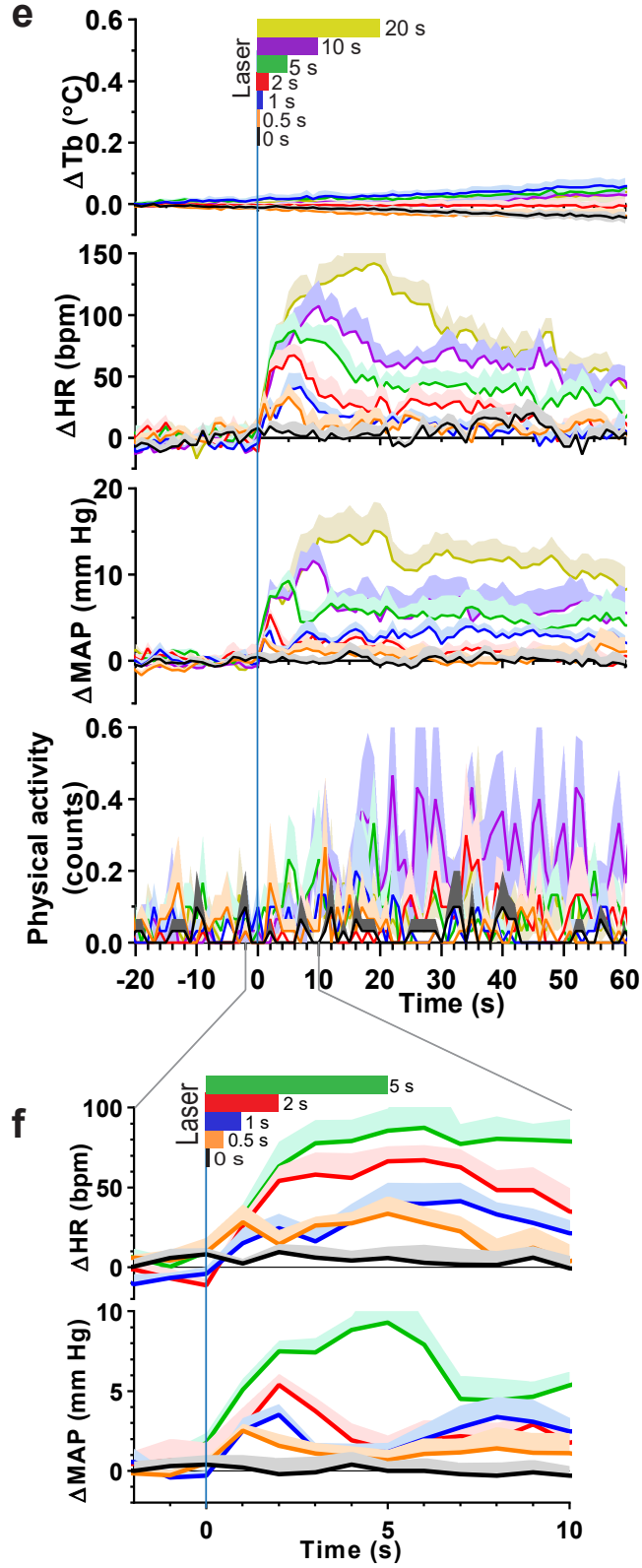

Figure $1 \mathrm{POA}^{\mathrm{BRS} 3}$ neurons are cold-sensitive and optogenetic stimulation increases body temperature, heart rate and mean arterial pressure. a) FOS expression (green) in BRS3 neurons (magenta) of $4 \mathrm{~h}$ cold $-\left(4{ }^{\circ} \mathrm{C}\right)$ or warm-exposed $\left(30^{\circ} \mathrm{C}\right)$ mice. Scale bar is $200 \mu \mathrm{m}, 80 \mu \mathrm{m}$ in inset. b) Average and individual percentages of colocalization of FOS in anterior (Bregma +0.50 
and +0.38$) \mathrm{POA}^{\mathrm{BRS} 3}$ neurons $(\mathrm{n}=4$ /group). $\mathrm{P}$ values from unpaired $\mathrm{t}$ test, cold vs warm. Data are re-graphed from (Pinol et al., 2018). c) Schematic of virus injection (top left) and placement of optic fiber (bottom left). ChR2-EYFP expression (green) in BRS3 (magenta) neurons in the MnPO of a BRS3-Cre;Ai14 mouse (right). Dotted line indicates fiber placement. Scale bar is 200 $\mu \mathrm{m}$. MnPO - median preoptic area; VMPO - ventromedial preoptic area; VOLT - vascular organ of lamina terminalis. d) Tb, HR, MAP, and physical activity response to 20 min laser stimulation (blue interval; $3 \mathrm{~s}$ on $1 \mathrm{~s}$ off; $20 \mathrm{~Hz} ; 10 \mathrm{~ms}$ pulses). mCherry controls (black, $\mathrm{n}=3$ ), ChR2 (red, $\mathrm{n}$ $=5)$. Data are average of 5 epochs/mouse, relative to epoch baseline ( -20 to $-1 \mathrm{~min})$; mean \pm s.e.m. Quantitation in right panels (intervals: Off, -10 to $-1 \mathrm{~min}$; On, 10 to $19 \mathrm{~min}$ for $\mathrm{Tb}$ and 0 to 9 min for HR, MAP, and physical activity; bars, means; gray lines, individual animals; P values from paired t test, Off vs On). e, f) Brief optogenetic stimulation increases HR and MAP, but not $\mathrm{Tb}$ or physical activity. Laser (continuous pulses; $20 \mathrm{~Hz} ; 10 \mathrm{~ms}$ pulses) stimulation is indicated at top in color-coded bars. Data are mean + s.e.m., $n=5$ mice (average of 10 epochs/mouse), relative to epoch baseline ( -59 to $0 \mathrm{~s})$. 


\section{Figure 2}

a
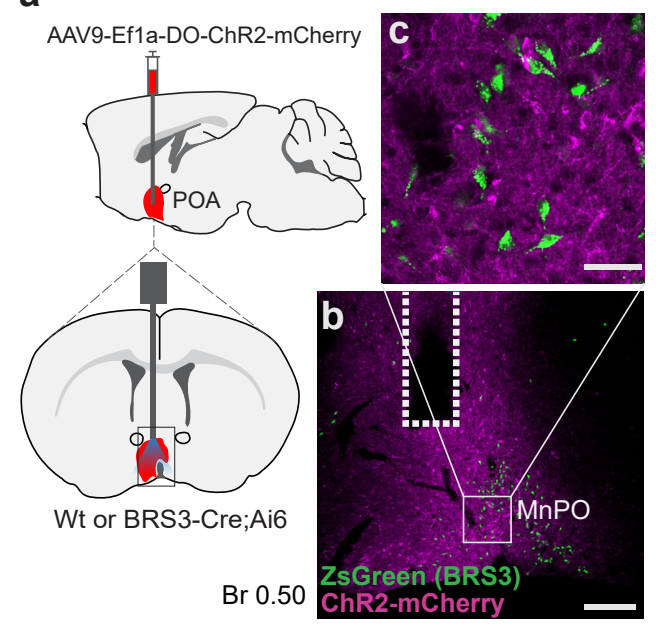

d

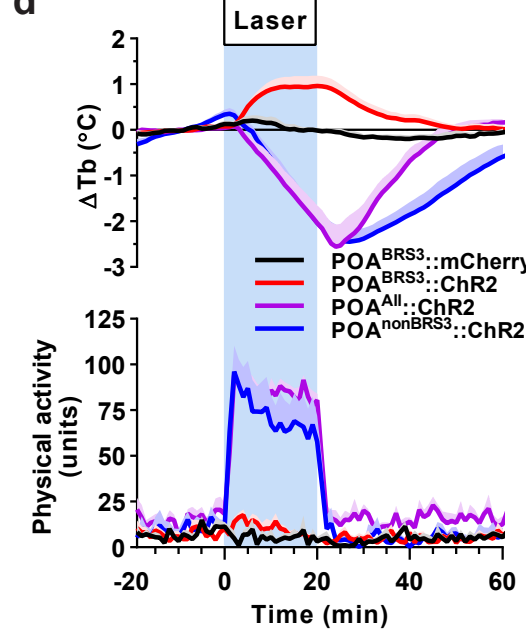

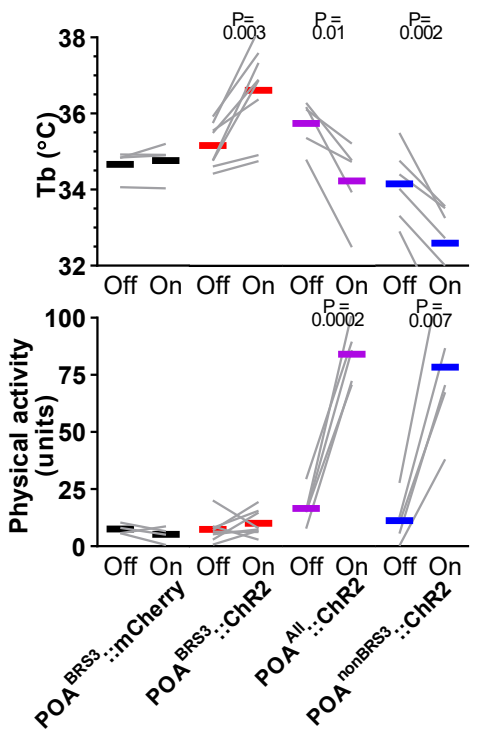

Figure 2 Global stimulation of POA neurons decreases body temperature and increases physical activity. a) Schematic of virus injection (top left) and optic fiber placement (bottom left). b,c) ChR2-EYFP expression in the MnPO of a BRS3-Cre;Ai14 mouse, with detail showing absence of ChR2-mCherry (magenta) expression in BRS3 (green) neurons. Dotted line indicates fiber placement. Scale bar: b) $200 \mu \mathrm{m}$, c) $40 \mu \mathrm{m}$. d) Tb and physical activity response to 20 minute laser stimulation (blue interval; $3 \mathrm{~s}$ on $1 \mathrm{~s}$ off; $20 \mathrm{~Hz} ; 10 \mathrm{~ms}$ pulses). $\mathrm{POA}^{\mathrm{BRS} 3}$ ::mCherry (black, $\mathrm{n}=4$ ), $\mathrm{POA}^{\mathrm{BRS} 3}:: \mathrm{ChR} 2$ (red, $\mathrm{n}=8$ ); $\mathrm{POA}^{\mathrm{All}}:$ :ChR2 (magenta, $\mathrm{n}=5$ ), $\mathrm{POA}^{\text {nonBRS3}}:: \mathrm{ChR} 2$ (blue, $\mathrm{n}=$ 6). Data are average of 5 epochs/mouse, relative to epoch baseline ( -20 to $-1 \mathrm{~min})$; mean + s.e.m. Quantitation in right panels (intervals: Off, -10 to $-1 \mathrm{~min}$; On, 10 to $19 \mathrm{~min}$ for $\mathrm{Tb}$ and 0 to $9 \mathrm{~min}$ for physical activity; bars, means; gray lines, individual animals; P values from paired t test, Off vs On). 


\section{Figure 3}

a

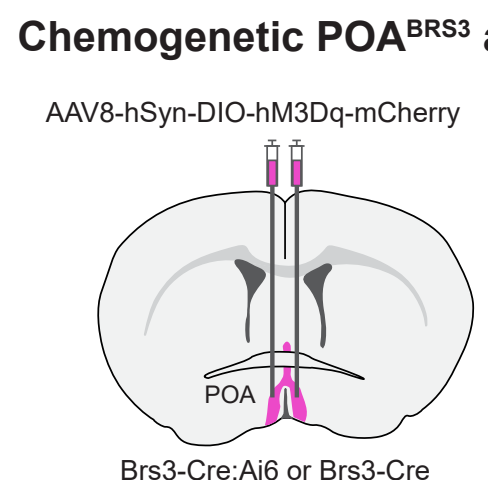

Bregma +0.38

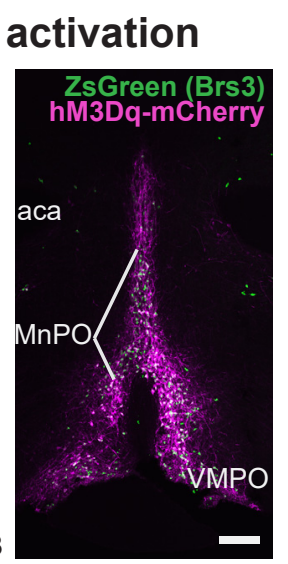

C

\section{Chemogenetic $\mathrm{POA}^{\mathrm{BRS} 3}$}

AAV8-hSyn-DIO-hM4Di-mCherry

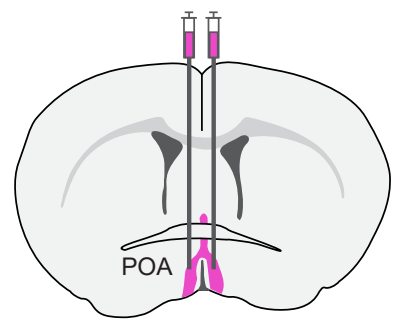

Brs3-Cre;Ai6 or Brs3-Cre

Bregma +0.26

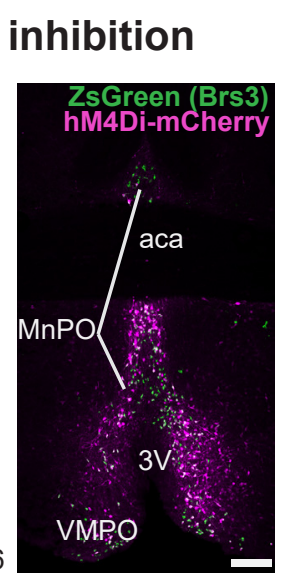

b

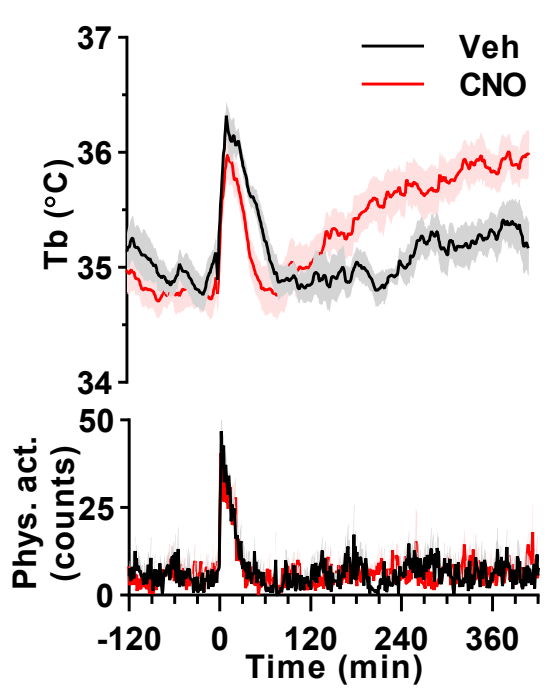

d
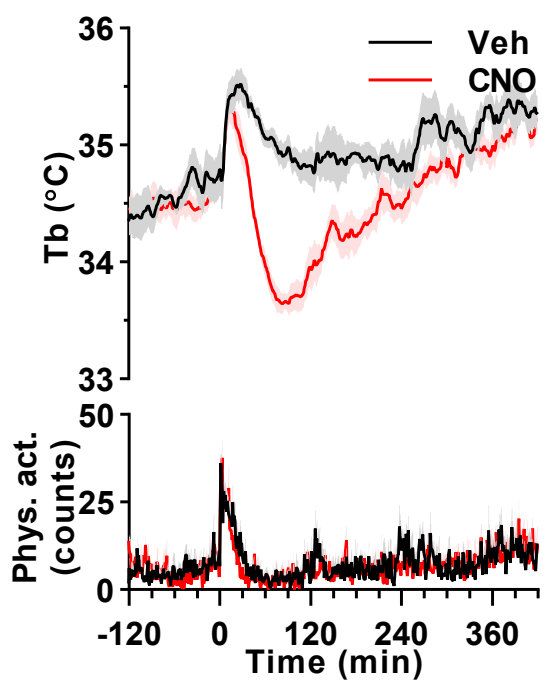
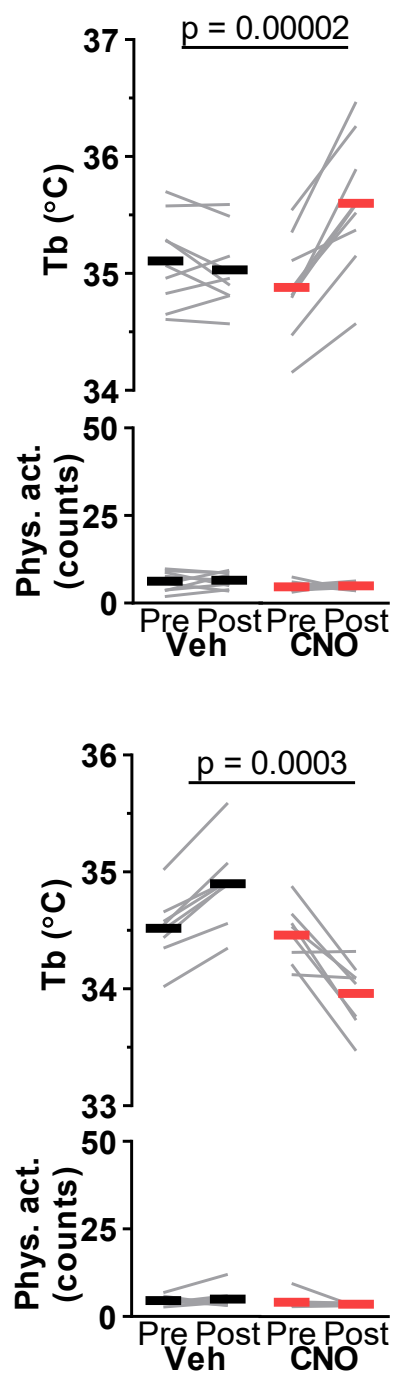

Figure 3 Bi-directional chemogenetic manipulation of $\mathrm{POA}^{\mathrm{BRS} 3}$ neurons. a,c) Schematic of virus injection and example of hM3Dq-mCherry (a) or hM4Di-mCherry (c) expression (magenta) in BRS3 (green) neurons in the anterior POA of a BRS3-Cre;Ai14 mouse. Scale bar is $200 \mu \mathrm{m} . \mathrm{b}, \mathrm{d}$ ) $\mathrm{Tb}$ and physical activity response to $\mathrm{CNO}(1 \mathrm{mg} / \mathrm{kg})$ or vehicle in $\mathrm{POA}^{\mathrm{BRS} 3}:: \mathrm{hM} 3 \mathrm{Dq}$ mice $(\mathrm{c} ; \mathrm{n}=$ 9, mean of two or three trials; Pre: -150 to -30 ; Post: 180 to $300 \mathrm{~min}$ ) or POA $^{\text {BRS3 }:: h M 4 D i(d ; n=}$ 8, mean of three trials; Pre: -150 to -30 ; Post: 60 to $180 \mathrm{~min}$ ) mice. P values from paired, twosided t-test on change from baseline, $\mathrm{CNO}$ vs vehicle. Data are mean + s.e.m in bottom left panel and \pm s.e.m. in top left panel. Bars, means; gray lines, individual animals in right panels. See also Figure S1. 


\section{Figure 4}
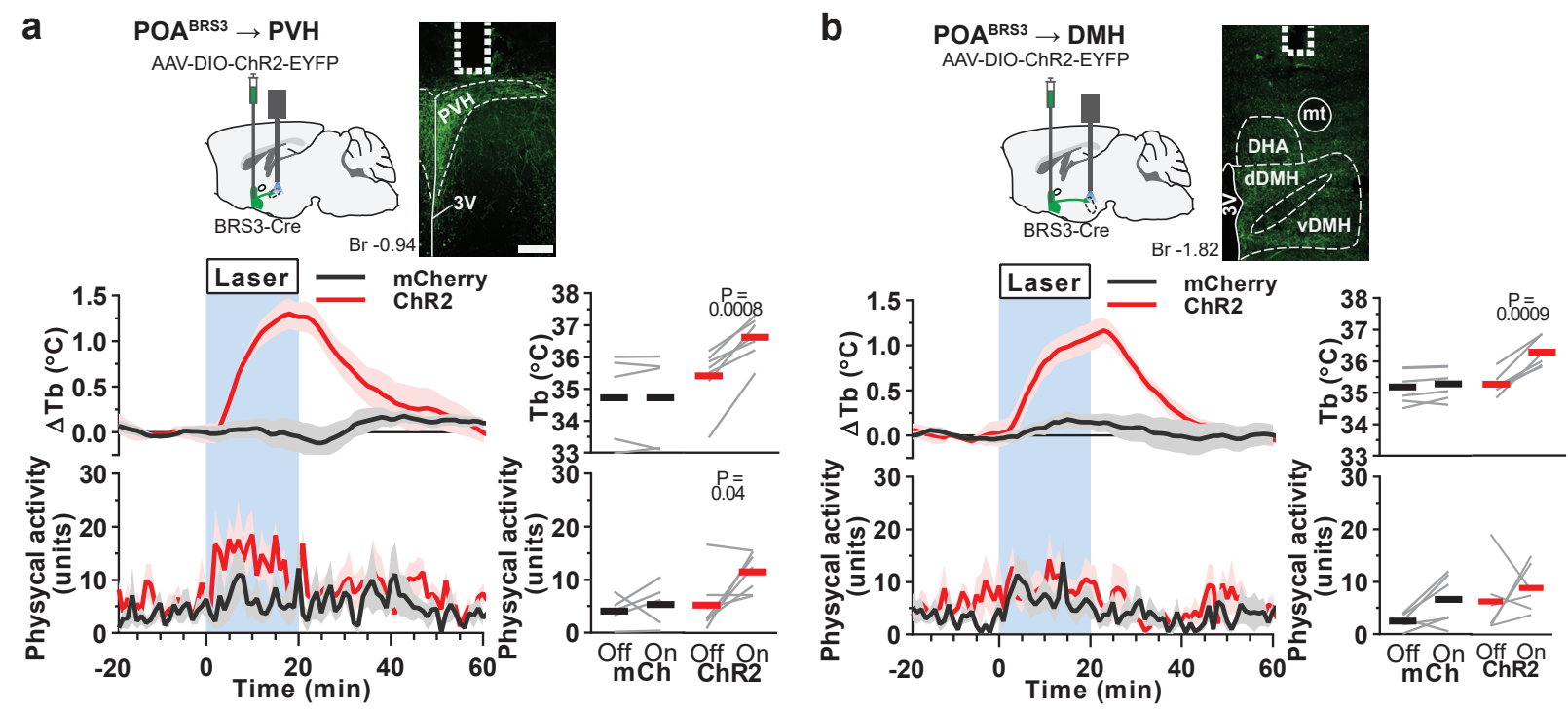

C

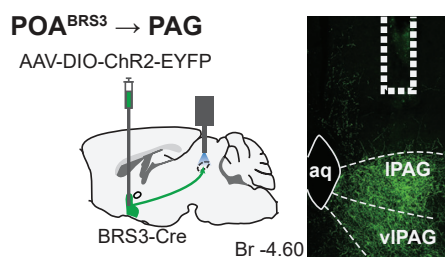

d

POA $^{\text {BRS3 }} \rightarrow$ PVT
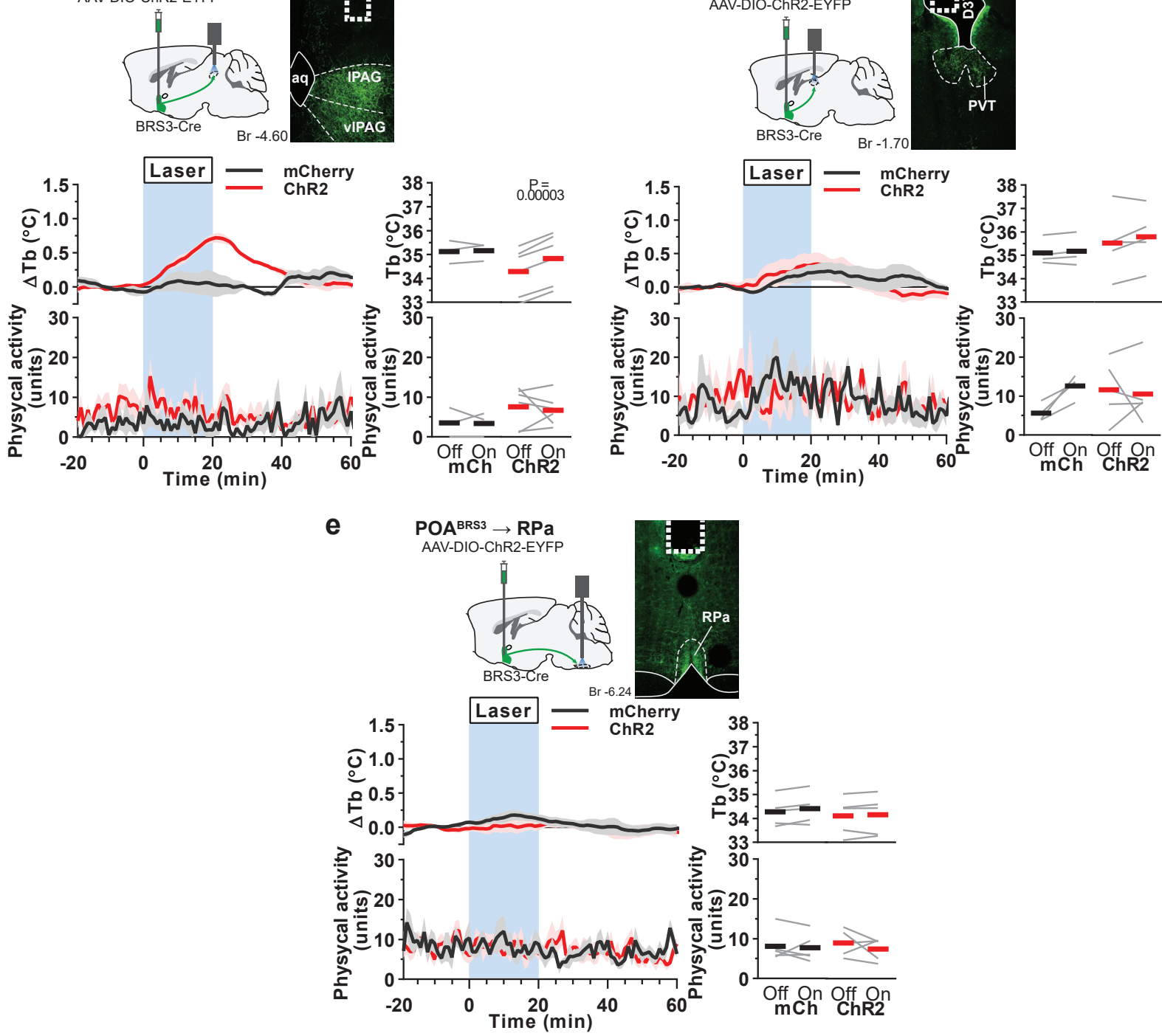
Figure 4 Optogenetic stimulation of $\mathrm{POA}^{\mathrm{BRS} 3} \rightarrow \mathrm{PVH}, \mathrm{POA}^{\mathrm{BRS} 3} \rightarrow \mathrm{DMH}$, or $\mathrm{POA}^{\mathrm{BRS} 3} \rightarrow \mathrm{PAG}$ axons increases $\mathrm{Tb}$. a-e) Top left: schematic of virus injection and placement of optic fiber. Top right: POA $^{\mathrm{BRS} 3}$ projections expressing ChR2-EYFP (green) and fiber placement (dotted line). Scale bar is $200 \mu \mathrm{m}$. Bottom left: Tb and physical activity response to $20 \mathrm{~min}$ laser stimulation (blue interval; $3 \mathrm{~s}$ on $1 \mathrm{~s}$ off; $20 \mathrm{~Hz} ; 10 \mathrm{~ms}$ pulses). mCherry controls (black, $\mathrm{n}=4-5)$, ChR2 (red, $\mathrm{n}=5-7)$. Data are average of 5-10 epochs/mouse, relative to epoch baseline ( -20 to $-1 \mathrm{~min})$; mean \pm s.e.m. Quantitation in bottom right panels (intervals: Off, -10 to $-1 \mathrm{~min}$; On, 10 to $19 \mathrm{~min}$ for $\mathrm{Tb}$ and 0 to 9 min for physical activity; bars, means; gray lines, individual animals; $\mathrm{P}$ values from paired t test, Off vs On). $3 \mathrm{~V}$ - third ventricle; Aq - aqueduct; DHA - dorsal hypothalamic area $\mathrm{dDMH}$ - dorsal part of the dorsomedial hypothalamus; D3V - dorsal part of third ventricle; $\mathrm{PVH}$ - paraventricular nucleus of the hypothalamus; PVT - paraventricular nucleus of the thalamus; 1PAG - lateral periaqueductal grey; vDMH - ventral part of the dorsomedial hypothalamus; vlPAG - ventrolateral periaqueductal grey; PVH - paraventricular nucleus of the hypothalamus; RPa - raphe pallidus. See also Figures S2, S3. 
Figure 5

a
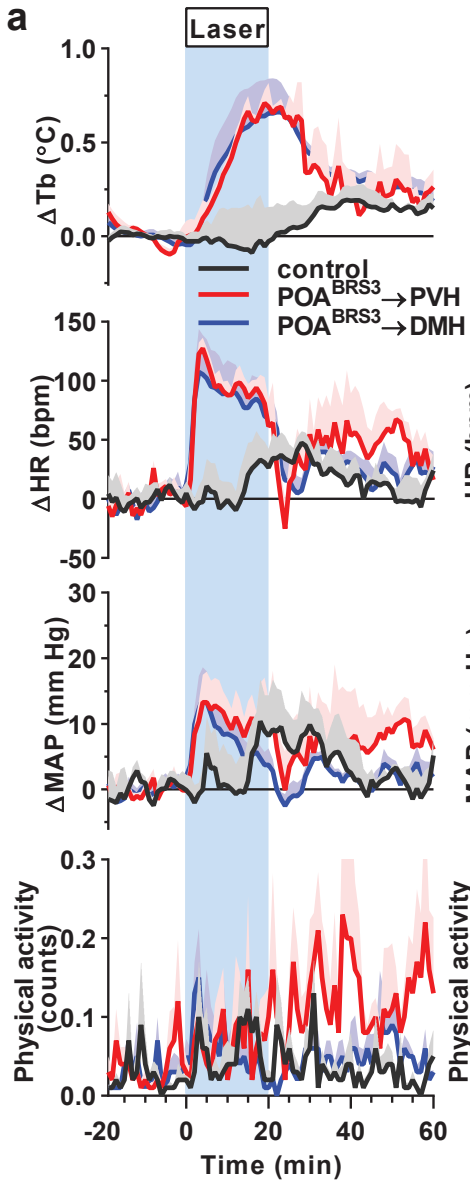

b
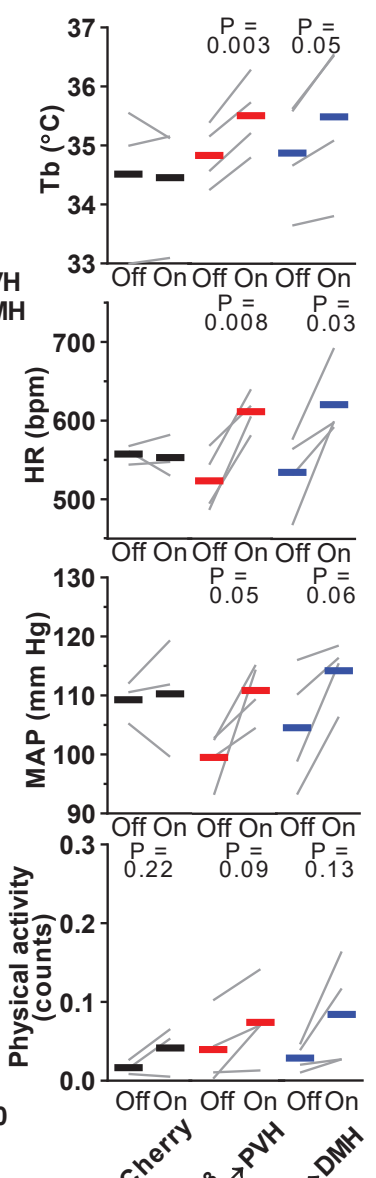
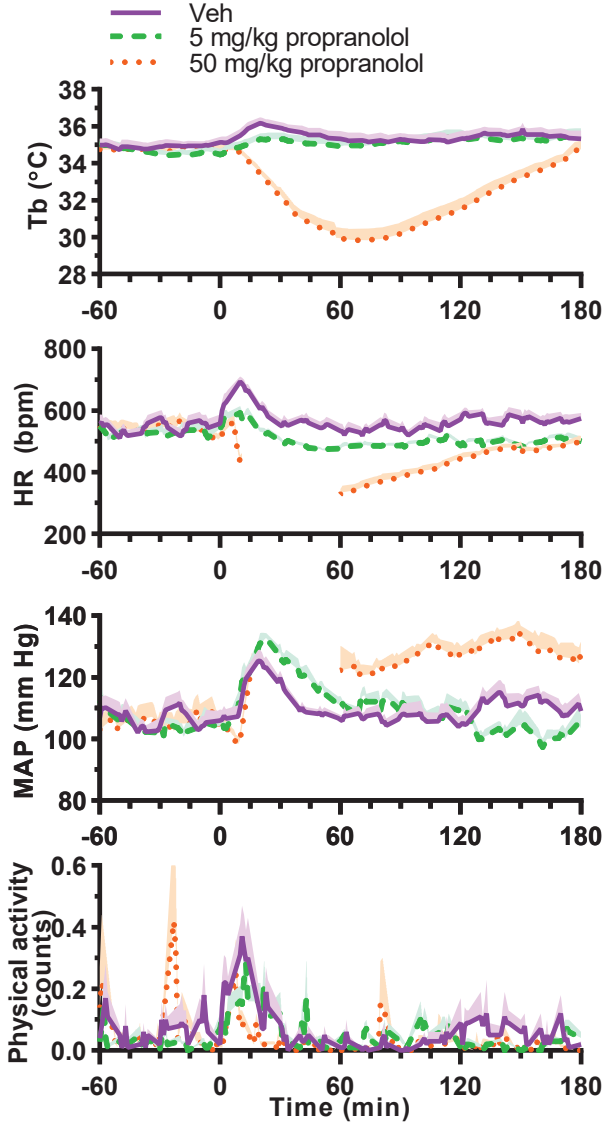

\section{C}
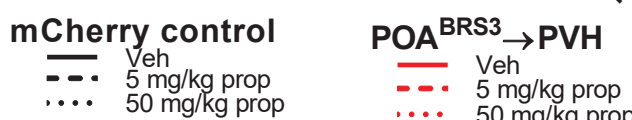

$\mathrm{POA}^{\mathrm{BRS} 3} \rightarrow \mathrm{DMH}$

... $50 \mathrm{mg} / \mathrm{kg}$ prop

.... $50 \mathrm{mg} / \mathrm{kg}$ prop

- - $5 \mathrm{mg} / \mathrm{kg}$ prop
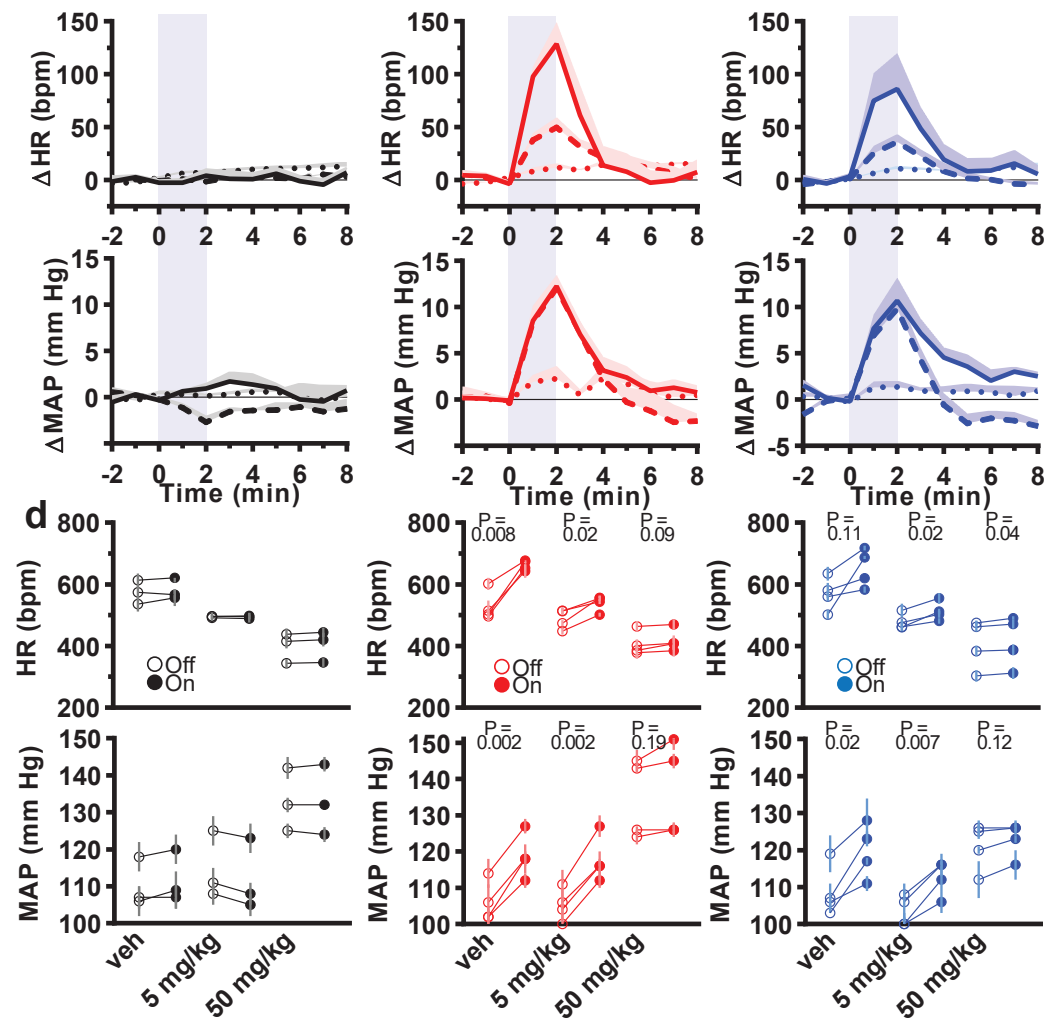

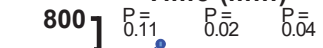

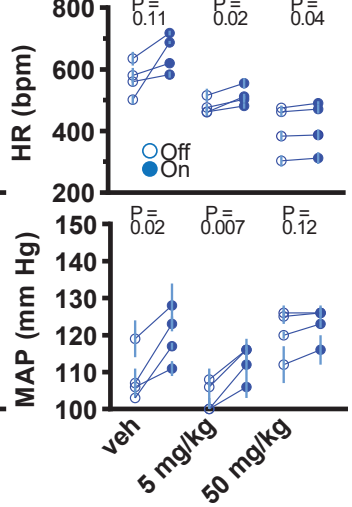


Figure $5 \mathrm{POA}^{\mathrm{BRS} 3} \rightarrow \mathrm{PVH}$ and $\mathrm{POA}^{\mathrm{BRS} 3} \rightarrow \mathrm{DMH}$ neurons increase $\mathrm{Tb}$ and $\mathrm{HR}$ via the sympathetic nervous system. a) Tb, HR, MAP, and physical activity response to 20 min laser stimulation (blue interval; $3 \mathrm{~s}$ on $1 \mathrm{~s}$ off; $20 \mathrm{~Hz} ; 10 \mathrm{~ms}$ pulses). mCherry controls (black, $\mathrm{n}=3$ ), $\mathrm{POA}^{\mathrm{BRS} 3} \rightarrow \mathrm{PVH}(\mathrm{red}, \mathrm{n}=4), \mathrm{POA}^{\mathrm{BRS} 3} \rightarrow \mathrm{DMH}$ (blue, $\left.\mathrm{n}=4\right)$; gray lines, individual animals. Data are average of 5 epochs/mouse, relative to epoch baseline ( -20 to $-1 \mathrm{~min})$; mean \pm s.e.m. Quantitation in bottom right panels (intervals: Off, -10 to $-1 \mathrm{~min}$; On, 10 to $19 \mathrm{~min}$ for $\mathrm{Tb}$ and 0 to 9 min for HR, MAP, and physical activity; P values from paired t test, Off vs On). In b-d, propranolol (vehicle, 5 , or $50 \mathrm{mg} / \mathrm{kg}$ i.p., as indicated) was injected at time 0. Starting at $30 \mathrm{~min}$, consecutive epochs of 2-min laser stimulation (1s on 1s off; $20 \mathrm{~Hz} ; 10 \mathrm{~ms}$ pulses) and 8 min laser off were performed. b) Effect of propranolol on Tb, HR, MAP, and physical activity. To isolate the effects of propranolol without confounding by optogenetic stimulation, minutes 6-10 (from laser onset) of each 10-minute epoch are graphed. Time 0 is vehicle/propranolol injection. Data are mean + s.e.m. $\mathrm{n}=11$ mice, pooled data. In the $50 \mathrm{mg} / \mathrm{kg}$ group, mean is not graphed between 15-60 min as blood pressure signal was lost in most mice; all mice have MAP and HR data after 60 min. Responses to drug (during 75-155 minutes) were compared to baseline (-60 to 0 minutes) and tested with one-way ANOVA, Tukey's multiple comparisons test ( $5 \mathrm{mg} / \mathrm{kg}$ : HR, p $=0.03$ and MAP, $\mathrm{p}=0.45 ; 50 \mathrm{mg} / \mathrm{kg}$ : HR, $\mathrm{p}<0.0001)$. $\mathrm{c}, \mathrm{d})$ Effect of stimulating $\mathrm{POA}^{\mathrm{BRS} 3} \rightarrow \mathrm{PVH}$ or $\mathrm{POA}^{\mathrm{BRS} 3} \rightarrow \mathrm{DMH}$ neurons on HR and MAP during propranolol treatment. mCherry controls (black, $\mathrm{n}=3$ ), $\mathrm{POA}^{\mathrm{BRS} 3} \rightarrow \mathrm{PVH}(\mathrm{red}, \mathrm{n}=4)$, $\mathrm{POA}^{\mathrm{BRS} 3} \rightarrow \mathrm{DMH}$ (blue, $\mathrm{n}=4$ ). Data are mean + s.e.m. of 8 epochs (during 75-155 min). In c, data in each epoch was normalized to its baseline ( -1 to $-0 \mathrm{~min}$ ) and the effect of laser stimulation (blue) is depicted as change from baseline. Data are mean + s.e.m. In d, the individual mouse data are presented. Open symbols are baseline (Off, from -1 to 0 minutes) and closed symbols are stimulated (On, from 1 to 2 minutes). $\mathrm{P}$ values from paired t test, Off vs On. Data are mean \pm s.e.m. of 8 epochs (during 75$155 \mathrm{~min})$. See also Figure S4. 


\section{Figure 6}

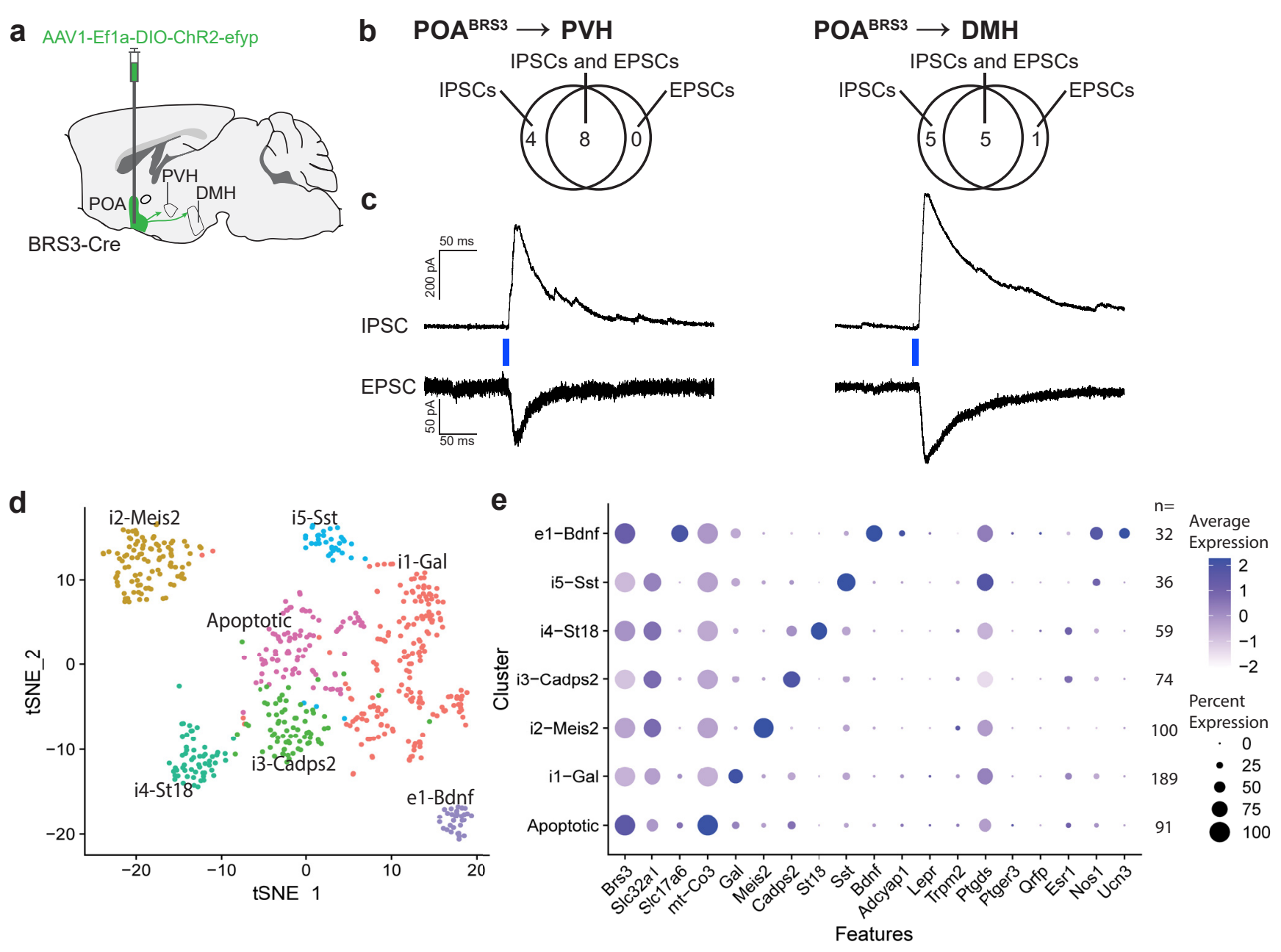

Figure $6 \mathrm{POA}^{\mathrm{BRS} 3} \rightarrow \mathrm{PVH}$ and $\mathrm{POA}^{\mathrm{BRS} 3} \rightarrow \mathrm{DMH}$ neurons are both inhibitory and excitatory and POA $^{\mathrm{BRS} 3}$ are in multiple clusters. a) Schematic showing injection of Cre-dependent ChR2-EYFPexpressing AAV in the POA and projections to $\mathrm{PVH}$ and DMH. b) Venn diagrams showing the number of $\mathrm{POA}^{\mathrm{BRS} 3} \rightarrow \mathrm{PVH}$ and $\mathrm{POA}^{\mathrm{BRS} 3} \rightarrow \mathrm{DMH}$ neurons with each type of postsynaptic current. EPSC, excitatory postsynaptic current; IPSC, inhibitory postsynaptic current. c) Voltageclamp trace of $\mathrm{POA}^{\mathrm{BRS} 3} \rightarrow \mathrm{PVH}$ and $\mathrm{POA}^{\mathrm{BRS} 3} \rightarrow \mathrm{DMH}$ stimulation in $\mathrm{PVH}$ - and DMH-containing brain slices. Recordings were made in the presence of tetrodotoxin $(500 \mathrm{nM})$ and 4aminorpyridine $(100 \mu \mathrm{M})$, showing monosynaptic inhibitory and excitatory input from the POA to both downstream hypothalamic areas. IPSCs recorded at $+10 \mathrm{mV}$ and EPSCs at $-55 \mathrm{mV}$. Traces are mean of $10-15$ stimulations per cell. d) tSNE plot of BRS3 neuron mRNA expression in the POA region with data from (Moffitt et al., 2018). e) Expression of selected mRNAs in the POA region BRS3 clusters. See also Figure S5. 


\section{Figure 7}

a

AAV5-EF1a-DIO-EYFP

or

AAVdj-CMV-DIO-EGFP-2a-TeNT

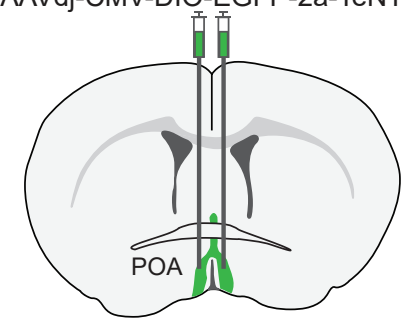

BRS3-Cre;Ai14 or BRS3-Cre Bregma +0.26

C

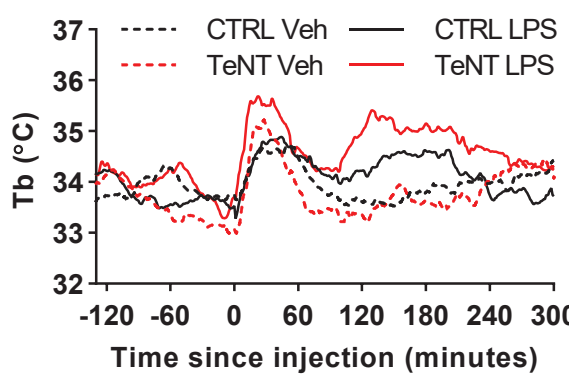

e

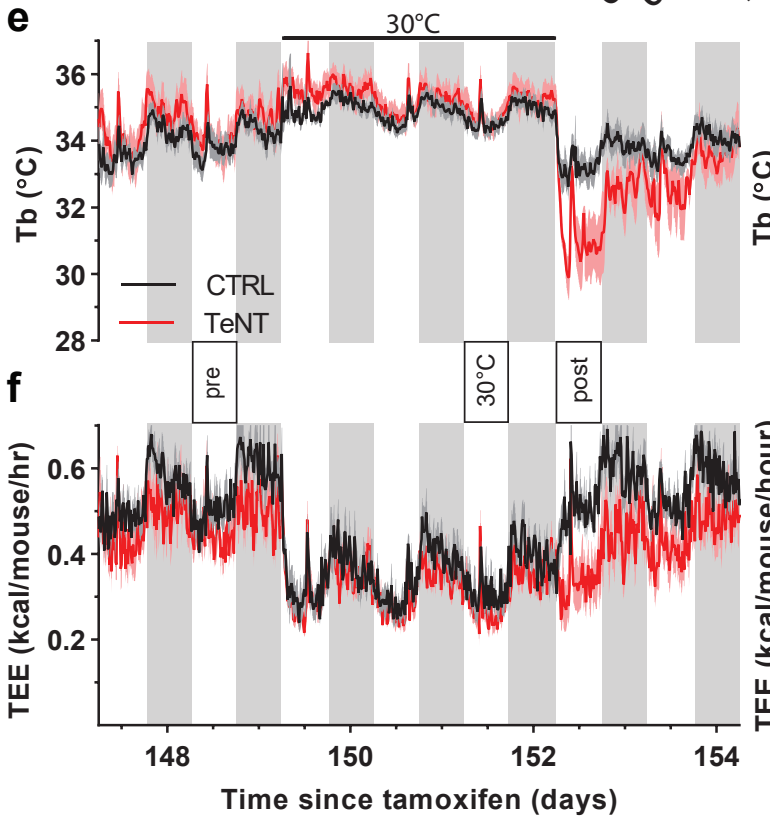

b
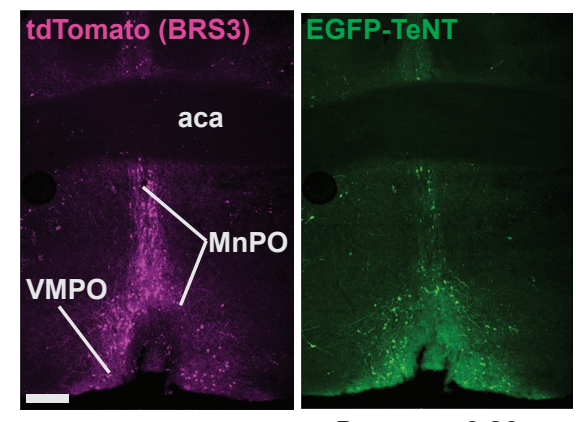

Bregma +0.26

d

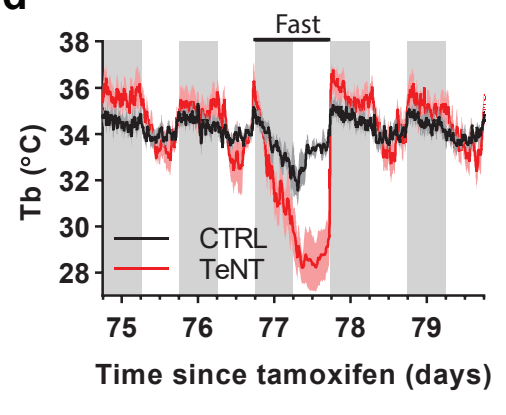

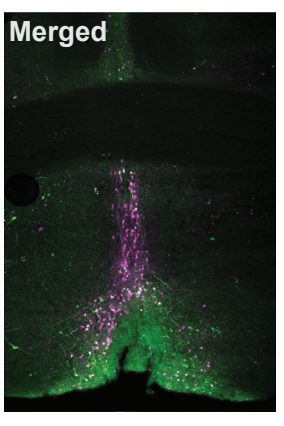

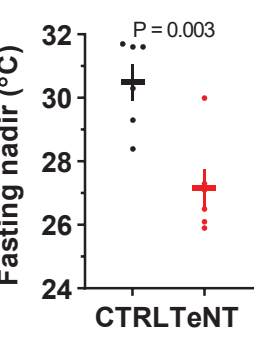

g

$22{ }^{\circ} \mathrm{C}$ adapted

$30{ }^{\circ} \mathrm{C}$ adapted
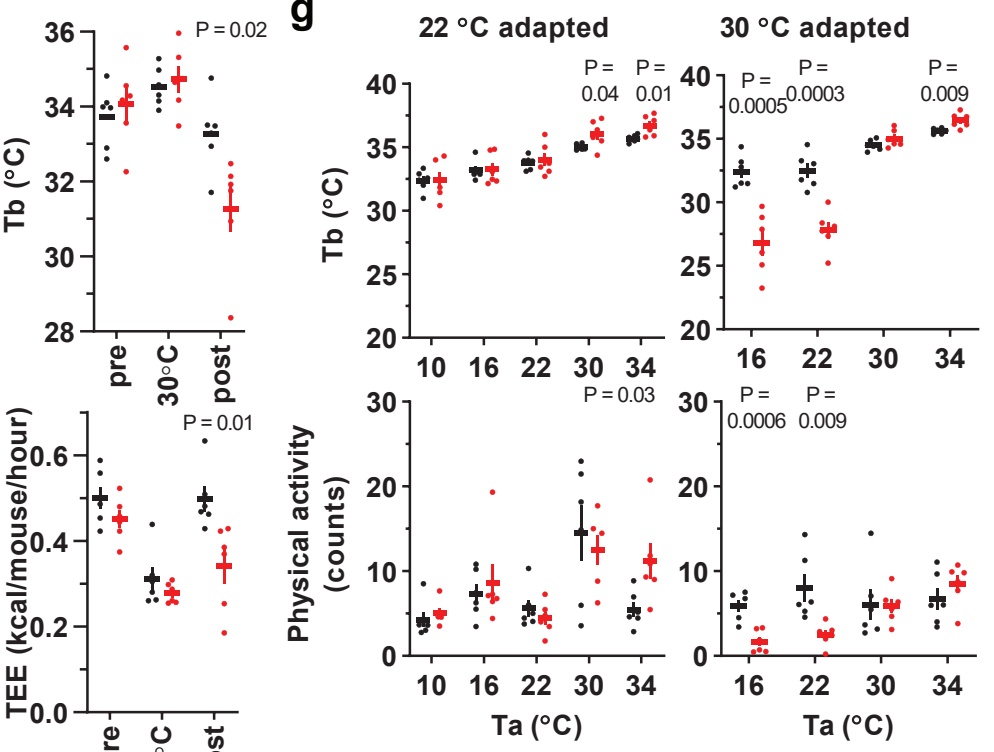

Figure 7 Silencing $\mathrm{POA}^{\mathrm{BRS} 3}$ neurons increases $\mathrm{Tb}$ variability and exaggerates $\mathrm{Tb}$ changes. a) Schematic of virus injection into the POA of BRS3-Cre mice (control, AAV-DIO-EYFP; silencing, AAV-DIO-EGFP-TeNT). b) Images of a POA ${ }^{\text {BRS3 }}$;Ai14::TeNT mouse (BRS3, magenta; TeNT, green). aca - anterior commissure; MnPO - median preoptic area; VMPO ventromedial preoptic area c) Tb response to lipopolysaccharide (LPS, $100 \mu \mathrm{g} / \mathrm{kg}$, i.p.) or vehicle (saline) and $\Delta \mathrm{Tb}\left(\mathrm{Tb}_{120 t 0210}\right.$ minus $\left.\mathrm{Tb}_{-120 t o-30}\right)$. Data are mean \pm s.e.m. (s.e.m. omitted from left for visual clarity); P value, paired $t$ test between vehicle and LPS and unpaired t test with unequal variance between delta Tb (LPS minus Veh) of CTRL and TeNT groups. d) Tb response to $24 \mathrm{~h}$ food deprivation and fasting $\mathrm{Tb}$ nadir (mean \pm s.e.m). $\mathrm{P}$ value, unpaired $\mathrm{t}$ test. $\mathrm{e}, \mathrm{f}) \mathrm{Tb}$ and total energy expenditure (TEE) of mice at $22{ }^{\circ} \mathrm{C}$, then 3 days at $30^{\circ} \mathrm{C}$, then $22{ }^{\circ} \mathrm{C}$. Quantitation in right panels of the indicated light phase 12-h intervals; P value, unpaired t test. g) Acute 
response to various Ta in mice acclimated to $22^{\circ} \mathrm{C}$ (left) or $30{ }^{\circ} \mathrm{C}$ (right). After $>5$ day of acclimation, during light phase mice were exposed to $180 \mathrm{~min}$ of the indicated $\mathrm{Ta}$. The mean $\mathrm{Tb}$ and physical activity at $60-180 \mathrm{~min}$ is shown. $\mathrm{P}$ value, unpaired $\mathrm{t}$ test. In all panels, $\mathrm{n}=6$ mice/group. See also Figure S6. 
Supplemental Fig 1

a b

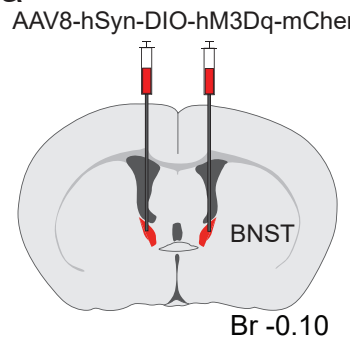

BRS3-Cre;Ai6

$\mathrm{Br}-0.10$ or BRS3-Cre
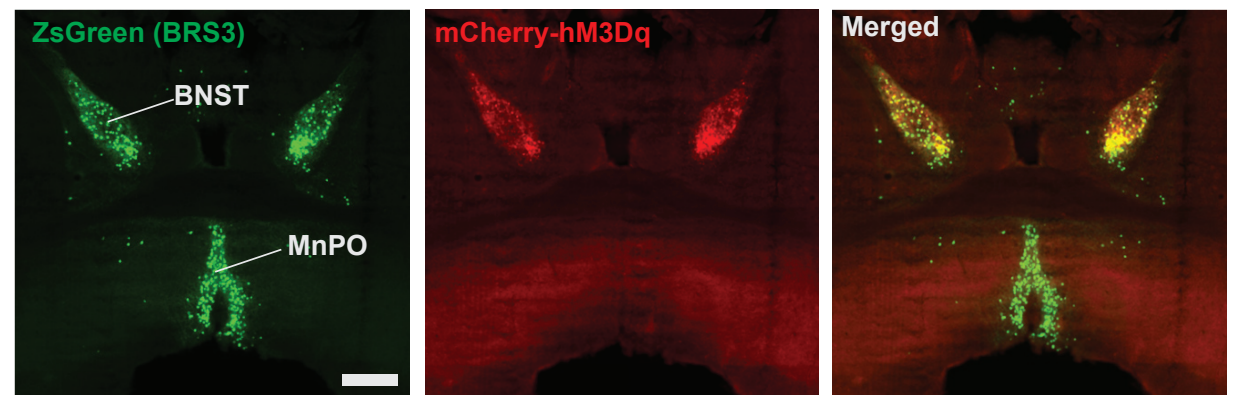

C
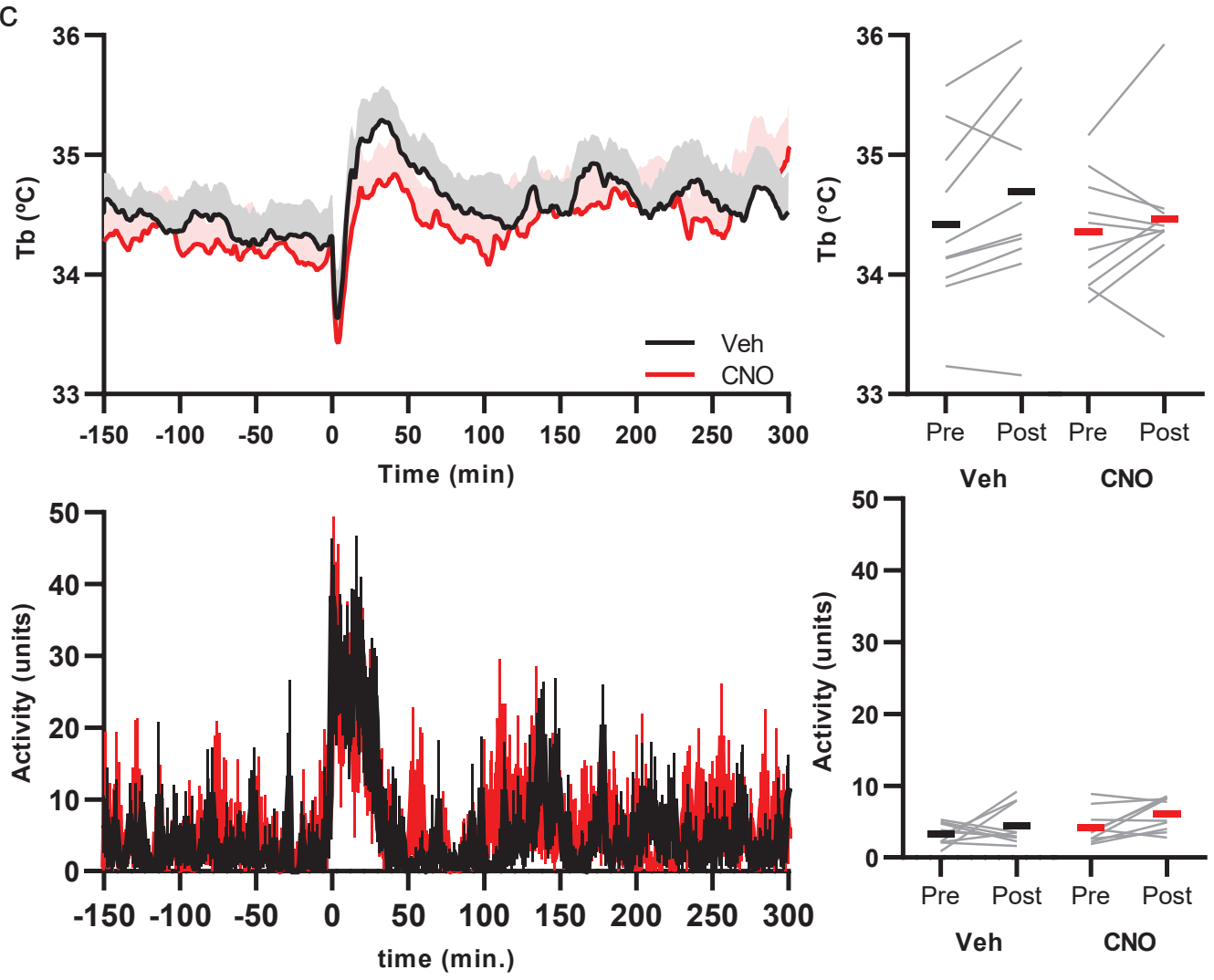

d

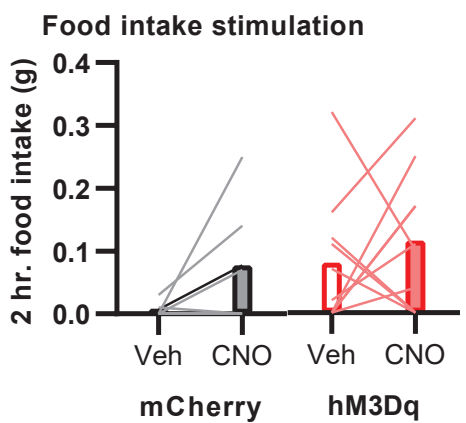

e

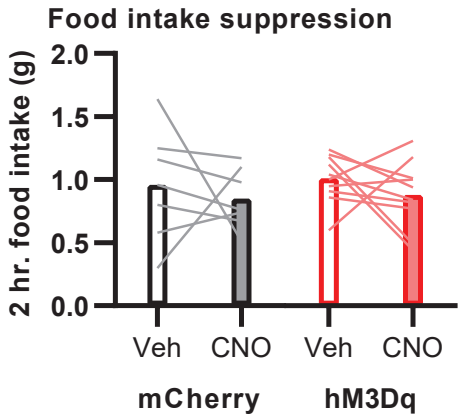


Supplemental Figure 1 Chemogenetic activation of BNST ${ }^{\mathrm{BRS} 3}$ neurons does not change Tb, physical activity or food intake. Related to Figure 3. a) Schematic of virus injection. b) hM3Dq expression (red) in BRS3 (green) neurons in the BNST of a BRS3-Cre;Ai14 mouse. Angle of coronal slice was adjusted to include the MnPO and BNST in the same slice. Scale bar is $500 \mu \mathrm{m}$ c,d) $\mathrm{Tb}$ and physical activity response to CNO $(1 \mathrm{mg} / \mathrm{kg})$ or vehicle in BNST ${ }^{\mathrm{BRS} 3}:: \mathrm{hM} 3 \mathrm{Dq}$ mice $(n=10)$. For quantification, Pre is mean from -150 to -30 and Post from 60 to $180 \mathrm{~min}$. No significant difference in paired two-sided t test on change from baseline, CNO vs vehicle. Data are mean + s.e.m. in top left panel. S.e.m. not graphed for visual clarity in bottom left. Black (vehicle) and red (CNO) bars represent means. d) Effect of CNO $(1 \mathrm{mg} / \mathrm{kg})$ on food intake at onset of light cycle in satiated BNST ${ }^{\mathrm{BRS} 3}: \mathrm{hM} 3 \mathrm{Dq}(\mathrm{n}=10 /$ group) and control $\mathrm{BNST}^{\mathrm{BRS} 3}:: \mathrm{mCherry}$ mice ( $=7 /$ group). e) Effect of CNO $(1 \mathrm{mg} / \mathrm{kg})$ on food intake at onset of dark cycle after 5 h fast in $\mathrm{BNST}^{\mathrm{BRS} 3}: \mathrm{hM} 3 \mathrm{Dq}$ mice $(\mathrm{n}=10$ /group) and control $\mathrm{BNST}^{\mathrm{BRS} 3}:: \mathrm{mCherry}$ mice $(\mathrm{n}=7$ /group). (c-e) Crossover design. 


\section{Supplemental Fig. 2}

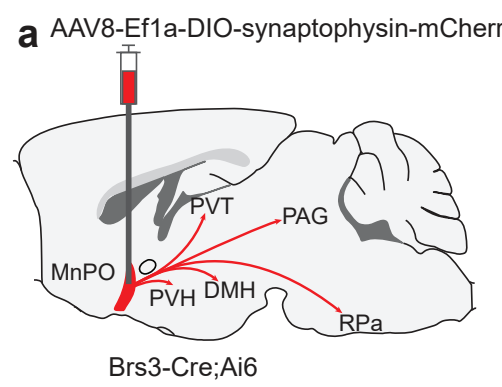

\section{b Injection site}

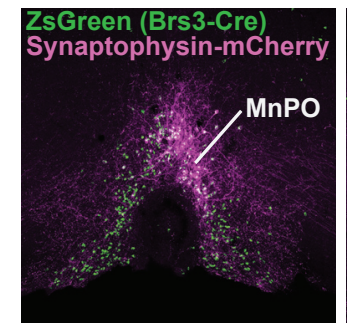

Bregma 0.50

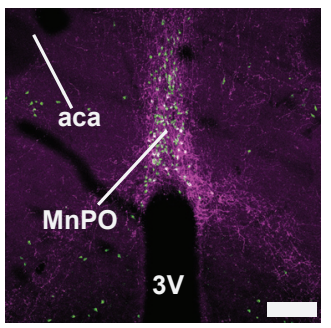

Bregma 0.26

\section{Anterograde projections}

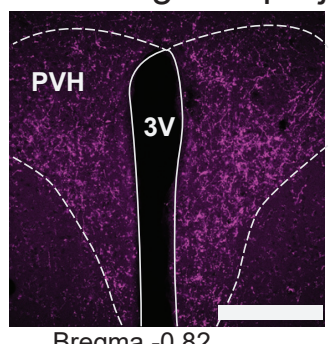

Bregma -0.82

d AAV-DIO- EnvA-G-deletedTVA-mCherry Rabies-GFP

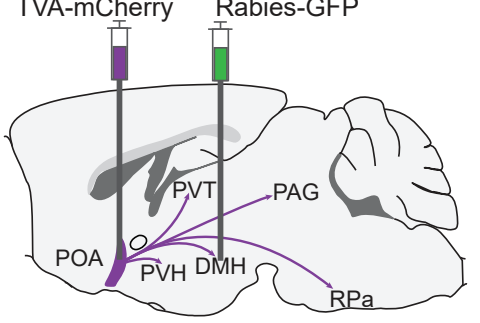

BRS3-Cre

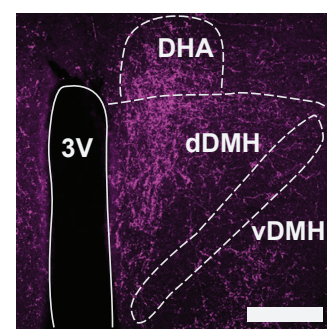

Bregma -1.82

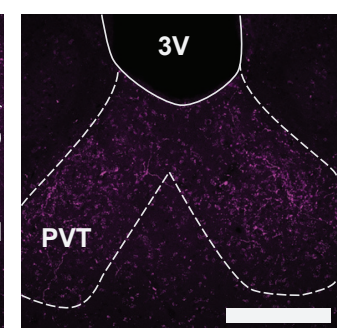

Bregma -1.82

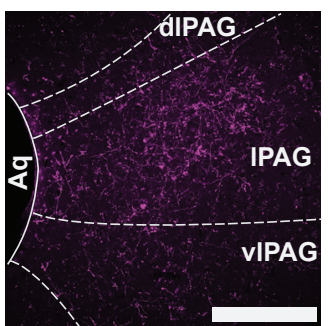

Bregma -4.72

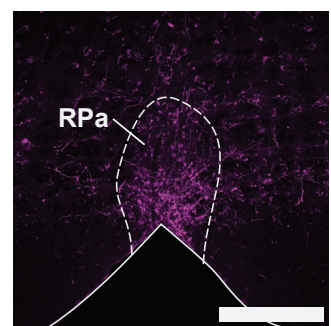

Bregma -6.0

\section{e Injection site}

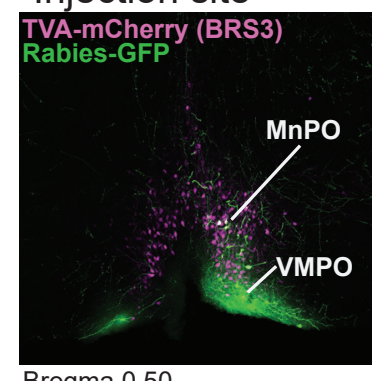

Bregma 0.50

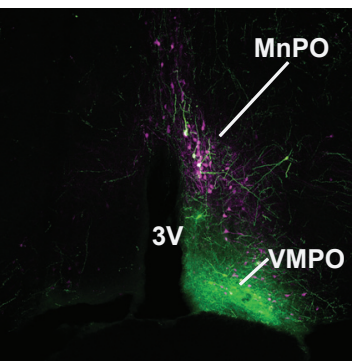

Bregma 0.26

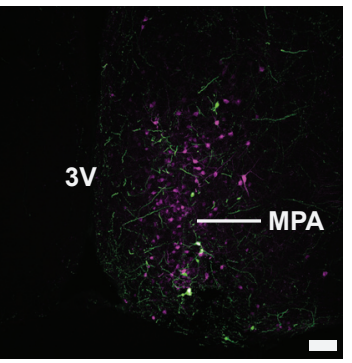

Bregma 0.02

f $\mathrm{POA}^{\mathrm{BRS} 3} \rightarrow \mathrm{DMH}$ collaterals

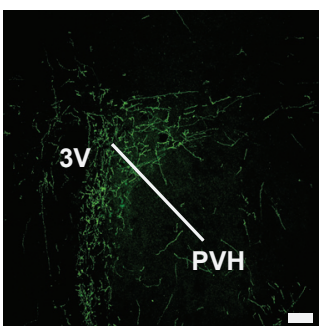

Bregma -0.82

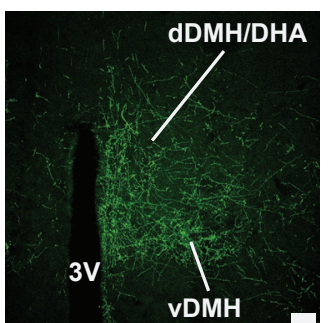

Bregma -1.82

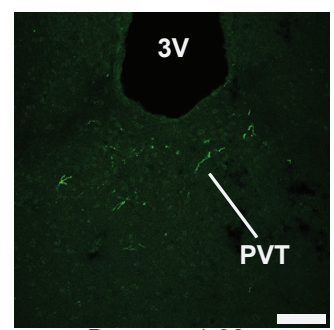

Bregma -1.82
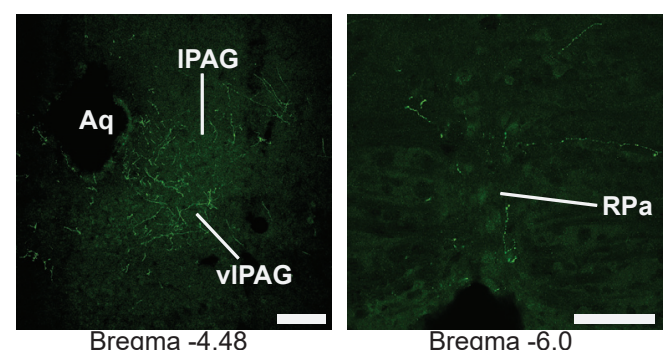

Bregma -6.0

Supplemental Figure 2 POA $^{\mathrm{BRS} 3}$ neurons project widely in the brain with collaterals. Related to Figure 4. a) Schematic of virus injection into BRS3-Cre;Ai14 mice for Cre-dependent synaptophysin mCherry expression and the major projections. b) Injection site verification showing that virus was limited to MnPO region of POA. BRS3 neurons are green and viral synaptophysin is magenta. c) Projection targets of $\mathrm{MnPO}^{\mathrm{BRS} 3}$ neurons. b,c) Scale bar is $200 \mu \mathrm{m}$. d) schematic of virus injection strategy in BRS3-Cre mice; Rabies-GFP was injected in the DMH 
$>4$ weeks after first injections and tamoxifen treatment. e) POA ${ }^{\text {BRS3 }}$ TVA-mCherry expressing neurons (magenta) and Rabies-GFP-expressing neurons (green), retrogradely infected through axon projections to DMH. f) Projection targets of $\mathrm{POA}^{\mathrm{BRS} 3} \rightarrow \mathrm{DMH}$ neurons. e,f) Scale bar is 100 $\mu \mathrm{m}$

$3 \mathrm{~V}$ - third ventricle; aca - anterior commissure; Aq - aqueduct; dDMH/DHA - dorsal part of the dorsomedial hypothalamus/dorsal hypothalamic area; dlPAG - dorsolateral periaqueductal grey; $\mathrm{MnPO}$ - median preoptic area; MPA - medial preoptic area; PVH - paraventricular nucleus of the hypothalamus; PVT - paraventricular nucleus of the thalamus; IPAG - lateral periaqueductal grey; RPa - raphe pallidus; vDMH - ventral part of the dorsomedial hypothalamus; vlPAG ventrolateral periaqueductal grey; VMPO - ventromedial preoptic area. 


\section{Supplemental Fig. 3}

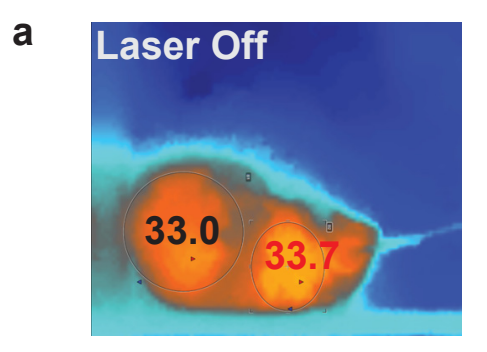

C

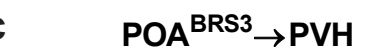
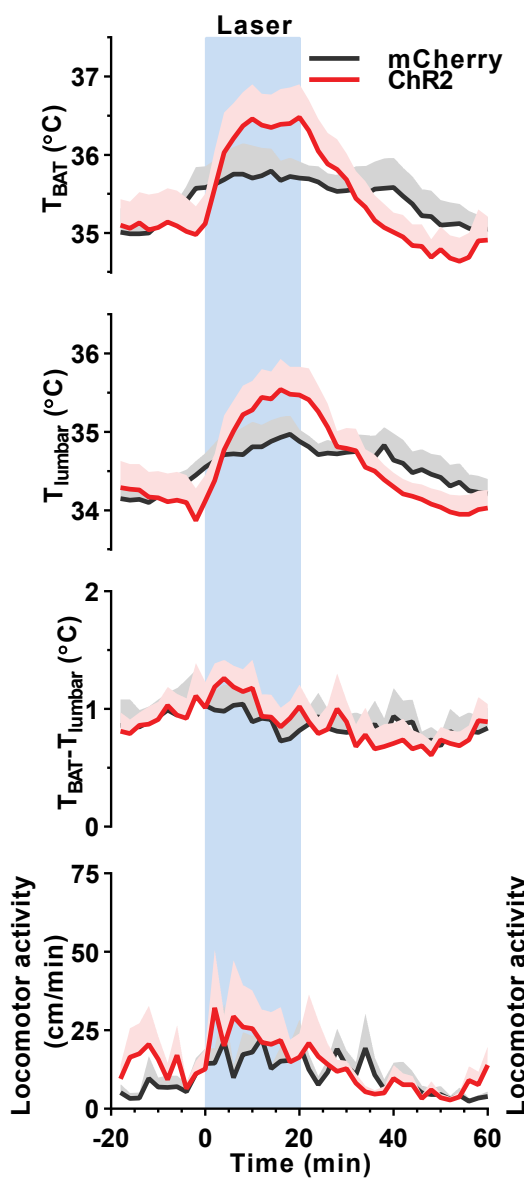
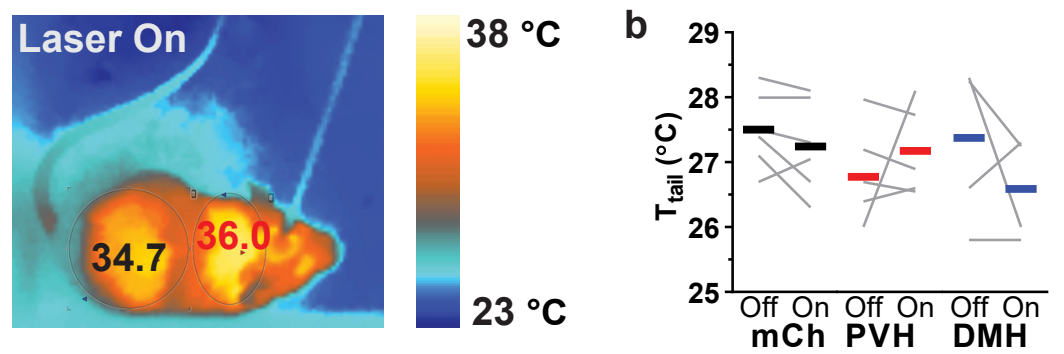

d $\quad \mathrm{POA}^{\mathrm{BRS} 3} \rightarrow \mathrm{DMH}$
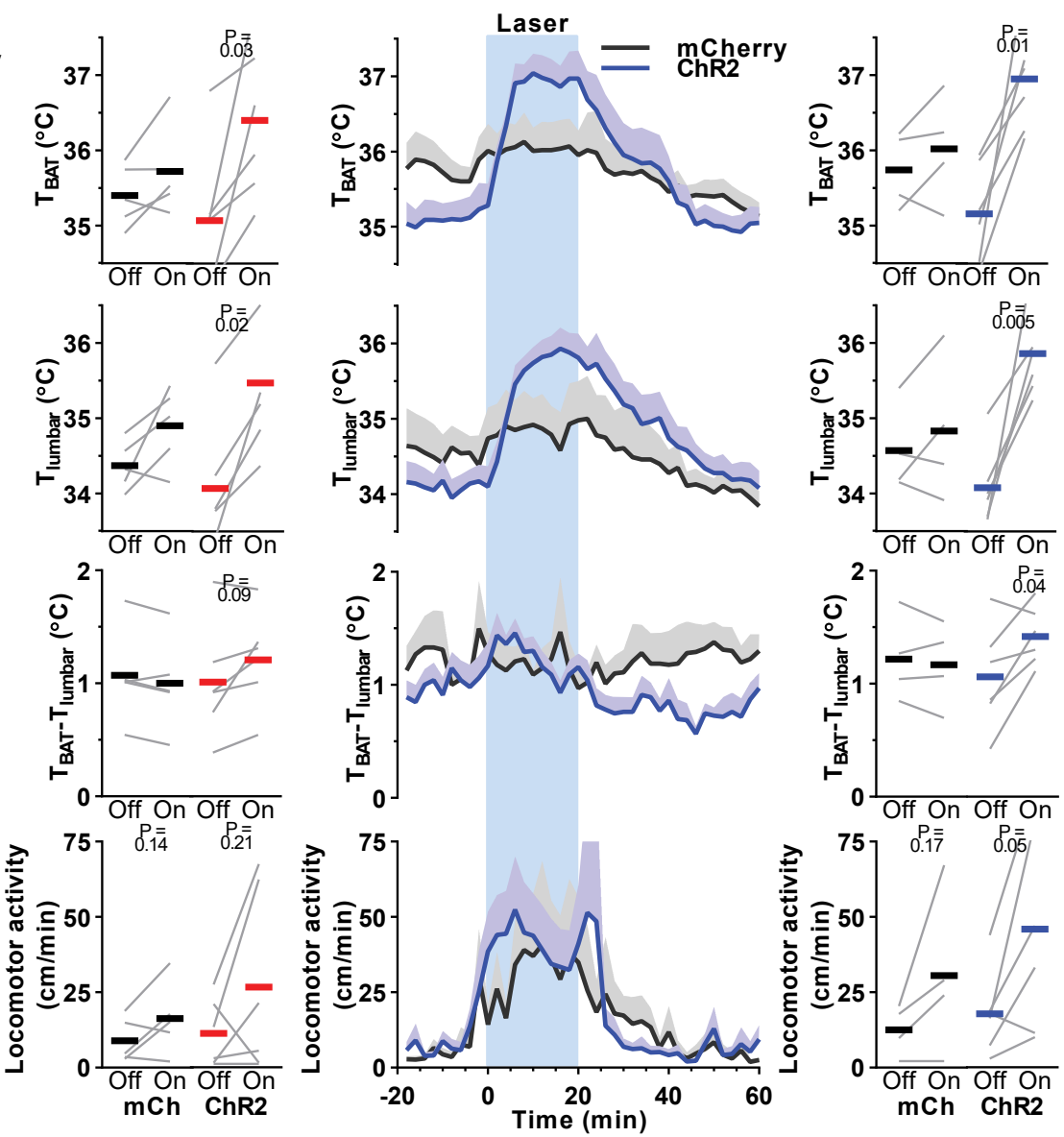

Supplemental Figure $3 \mathrm{POA}^{\mathrm{BRS} 3} \rightarrow \mathrm{PVH}$ and $\mathrm{POA}^{\mathrm{BRS} 3} \rightarrow \mathrm{DMH}$ neurons increase $\mathrm{Tb}$ through BAT activation. Related to Figure 4. a) $\mathrm{POA}^{\mathrm{BRS} 3} \rightarrow \mathrm{PVH}$ mouse with laser off (left) and on for 6 minutes (right). Infrared camera interscapular ( $\mathrm{T}_{\mathrm{BAT}}$; red) and lumbar ( $\mathrm{T}_{\text {lumbar}}$; black) skin temperature. $\mathrm{b}$ ) Mean (bars) and individual (gray lines) tail temperature $\left(\mathrm{T}_{\text {tail }}\right)$ before and during stimulation. POA ${ }^{\mathrm{BRS} 3} \rightarrow \mathrm{PVH}:: \mathrm{mCh}$ erry and $\mathrm{POA}^{\mathrm{BRS} 3} \rightarrow \mathrm{DMH}:: \mathrm{mCh}$ erry mice are combined in the control group. $\mathrm{c}, \mathrm{d}) \mathrm{T}_{\mathrm{BAT}}, \mathrm{T}_{\text {lumbar }}$, their difference $\left(\mathrm{T}_{\mathrm{BAT}}-\mathrm{T}_{\text {lumbar }}\right)$, and physical activity during optogenetic stimulation (blue interval; 1 s on $3 \mathrm{~s}$ off; $20 \mathrm{~Hz} ; 10$ ms pulses) of $\mathrm{POA}^{\mathrm{BRS} 3} \rightarrow \mathrm{PVH}$ (c, red, $n=6)$ and $\mathrm{POA}^{\mathrm{BRS} 3} \rightarrow \mathrm{DMH}(\mathrm{d}$, blue, $\mathrm{n}=6)$ projections and respective mCherry controls (black, $n=4-5)$. Data are average of 3 epochs/mouse, relative to epoch baseline (-20 to $-1 \mathrm{~min})$; 
mean \pm s.e.m Quantitation in right panels uses intervals: Off, -10 to $-2 \mathrm{~min}$; On, 10 to $18 \mathrm{~min}$ for $\mathrm{T}_{\mathrm{BAT}}$ and $\mathrm{T}_{\text {lumbar, }} 0$ to $8 \mathrm{~min}$ for locomotor activity, and Off, -4 to $0 \mathrm{~min}$; On, 2 to 6 min for $\mathrm{T}_{\mathrm{BAT}}-\mathrm{T}_{\text {lumbar. }}$ Experiments were performed at $25^{\circ} \mathrm{C}$. Bars are means; gray lines, individual animals; P values from paired t test, Off vs On. 


\section{Supplemental Fig. 4}
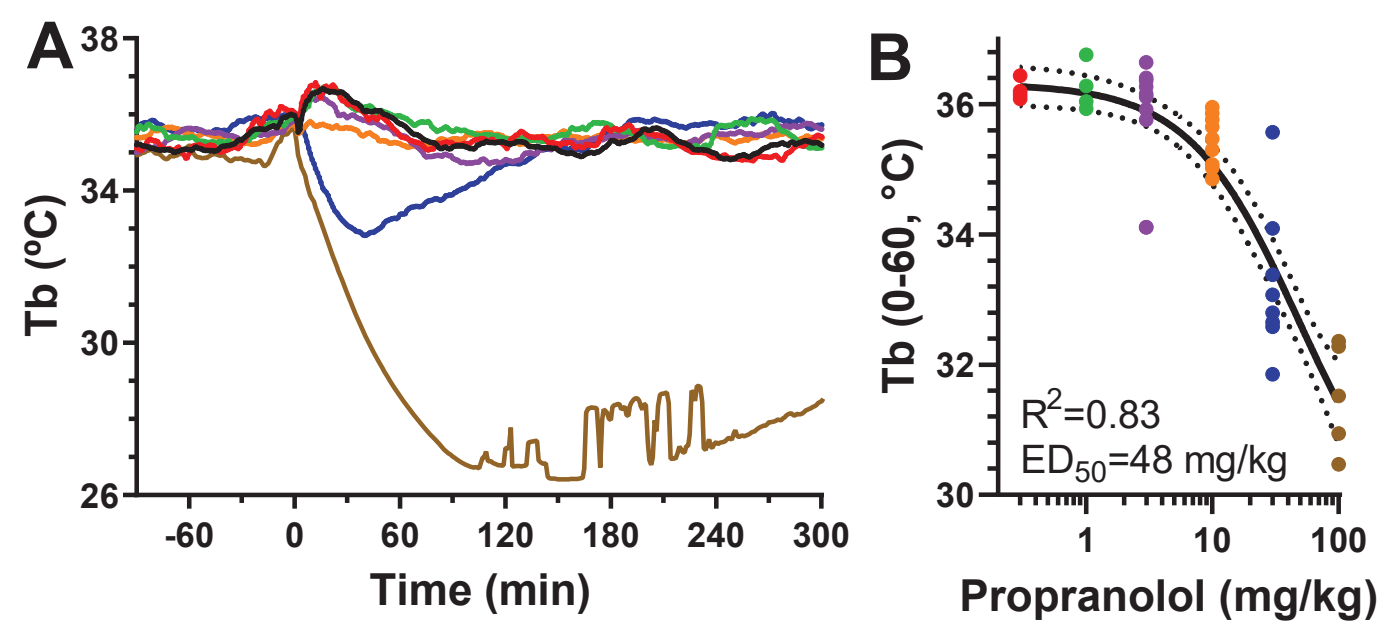

Supplemental Figure 4 Effect of propranolol on body temperature. Related to Figure 4. a) Wildtype mice were treated with the indicated dose of propranolol (color key in b) or vehicle (10\% DMSO for 30 and $100 \mathrm{mg} / \mathrm{kg}$; water for other doses) at time $0 . \mathrm{b}$ ) Tb (mean of 0-60 min after dosing) data were non-linearly fit using Prism to $\mathrm{Tb}=$ bottom $+($ top-bottom $) /\left(1+\left(\right.\right.$ dose $\left.\left./ \mathrm{ED}_{50}\right)\right)$, giving parameters $\mathrm{ED}_{50}=48 \mathrm{mg} / \mathrm{kg}$, bottom $=29.0{ }^{\circ} \mathrm{C}$, and top $=36.1{ }^{\circ} \mathrm{C}$, with $\mathrm{R}^{2}=0.83$ and $\mathrm{DF}$ $=47$. The fitted curve and its $95 \%$ confidence interval are in black. 
Supplemental Fig. 5
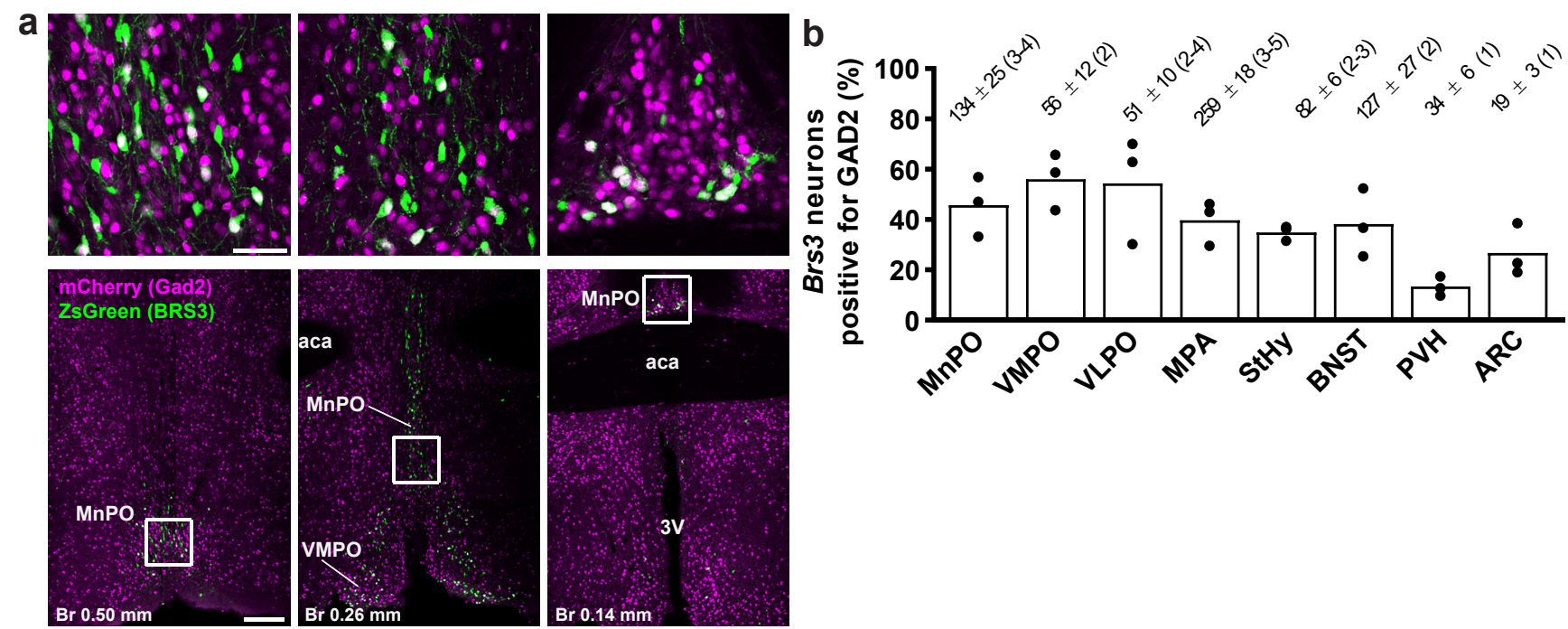

C

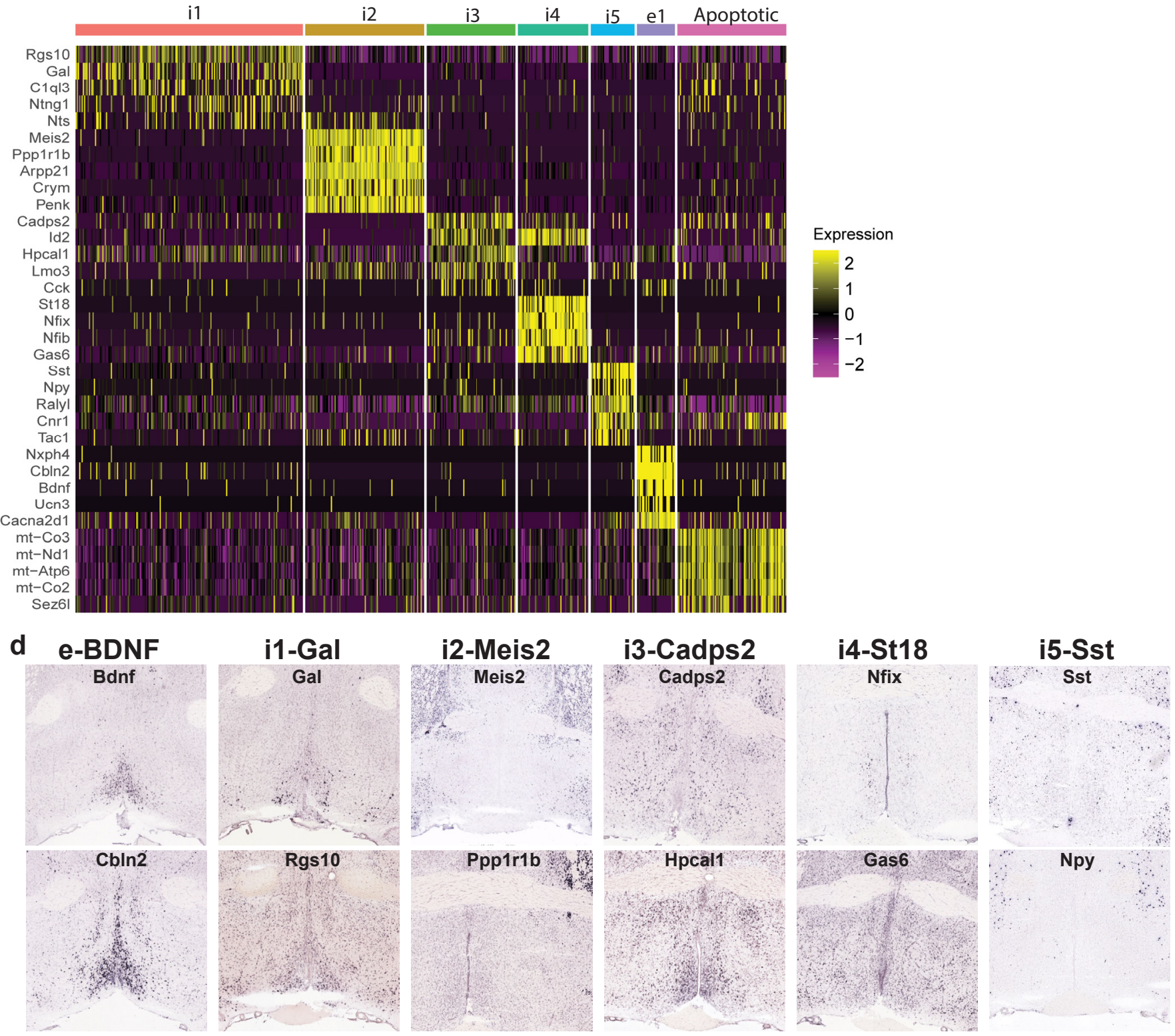


Supplemental Figure 5 POA $^{\mathrm{BRS} 3}$ neurons are a mix of excitatory and inhibitory clusters. Related to Figure 5. a) BRS3 (green) and GAD2 (magenta) are expressed in overlapping populations in the MnPO and VMPO in BRS3-Cre;Ai6;Gad2-mCherry mice. Scale bar overview image is $200 \mu \mathrm{m}$, inset $50 \mu \mathrm{m}$. b) Quantification of BRS3 neurons expressing GAD2. The number of double positive neurons \pm s.e.m. in the indicated region and (number of slices/mouse counted) are indicated; $n=3$ mice. c) Expression profile of several marker mRNAs for the POA region BRS3 clusters. Data from Moffit et al., 2018. d) Allen Brain Atlas ISH images (http://mouse.brain-map.org/) for two of the marker mRNAs (aside of BRS3 and Vglut2 or Vgat) for each cluster for the POA region. 


\section{Supplemental Figure 6}

a

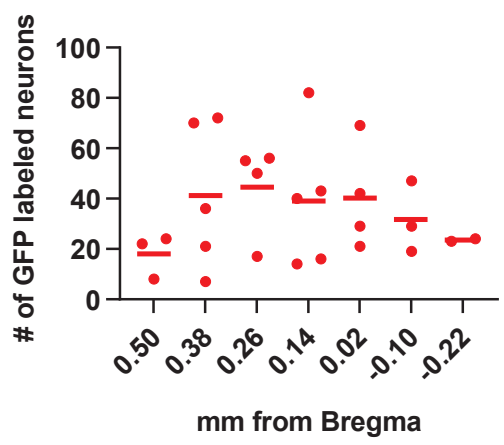

b

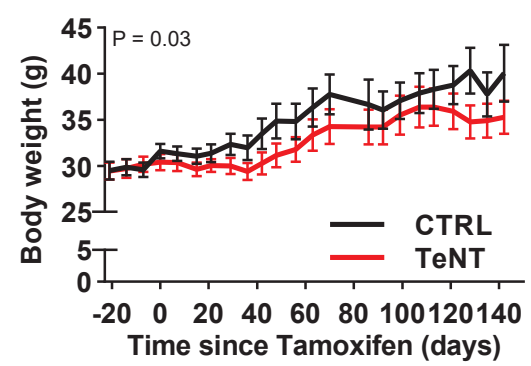

C

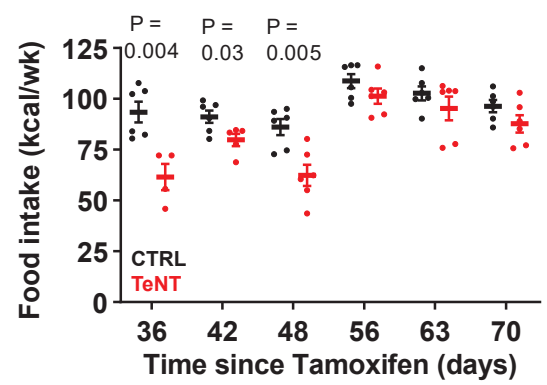

d

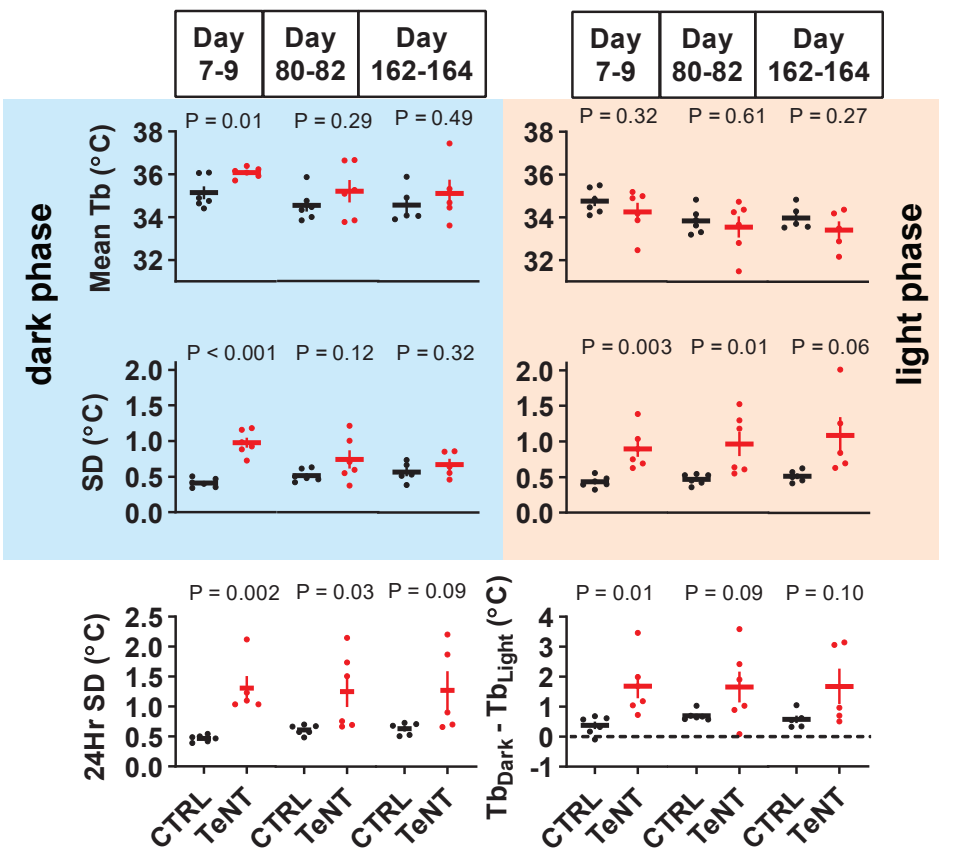

e

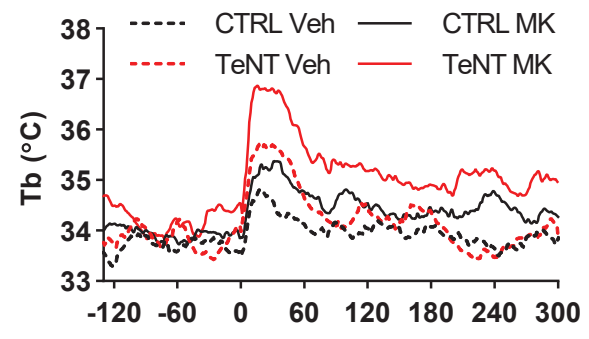

Time since injection (minutes)

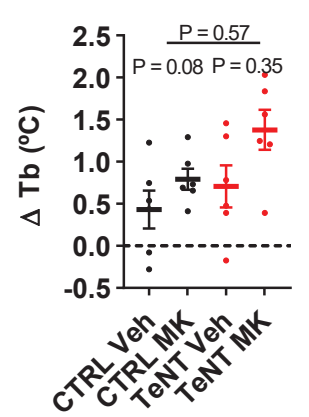

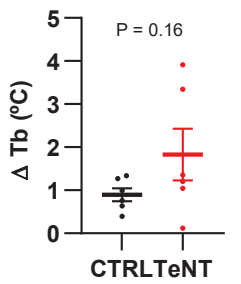
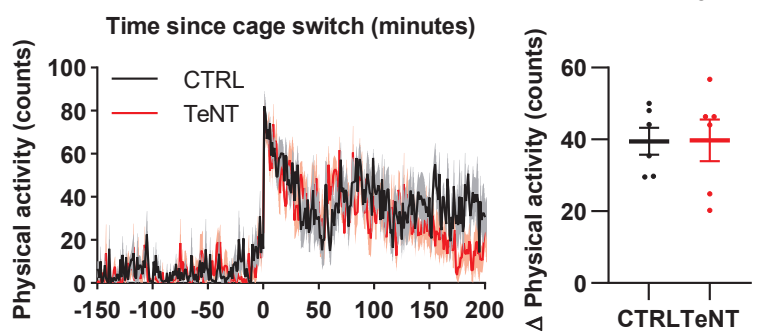

g
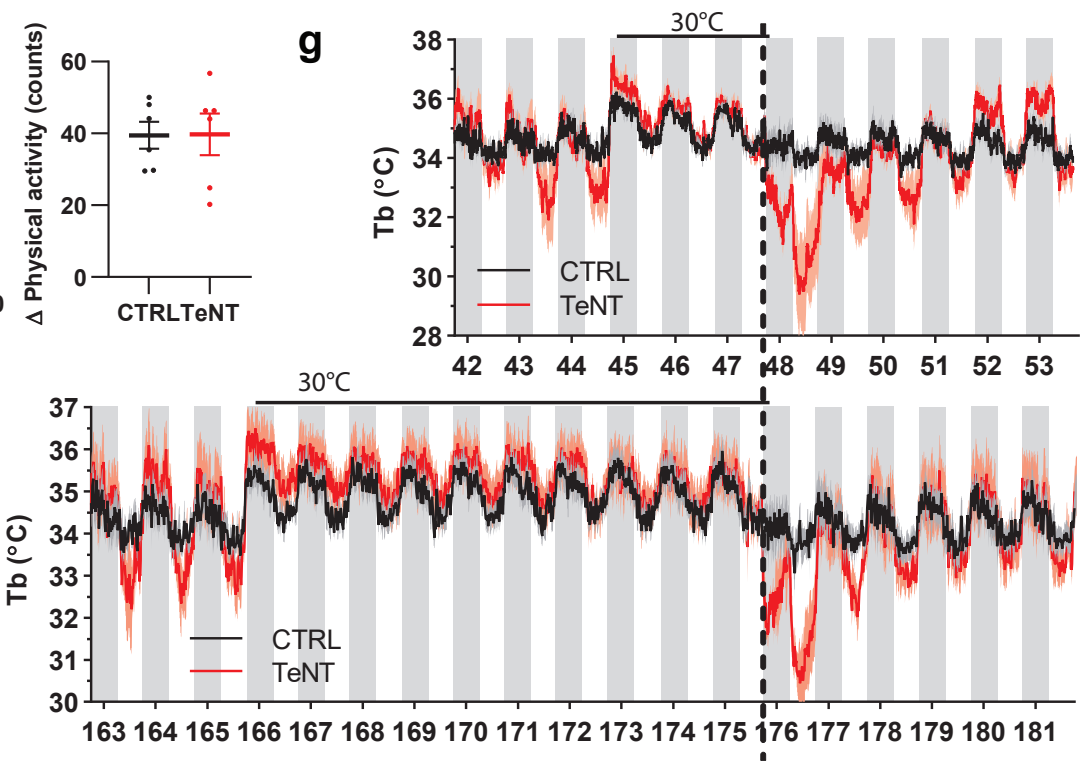

Time since Tamoxifen (days) 
Supplemental Figure 6 Silencing $\mathrm{POA}^{\mathrm{BRS} 3}$ neurons increases $\mathrm{Tb}$ variability and exaggerates $\mathrm{Tb}$ changes. Related to Figure 7. a) Number of EYFP labeled (TeNT) neurons in the POA at the indicated distance from Bregma. Every third section was counted from each mouse. $b$ ) $\mathrm{POA}^{\mathrm{BRS} 3}::$ TeNT mice gain less body weight than do controls. $\mathrm{P}$ value, repeated measures ANOVA. c) Reduced food intake in $\mathrm{POA}^{\mathrm{BRS} 3}:$ :TeNT mice at 4-6 weeks after starting tamoxifen treatment. $P$ values, unpaired t test. d) At indicated number of days after starting tamoxifen treatment, $\mathrm{Tb}$ was measured each minute during $72 \mathrm{~h}$ intervals and the $\mathrm{Tb}$ and standard deviation (SD) during dark (left) and light (right) phases was measured. The circadian amplitude (Tb dark- $^{-}$ Tblight $)$ and the $\mathrm{Tb}$ span $\left(95^{\text {th }}-5^{\text {th }} \mathrm{Tb}\right.$ percentiles $)$ of the full intervals were also calculated. Data are mean \pm s.e.m. P values, unpaired t test. e) Tb response to MK-5046 (10 mg/kg, i.p.) or vehicle (saline) and $\Delta \mathrm{Tb}\left(\mathrm{Tb}_{60 t o 1} 180\right.$ minus $\left.\mathrm{Tb}_{-150 t o-30}\right)$. Data are mean \pm s.e.m. (s.e.m. omitted from left for visual clarity); P value, paired t test between vehicle and MK-5046 and unpaired t test with unequal variance between delta $\mathrm{Tb}$ (MK-5046 minus vehicle) of CTRL and TeNT groups. f) $\mathrm{Tb}$ and physical activity response to switching mice to a clean cage. $\Delta \mathrm{Tb}$ is $\mathrm{Tb}_{0 \text { to60 }}$ minus $\mathrm{Tb}$ 90to-30; $\Delta$ Physical activity was calculated the same way. Data are mean \pm s.e.m. g) Acclimation and $\mathrm{Tb}$ response in mice exposed for 3 days (top) vs 10 days (bottom) to $30^{\circ} \mathrm{C}$, otherwise at 22 ${ }^{\circ} \mathrm{C}$. Data are mean \pm s.e.m. In all panels, $n=6$ mice/group, except for a) with $n=5$ mice. 


\section{Supplemental Figure 7}

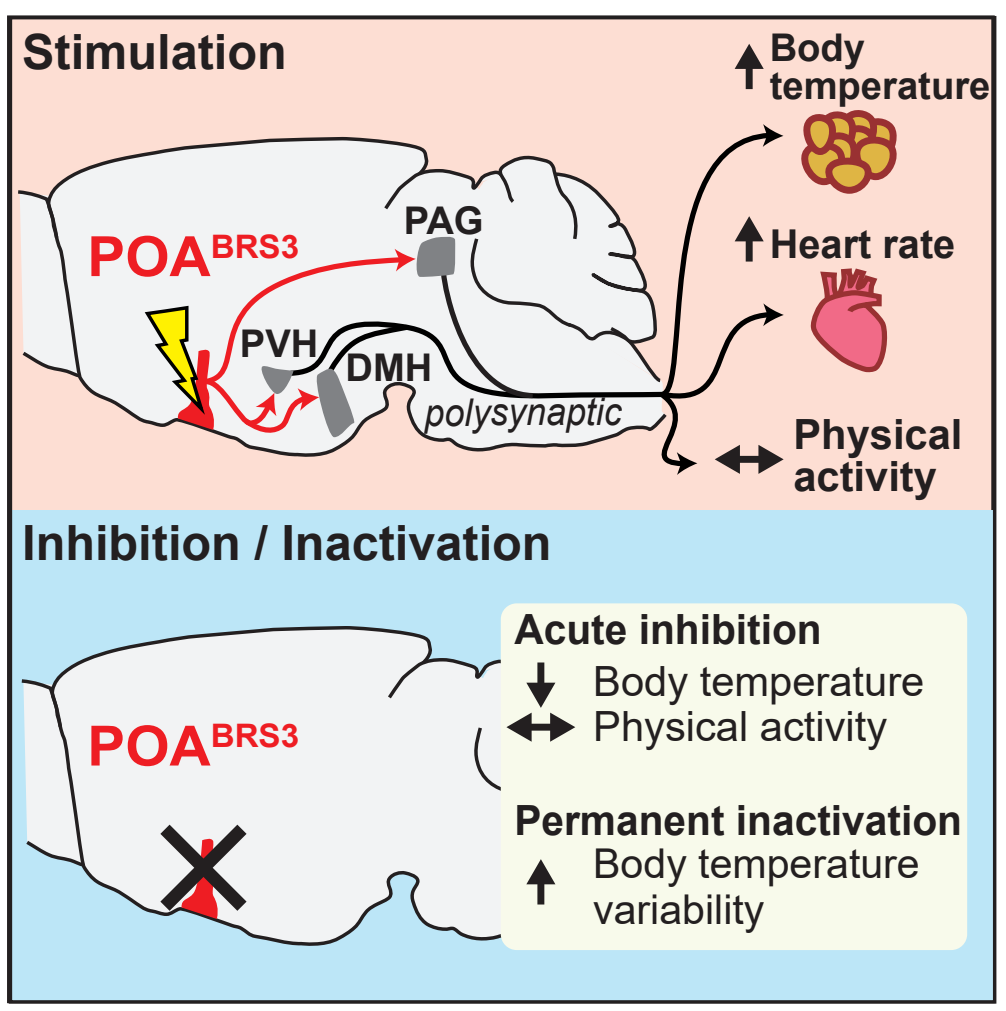

Supplemental Figure $7 \mathrm{POA}^{\mathrm{BRS} 3}$ neurons (red) use projections to $\mathrm{PVH}$ and DMH to drive sympathetic output to BAT and heart, thereby increasing $\mathrm{Tb}$ and $\mathrm{HR}$. $\mathrm{POA}^{\mathrm{BRS} 3}$ neurons also increase $\mathrm{Tb}$ through a projection to PAG. Acute inhibition decreases $\mathrm{Tb}$, indicating a roll in cold-defense for $\mathrm{POA}^{\mathrm{BRS} 3}$ neurons. Permanent inactivation increases $\mathrm{Tb}$ variability and causes undershoot and overshoot of $\mathrm{Tb}$ setpoint during metabolic interventions. 